\title{
Uncertainty and Sensitivity Analysis for Two-Phase Flow in the Vicinity of the Repository in the 1996 Performance Assessment for the Waste Isolation Pilot Plant: Undisturbed Conditions
}

\author{
J.C. Helton ${ }^{a}$, J.E. Bean ${ }^{b}$, K Economye, J.W. Garner ${ }^{d}$, R.J. MacKinnone, J. Millere, J.D. Schreiber, and P. Vaughre \\ aDepartment of Mathematics, Arizona State University, Tempe, AZ 85287 USA; bNew Mexico Engineering
}

Research Instime, Albuquerque, NM 87106 USA; 'GRAM, Inc., Albuquerque, NM 87112 USA; dPiru

Associates, Abuquerque, NM 87106 USA; 'Sandia National Laboratories, Albuquerque, NM 87185 USA

\begin{abstract}
Uncertainty and sensitivity analysis results obtained in the 1996 performance assessment for the Waste Isolation Pilot Plant are presented for two-phase flow in the vicinity of the repository under undisturbed conditions. Techniques based on Latin hypercube sampling, examination of scatterplots, stepuise regression analysis, partial comelation amalysis and rank transformations are used to investigate brine inflow, gas generation, repository pressure, brine saturation, and brine and gas outflow. Of the variables under study. repository pressure istpotentially the most important due to its influence on spallings and direct brine releases, with the uncertainty in its value being dominated by the extent to which the microbial degradation of cellulose takes place, the rate at which the corrosion of steel takes place, and the amount of brine that drains from the surrounding disturbed rock zone into the repository.

Key Words: BRAGFLO, compliance certification application, epistemic uncertainty, Latin hypercube sampling, performance assessment, radioactive waste, sensitivity analysis, subjective uncertainty, transuranic waste, two-phase flow, uncertainty analysis, undisturbed conditions, Waste Isolation Pilot Plant.
\end{abstract}

Please send page proof to:

Jon C. Helton

Department 6848. MS 0779

Sandia National Laboratories

Albuquerque. NM 87185-0779, USA

Phone: $505-284-4808$

Fax: $505-844-2348$

email: jchelto@isandia.gov 


\section{DISCLAIMER}

This report was prepared as an account of work sponsored by an agency of the United States Government. Neither the United States Government nor any agency thereof, nor any of their employees, make any warranty, express or implied, or assumes any legal liability or responsibility for the accuracy, completeness, or usefulness of any information, apparatus, product, or process disclosed, or represents that its use would not infringe privately owned rights. Reference herein to any specific commercial product, process, or service by trade name, trademark, manufacturer, or otherwise does not necessarily constitute or imply its endorsement, recommendation, or favoring by the United States Government or any agency thereof. The views and opinions of authors expressed herein do not necessarily state or reflect those of the United States Government or any agency thereof. 


\section{DISCLAIMER}

Portions of this document may be illegible in electronic image products. Images are produced from the best available original document. 


\section{Introduction}

Uncertainty and sensitivity analysis results for fluid flow in the vicinity of the repository under undisturbed conditions obtained as part of the 1996 performance assessment (PA) for the Waste Isolation Pilot Plant (WIPP) are presented. A following paper will present results for disturbed conditions. ${ }^{1}$

The results under study were calculated with the BRAGFLO program ${ }^{2}$ for the three replicated Latin hypercube samples (LHSs) (i.e., R1, R2, R3) described in Eq. (7) of Ref. 3. In particular, the results under consideration are the outcomes of the 300 EO BRAGFLO calculations indicated in Table 6 of Ref. 4. The topics considered are brine inflow (Sect. 2), gas generation (Sect. 3), pressure (Sect. 4), brine saturation (Sect. 5), and brine and gas outflow (Sect. 6). In each section, a number of results calculated by BRAGFLO are examined with sensitivity analysis techniques based on examination of scatterplots, partial correlation coefficients, and stepwise regression anatysis (Sect 3.5, Ref. 5). The sensitivity analyses make extensive use of rank-transformed data, ${ }^{6}$ the STEPWISE program ${ }^{7,8}$ for stepuise regression analysis, and the PCCSRC program ${ }^{9}, 10$ for the calculation of partial correlation coefficients. The specific BRAGFLO results considered are listed in Table 1, which can be used to obtain exact definitions of the individual variables under consideration; further, the uncertain analysis inpurs are described in Table 1 of Ref. 3.

The sensitivity analysis results will be based on all 300 observations (i.e., replicates $R 1, R 2$ and $R 3$ will be pooled for the performance of sensitivity analyses with scatterplots, partial correlation coefficients and stepwise regression analyses), which permits the analysis results to be based on all available information. Similarly, summaries of uncertainty based on box plots will also use all 300 observations. In contrast, distributions of timedependent results will typically be shown for only replicate Rl to avoid the presentation of plots with so many individual curves that they are unreadable. However, mean and percentile curves (Sect. 5, Ref. 11) will typically be obtained from all 300 observations.

The results in this presentation were obtained in support of the U.S. Department of Energy's (DOE's) compliance certification application (CCA) for the WIPP12 and are based on material contained in Chapt. 7 of Ref. 13.

\section{Undisturbed Conditions: Brine Inflow}

The anhydrite marker beds (Fig. 1, Ref. 2) provide the only significant pathway by which brine can flow from the Salado Formation to the repository from areas beyond the disturbed rock zone (DRZ), with this flow tending to take place at a relatively constant rate (Fig. 1). However, the dominant source of brine into the repository is drainage from the DRZ. which primarily takes place over the first 50 to $100 \mathrm{yr}$ of the calculation due to the enhanced permeability of the DRZ (i.e. $1 \times 10^{-15} \mathrm{~m}^{2}$ ) over that of the original, undisturbed halite (i.e.. $k=10^{x} . x=H A L P R M$ ) 
(Fig. 1). The highest cumulative brine inflow in Fig. 1 results for the sample element (i.e., element 23 in replicate $\mathrm{R} 1)$ that has the second highest value for anhydrite permeability (i.e., $k=10^{x}=7.94 \times 10^{-18} \mathrm{~m}^{2}, x=A N H P R M$ ) and also one of the higher brine far-field pore pressures (i.e., SALPRES $=1.31 \times 10^{7} \mathrm{~Pa}$ ).

The brine inflows from the anhydrite marker beds can occur from MB 138, Anhydrites a and $b$, and MB 139 at both the northern and southern ends of the computational grid (Fig. 1, Ref. 2). As shown by the box plots ${ }^{14}$ in Fig 2, the flow from MB 139 exceeds the flow from Anhydrites $a$ and $b$, which in turn exceeds the flow from MB 138. For a given marker bed, the flows from the north tend to be smaller than the flows from the south (Fig. 2). As already noted, total inflow to the repository exceeds total flow from the marker beds because of drainage from the DRZ.

Box plots (Fig. 2) provide an alternative way to display the information in a distribution function. The endpoints of the boxes are formed by the lower and upper quartiles of the data, that is $x_{0.25}$ and $x_{0.75}$. The vertical line within the box represents the median, $x_{0.50}$. The mean is identified by the large dot. The bar on the right of the box extends to the minimmon of $x_{0.75}+1.5\left(x_{0.75}-x_{0.25}\right)$ and the maximum value. In a similar manner, the bar on the left of the box extends to the maximum of $x_{0.25}-1.5\left(x_{0.75}-x_{0.25}\right)$ and the minimum value. The observations falling outside of these bars are shown with crosses. In symmetric distributions, these values would be considered outliers. Box plots contain the same information as a distribution function, but in a somewhat reduced form Further, their flantened shape makes it convenient to place many distributions on a single plot and also to compare different distriburions.

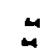

As examination of Figs 2 and 3 shows, considerable uncertainty exists with respect to the amount of brine that will flow out of the marker beds and into the repository. The performance of a stepwise regression analysis (Sect. 3.5 , Ref. 5) between cumulative brine flow (Fig. 2) and variables in the LHS provides a way to assess the contribution of individual variables to this uncertainty, with variable importance being indicated by the order in which variables enter the regression model, the changes in $R^{2}$ values as additional variables enter the regression model, and the standardized regression coefficients of the variables in the final regression model (Table 2). The candidate independent variables for the regression analyses in Table 2 consist of the following 29 variables in Table 1 of Ref. 3 that are used as input to BRAGFLO: Brooks-Corey pore distribution parameter for anhydrite ( $A N H B C E X P)$, pointer variable for selection of relative permeability model for use in anhydrite ( $A N H B C V G P$ ), logarithm of anhydrite permeability (ANHPRM), residual brine saruration in anhydrite (ANRBRSAT), residual gas sanuration in anhydrite (ANRGSSAT), logarithm of borehole permeability (BHPRM), logarithm of bulk compressibility of brine pocket ( $B P C O M P$ ), initial pressure in brine pocket (BPINTPRS), logarithrn of brine pocket permeability (BPPRM). pointer variable for selection of brine pocket volume (BPVOL), halite porosity (HALPOR). logarithm of halite permeability (HALPRM), initial brine pressure, without the repository being present, at a reference point located in the center of the combined shafts at the elevation of the midpoint of MB 139 (SALPRES). Brooks-Corey pore distriburion paramerer for shaf (SHBCEXP), logarithm of permeability of asphalt componem of shaft seal (SHPRMASP). logarithm of permeability for clay components of shaft (SHPRMCLY). logarithm of 
permeability for concrete component of shaft seal for 0 to $400 \mathrm{yt}$ (SHPRMCON), logarithm of permeability of DRZ surrounding shaft (SHPRMDRZ), pointer variable used to select permeability in crushed salt component of shaft seal at different times (SHPRMHAL), residual brine saturation in shaft (SHRBRSAT), residual gas saturation in shaft (SHRGSSAT), increase in brine saturation of waste due to capillary forces (WASTWICK), scale factor used in definition of stoichiometric coefficient for microbial gas generation (WFBETCEL), corrosion rate for steel under inundated conditions in the absence of $\mathrm{CO}_{2}$ (WGRCOR), microbial degradation rate for cellulose under humid conditions (WGRMICH), microbial degradation rate for cellulose under inundated conditions (WGRMICD), pointer variable for microbial degradation of cellulose (WMICDFLG), residual brine saturation in waste (WRBRNSAT), and residual gas saturation in waste (WRGSSAT). The variables bulk compressibility of anhydrite (ANHCOMP) and bulk compressibility of halite (HALCOMP) were also used as input BRAGFLO but were not included as variables in the regression analysis because the -0.99 rank comrelations inmosed on the variable pairs (ANHCOMP, ANHPRM) and (HALCOMP, HALPRM) (Sect 5, Ref. 3) results in unstable regression results (Sect. 7.2, Ref. 13). For the results presented in Table 1 and other similar tables, variables were required to be significant at the $0.02 \alpha$-level to enter a regression model and to remain significant at the $0.05 \alpha$-level to be retained in a regression model.

The regression analyses in Table 2 are all relatively successful in the sense that they have $R^{2}$ values between 0.86 and 0.90 . For brine inflow from the marker beds, the two dominant variables in the regression analyses in Table 2 are WMICDFLG and ANHPRM. The negative effect indicated for WMICDFLG results because increasing WMICDFLG increases gas generation and thus pressure in the repository, which in turn increases resistance to brine flow out of the marker beds. The positive effect indicated for $A N H P R M$ results from decreased resistance to brine flow in the marker beds. Small negative effects are indicated for HALPOR, WASTWICK, WGRCOR and WGRMICI, with these effects resulting because each of these variables tends to increase gas generation and thus resistance to brine flow out of the marker beds due to increased repository pressure. The variable HALPOR will be discussed in more detail in conjunction with total brine flow into the repository. A small positive effect is indicated for SALPRES, with this effect resulting because increasing SALPRES tends to increase the pressure gradient between the marker beds and the repository.

The variable HALPRM appears with negative regression coefficients for brine flow out of MB 138 North and MB 138 South and appears with positive regression coefficients for brine flow out of Anhydrites a and b North, Anhydrites $\mathrm{a}$ and $\mathrm{b}$ South, MB 139 North and MB 139 South. The reason for this behavior is not immediately apparent but is probably related to the assigned comelations berween permeability and compressibility and the complex interactions between permeability and compressibility in determining brine flow into and through the marker beds. All things being equal, increasing $H A L P R M$ should reduce resistance to flow in the halite and as a result, increase brine inflow to the marker beds and thus to the repository. Similarly, increasing HALCOMP should increase brine discharge from the halite for a given drop in pressure and, as a result, increase brine inflow to the marker beds and thus to the repository. Thus. HALPRM and HALCOMP should both have positive effects on brine 
discharge from the marker beds to the repository. The appearance of HALPRM in Table 2 with both positive and negative effects on brine discharge probably results from the -0.99 rank comelation between HALPRM and HALCOMP, which produced a complex pattern of correlations between HALPRM, HALCOMP and brine discharge (Table 3).

It is not immediately apparent why SHRGSSAT appears in Table 2 for brine flow out of Anhydrites a and $\mathrm{b}$. The effect of SHRGSSAT is very small (i.e., the change in the $R^{2}$ values with its addition is $<0.01$ ) and its selection may be due to effects related to brine and gas movement across the part of the computational grid that corresponds to the shaft in the repository and DRZ (i.e., regions 10,11 in Fig. 1, Ref. 2). It is also possible that the effect may be spurious.

For total brine inflow to the repository, the dominant variable in the regression analysis is HALPOR (Table 2). The positive effect indicated for HALPOR results because increasing HALPOR increases the amount of brine in the DRZ that is available to drain downward into the repository. This increased brine results in greater gas generation due to corrosion and hence higher pressures in the repository. The association of higher pressures with increasing values for HALPOR is why HALPOR has a negative effect on brine flow from the marker beds to the repository. Speciñcally, increased repository pressure reduces the gradient between the marker beds and the repository and thus reduces the rate at which brine flows out of the marker beds. Smaller effects are indicated for WMICDFLG and ANHPRM. As previously discussed, increasing WMICDFLG reduces brine inflow from the marker beds by increasing pressure in the repository and increasing $A N H P R M$ increases brine inflow from the marker beds by decreasing resistance to flow.

An alternative way to assess the sensitivity of analysis outcomes to uncertain inputs is by calculating partial rank correlation coefficients (PRCCs) between analysis outcomes and uncertain inputs (Sect. 3.5, Ref. 5). When the predicted outcomes are time dependent, the change in the PRCCs through time will indicate changing variable importance. The outcome of such an analysis for the brine flows in Fig. 1 is shown in Fig. 3. The variables ANHCOMP and HALCOMP have been excluded from the calculation of the PRCCs in Fig. 3. Due to the -0.99 rank correlation within the pairs (ANHPRM, ANHCOMP) and (HALPRM, HALCOMP), neither variable within a pair would appear in an analysis based on PRCCs. Fig. 3 and other similar figures show the PRCCs for all variables whose PRCC exceeds 0.5 in absolute value at some point in time.

The dominant variables for cumulative brine outflow from the marker beds identified with PRCCs are ANHPRM, WMICDFLG and HALPRM (Fig. 3), which is consistent with the results obtained in the regression analysis (Table 2). The positive effects for ANHPRM and HALPRM result because of reduced resistance to flow in the marker beds and in the Salado halite, respectively. The negative effect for WMICDFLG results because of increased pressure in the repository and hence an increased resistance to flow out of the marker beds. 
The dominant variables for cumulative brine flow into the repository identified with PRCCs are $H A L P O R$, WMICDFLG and ANHPRM, which is also consistent with the results obtained in the regression analysis (Table 2). The negative effect indicated for SALPRES at very early times may be spurious. As a reminder, PRCCs provide a measure of the linear relationship between two variables after a correction has been made for the effects of all other variables under consideration. As HALPOR has a PRCC of approximately 1 when SALPRES appears to have a negative effect, the amount of uncertainty being accounted for by SALPRES or any other variable is actually quite small after the correction is made for the effects of HALPOR. In the regression analysis, SALPRES is not identified as having a discernible effect on brine inflow to the repository over 10,000 yr (Table 2). The positive effects indicated for $H A L P O R$ and $A N H P R M$ result from increased brine drainage from the DRZ and increased brine flow from the marker beds, respectively. The negative effect for WMICDFLG results from increased pressure in the repository and hence increased resistance to flow out of the marker beds.

The examination of scatterplots provides an additional way to assess the effects of uncertain variables on analysis outcomes of interest. The two most important variables identified in Table 2 and Fig. 3 for brine outflow from the marker beds are WMICDFLG and ANHPRM. The corresponding scatterplots show well-defined relationships between these two variables and cumulative brine outflow from the marker beds over $10.000 \mathrm{yt}$ (Fig. 4). Similarly, the dominant variable for cumulative brine inflow to the repository over $10,000 \mathrm{yr}$ is $H A L P O R$, with the corresponding scatterplot again showing a well-defined relationship (Fig. 5).

Flow down the shaft constitutes another possible brine inflow pathway to the repository. However, the amount of brine entering the repository by flow out of the shaft (Fig. 6) is insignificant relative to other sources of brine inflow (Fig. 2). Specifically, flow out of the shaft is on the order of a few 10's of cubic meters of brine (Fig. 6) while flow out of the marker beds is on the order of 1,000's to 10,000's of cubic meters of brine (Fig. 2).

\section{Undisturbed Conditions: Gas Generation}

Gas generation results from the corrosion of steel and the microbial degradation of cellulose (Fig. 7). The discretized character of cumulative gas generation for microbial degradation derives from the variable WMICDFLG, which takes on three values. Specifically, one value, which has a probability of 0.25 , specifies the inclusion of rubber and plastics in the inventory of cellulose available for microbial degradation and results in the upper group of curves in Fig. 7; one value, which also has a probability of 0.25 , specifies the exclusion of rubber and plastics from the inventory of cellulose available for microbial degradation and results in the middle group of curves in Fig. 7 ; and one value, which has a probability of 0.5 , specifies that no microbial degradation of cellulose will take place and results in the lower group of curves in Fig. 7. The leveling off of the curves for microbial gas generation in Fig. 7 results from exhaustion of the cellulose inventory (Fig. 8). 
Microbial gas generation takes place at different rates under humid and inundated conditions. Overall, more gas generation takes place under inundated than humid conditions (Fig. 9). However, the occurrence of gas generation under humid or inundated conditions does not affect the total amount of gas generated by microbial action as indicated by the lack of variability around the two asymptotes in Fig. 7.

Total gas generation is obtained by combining gas generation due to corrosion and gas generation due to microbial degradation (Fig. 10), with the larger contribution coming from corrosion (Fig. 7). However, microbial degradation still makes a substantial contribution to the total uncertainty in gas generation.

As akready indicated, gas generation due to microbial degradation is dominated by WMICDFLG. For gas generation due to corrosion, the dominant variables are WGRCOR and HALPOR, with a smaller effect indicated for WASTWICK (left frame, Fig. 11). The variables WGRCOR and WASTWICK are important at early times because increasing each of these variables increases the rate at which gas is generated. However, over the longer term, the amount of gas generated by corrosion depends on the amount of steel undergoing corrosion, which in turn depends on the amount of brine available for the corrosion process. As a reminder, brine is consumed in the corrosion process, with the result that the amount of gas generated by corrosion can be limited by the amount of brine present in the repository. The positive effect indicated for HALPOR results because HALPOR is the dominant variable with respect to the amount of brine entering the repository (Table 2, Figs. 3, 5).

For total gas generation due to corrosion of steel and microbial degradation of cellulose, the dominamt variables are WMICDFLG and HALPOR, with WMICDFLG controlling the uncertainty in the amount of gas generated by microbial degradation and HALPOR controlling the uncertainty in the amount of gas generated by corrosion (right frame, Fig. 5). Smaller positive effects are indicated for WGRCOR and WASTWICK, which affect the rate at which corrosion takes place, with these effects becoming less important with increasing time.

Stepwise regression analysis provides an altemative way to investigate the uncertainty in gas generation (Table 4). For cumulative gas generation over 10,000 yr due to corrosion, the dominant variable is HALPOR, which controls the amount of brine entering the repository. Positive effects are also indicated for WGRCOR and WASTWICK due to their role in increasing the rate of corrosion. The variable WMICDFLG appears in the regression model with a negative regression coefficient due to its role in reducing brine inflow to the repository (Table 2 , Figs. 3, 4). The variable ANHPRM also appears in the regression model with a positive regression coefficient, which is consistent with its roie in increasing brine flow into the repository (Table 2. Figs. 3, 4). The appearance of BPINTPRS at the final step of the analysis is spurious, as may also be the case for the selection of SHRGSSAT at Step 5. However, it is also possible that SHRGSSAT affects gas and brine flow patterns within the repository. The exclusion of SHRGSSAT and BPINTPRS from the regression analysis reduces the $R^{2}$ value of the final regression model from 0.76 to 0.75 . 
As discussed in conjunction with Fig. 7, WMICDFLG completely controls the amount of gas generation due to microbial degradation. For total gas generation due to conosion and microbial degradation, WMICDFLG is also the dominant variable (Table 4). After WMICDFLG, the regression analysis for total gas generation selects variables also selected in the regression analysis for gas generation due to corrosion (i.e., HALPOR, WGRCOR, WASTWICK, SHRGSSAT, ANHPRM). The two dominant variables with respect to total gas generation are WMICDFLG and $H A L P O R$, with these two variables producing patterns that are easily identified in scatterplots (Fig. 12). The three bands of points in the scatterplot for HALPOR result from the effects of the three values that WMICDFLG can take on

The analysis outcomes amount of gas generated by corrosion (Fig. 7), amount of steel remaining in the repository (Fig. 8) and amount of brine consumed by corrosion (Fig. 13) are highly correlated (Fig. 14). Thus, the sensitivity analysis results for amount of gas generated by corrosion (Fig. 11, Table 4) are also indicative of the variables affecting the amount of steel remaining in the repository and the amount of brine consumed by corrosion.

The computational grid used in the 1996 WIPP PA is based on dividing the repository into a single lower, or downdip, waste panel and nine upper waste panels, with the panel closures placed between these two groups of panels (Figs. 1, 3, Ref. 2). For disturbed conditions, BRAGFLO calculations are performed with the assumption that the associated drilling intrusion takes place into the single lower panel. Further, spallings and direct brine release calculations distinguish between drilling intrusions into upper and lower waste panels. The rationale for this selection was based on the belief that intrusions into a downdip panel might be somewhat worse from a release perspective than intrusions into an updip panel due to brine flow down the $1^{\circ}$ dip on which the repository is constructed. Given the role that distinctions between intrusions into upper and lower waste panels will play in the release calculations, it is useful to examine the differences in conditions in these two sets of panels.

On a fractional basis, more steel is consumed in the lower waste panel than in the upper waste panels (Fig. 15). This pattern occurs because the lower waste panel receives more brine inflow relative to its volume than the upper waste panels. As indicated by the many level curves for fraction of steel in the upper waste paneis, the corrosion of steel ceases for many sample elements due to brine depletion. In contrast, this behavior is less pronounced for the lower waste panel, which receives more brine inflow from the marker beds relative to its volume than does the upper waste panels. Also, the lower waste panel receives brine that initially enters the upper waste panels and then flows doun dip into the lower waste panel.

The variables WGRCOR, WASTWCK and HALPOR have negative effects on the amount of steel remaining in both the upper and lower waste panels (Fig. 15). That is, increasing each of these variables tends to decrease the fraction of steel remaining. The variable WMICDFLG also appears in the analysis for the lower waste panel (Fig. 15). The appearance of WMICDFLG in the analysis for the lower waste panel but not the upper waste panels results because reducing brine inflow from the marker beds has a greater impact on a per unit volume basis in the 
lower waste panel than it does in the upper waste panels. Specifically, the volume of the upper waste panels is 9 times the volume of the lower waste panel. Thus, as similar amounts of brine flow out of the marker beds at the northern and southern ends of the computational grid (Fig. 2), the lower waste panel receives approximately 9 times more brine from the marker beds for each unit of steel that it contains than is received by the upper waste panels. Due to the linkage of gas generation and removal of steel (Fig. 14) and the fact that most gas generation takes place in the upper waste panels, the PRCCs in Fig. 15 for the fraction of steel remaining in the upper waste panels and the PRCCs in Fig. 11 for gas generation from corrosion appear with the appropriate reversal in sign.

Regression analysis can also be used to investigate variable importance with respect to fraction of steel remaining in the upper and lower waste panels (Table 5). For the upper panels, HALPOR, WGRCOR and WASTWICK have negative effects on the fraction of steel remaining, which is consistent with the analysis with PRCCs (Fig. 15). The variable WMICDFLG is also indicated as having a small positive effect, which is consistent with its roie in impeding brine inflow from the marker beds. Small effects are also indicated for SHRGSSAT and BPINTPRS, with the selection of BPINTPRS and possibly the selection of both variables being spurious. However, it is also possible that SHRGSSAT may affect gas and brine flow patterns within the repository. For the lower panel, WMICDFLG, WGRCOR and HALPOR have effects consistent with those observed in the analysis with PRCCs (Fig. 15). The variables ANHPRM and HALPRM are selected with negative regression coefficients, which corresponds to the role that these variables play in increasing brine flow to the repository (Table 2). The selection of SHRGSSAT at the end of the regression may be spurious. For perspective, Fig. 16 shours scatterplots for the first three variables selected in each regression for fraction of steel remaining.

The patterns of steel consumption in the upper and lower waste panels propagate through into the panterns of gas production (Fig. 17). When microbial degradation takes place, all the cellulose in the repository is consumed by 2000 yr (Fig. 8), with the result that the time-dependent patterns of gas generation after 2000 yr are determined by corrosion. Thus, the more pronounced cessation of steel consumption in the upper waste panels than in the lower waste panel (Fig. 15) carries through to a corresponding leveling off of gas production in the upper waste panels (Fig. 17).

The dominant variables with respect to gas production in the upper and lower waste panels are WMICDFLG, HALPOR, WGRCOR and WASTWICK, although there is some difference in their relative effects between the upper and lower panels (Fig. 17). For example, WMICDFLG remains more important over time for gas generation in the upper paneis than in the lover panel. The upper and lower panels produce similar amounts of gas by microbial degradation on a unit volume basis; however, the lower panel produces more gas due to corrosion on a unit volume basis because of greater availability of brine. As a result, WMICDFLG is more important with respect to gas generation in the upper paneis than in the lower panel. Similarly. HALPOR is more important to gas generation due to corrosion in the upper panels than in the lower panel due to the reduction of the imponance of HALPOR in the 
lower panel owing to the inflow of brine from the marker beds. Similar results for gas generation in the upper and lower panels are also obtained with regression analysis (Table 5).

\section{Undisturbed Conditions: Pressure}

Pressure in the repository under undisturbed conditions influences the extent to which contaminated brine migrates from the repository into the marker beds and also the size of the spallings ${ }^{15}$ and direct brine ${ }^{16}$ releases associated with initial drilling intrusions into the repository. Thus, repository pressure is one of the most important results obtained from modeling brine and gas flow in the vicinity of the repository.

The pressure in the repository tends to initially increase rapidly and then to either approach an asymptote or show a decreased rate of increase (Fig. 18). The results in Fig. 18 are for the lower waste panel (Fig. 1, Ref. 2); however, due to limited resistance to gas flow in the DRZ and panel closures, pressure is almost the same throughout the repository, operations area and experimental area. The 1996 WIPP PA was performed with three replicated LHSs of size 100 (Sect 8, Ref. 3), with the results for repository pressure being quite stabie across replicates (Fig. 19). Thus, the distribution of this important variable that results from subjective uncertainty is being estimated quite well within the analysis.

The dominant contributor to the uncertainty in pressure is MMICDFLG (Fig. 18), with pressure tending to increase as WMICDFLG increases. As previously discussed, WMICDFLG controls the amount of gas gherated by microbial degradation of cellulose. At early times WGRCOR and WASTWICK are also important with respect to pressure, with pressure tending to increase as each of these variables increases. Increases in WGRCOR and WASTWICK tend to increase gas pressure at early times by increasing the rate at which steel is consumed by corrosion. However, neither variable affects the total amount of corrosion that will take place, with the result that their influence on pressure tends to decrease with time. In contrast, HALPOR has little effect on pressure at early times, but increases steadily in importance with time. This effect results because corrosion occurs only under inundated conditions. Given that corrosion consumes brine, increased brine in the repository results in more corrosion and hence in higher pressures. As discussed in Sect. 2, HALPOR is the dominant determinant of the amount of brine that enters the repository and hence of the amount of gas produced by comosion. The variable HALPOR has little or no effect on pressure at earlier times because of the availability of brine from other sources and the dominance of gas generation by the microbial degradation of cellulose. However, at later times it is the brine infiow associated with HALPOR that allow's corrosion to continue.

There is a well-defined relationship between cumulative gas generation and repository pressure (Fig. 20). with the results at 10,000 y showing slightly more scanter than the results at $2000 \mathrm{yt}$ due to increased time for gas migration into the marker beds. The strong positive correlation berween gas generation and repository pressure 
results in the PRCCs in Fig. 11 for total gas generation and the PRCCs in Fig. 18 for repository pressure being almost identical.

Stepwise regression analysis (Table 6) provides an alternative to the analysis based on PRCCs in Fig. 18. The first three variables identified in the regression analysis are WMICDFLG, HALPOR and WGRCOR, which are also the top three variables identified in the analysis with PRCCs at 10,000 yr. In addition, the regression analysis also identifies positive effects for ANHPRM and SALPRES. Increased values for ANHPRM tend to increase brine flow out of the marker beds and thus increase pressure by increasing gas generation due to corrosion (Tables 2,4 ). Increased values for SALPRES tend to reduce gas and brine movement into the marker beds and thus increase pressure in the repository. Increased values for SHRGSSAT are associated with increased gas generation due to corrosion (Table 4) and thus increased gas pressure in the repository; however, the selection of SHRGSSAT in Table 4 may be spurious. It is also possible that SHRGSSAT may effect gas and brine movement across the computational cells associated with the shaft (i.e., regions 10, 11 in Fig. 1, Ref. 2). Because of the strong positive correlation berween gas generation and pressure (Fig. 20), the regression analysis in Table 6 for repository pressure and the regression analysis in Table 4 for total gas generation are very similar.

Pore volume in the repository (Fig. 21) changes in response to changes in pressure (Fig. 22). Due to the strong positive correlation between pore volume and pressure, sensitivity analysis for pore volume produces results similar to those obtained for repository pressure (Fig. 18, Table 6). The coupling between pore volume and pressure is implemented in the calculation through relationships determined with the SANTOS program (Sect. 4, Ref 2 ).

\section{Undisturbed Conditions: Brine Saturation}

Linilike pressure, there is considerable variation between the brine saturation conditions at the southern and northern ends of the repository (Fig. 23). At both ends, brine saturation increases rapidly in the first 50 to $1000 \mathrm{yr}$ due to brine flow from the DRZ (Fig. 1) and reduction in pore volume due to compaction of the waste (Fig. 21). After this period of rapid increase, brine saturation tends to decrease as brine is consumed more rapidly by corrosion than it is replaced by inflow. Due to the computational grid in use (Fig. 1, Ref. 2), the lower waste panel receives more brine inflow from the marker beds relative to its size than the upper waste panels (Fig. 2). The lower panel is also at the doundip end of the repository, with the result that it can also receive brine flowing down from the upper paneis. As a result the lower panel receives more brine on a unit volume basis than the upper panels and thus tends to have a higher brine saturation.

Brine saturation is dropping to zero for some sample elements. with this tending to occur less often for the lower waste panel than for the upper waste panels (Fig. 23). Further. brine saturation is more likely to remain at zero for the upper waste panels than the lower uaste panel. When brine saturation goes to zero in a given computational cell (Fig. 3. Ref. 2). corrosion stops but will resume if brine saturation subsequently increases. The complete cessation of 
corrosion is indicated by the level steel fraction curves in Fig. 15, with such cessation occurring for more sample elements in the upper waste panels than in the lower waste panel.

The estimated mean and percentile curves for brine saturation show less stability across replicates than the curves for pressure (Figs. 19, 24). This reduced stability results from a limited number of sample elements producing very high brine saturations while most sample elements produce much lower brine saturations (Fig. 23).

The dominant variables with respect to the uncertainty in brine saruration in the lower waste panel are $H A L P O R$, WMICDFLG, WGRCOR, WASTWICK and ANHPRM (Fig. 23). The positive effect for HALPOR results because increasing HALPOR increases the flow of brine into the lower waste panel from the DRZ in the first 50 to $100 \mathrm{yt}$ of the calculation and thus contributes to the rapid rise in brine sanuration during this early time period (Fig. 23). However, some of this rapid initial increase in brine saturation is also due to the compaction of the repository at early times (Fig. 21). The negative effect for WMICDFLG results because increasing WMICDFLG increases pressure in the repository, which in turn increases pore volume and decreases brine inflow from the marker beds. Both of the preceding effects will tend to reduce brine saturation. The negative effects for WGRCOR and WASTWICK result from increasing the rate at which brine is consumed by corrosion, which in turn tends to reduce brine saturation by both removing brine and increasing pore volume due to increased pressure. Finally, the positive effect for $A N H P R M$ results because increasing $A N H P R M$ increases brine flow from the marker beds and thus increases saturation in the lower waste panel.

Similar effects are also indicated for HALPOR, WMICDFLG, WGRCOR and WASTWICK in the analysis for brine sanuration in the upper waste panels (Fig. 23). However, the patterns of importance for HALPOR and WMICDFLG are changed, with HALPOR showing greater importance over the entire 10,000 yr period than for the lower waste panel and WMICDFLG showing a significant effect at only early times. These changes occur because brine inflow from the marker beds is more important in determining saturation in the lower waste panel than in the upper waste panels, with the result that WMICDFLG has more influence through time on the saturation conditions in the lower waste panel than on the saturation conditions in the upper waste panels. Because WMICDFLG has less effect through time on the sanuration conditions in the upper panels, HALPOR will correspondingly tend to remain more important through time.

Regression analysis provides an altemative way to investigate the effect of uncertain variables on brine saturation in the upper and lower waste panels (Table 7) and produces results similar to those obtained with PRCCs (Fig. 23). For the lower panel the variabies HALPOR, WMICDFLG, WGRCOR, WASTWICK and ANHPRM identified with PRCCs are also identified in the regression analysis with effects of the same sign (i.e.. saturation increases as HALPOR and ANHPRM increase and saturation decreases as WMICDFLG. WGRCOR and WASTWTCK increase). Furher. the regression analysis identifies $W R B R N S A T$ and HALPRM as having negative and positive effects. respectively: on brine samuation in the lower panel. The positive effect for HALPRM results because 
increasing HALPRM tends to increase brine flow into the repository. The reason for the negative effect associated with WRBRNSAT is not clear; intuitively, it seems like increasing WRBRNSAT should increase brine saturation. A possibility is that increasing WRBRNSAT makes it more difficult for brine to flow into the repository as brine saturation is reduced below WRBRNSAT in individual computational cells due to consumption in the corrosion process. Another possibility is that the use of brine saturation and WASTWICK to define an effective saturation for the implementation of corrosion (i.e., $S_{b, e p)}$ ) may result in the small negative effect observed for WRBRNSAT.

For the upper waste panels, the variables HALPOR, WGRCOR, WMICDFLG and WASTWICK are identified in both the PRCC analysis (Fig. 23) and the regression analysis (Table 7) as having similar effects on brine saturation. In addition, the regression analysis also identifies WRBRNSAT, HALPRM and ANHPRM. The positive effects for HALPRM and ANHPRM result from increasing brine inflow to the repository. It is also possible that increasing HALPRM and ANHPRM may increase brine saturation by increasing gas movement away from the repository, which would reduce pressure and thereby reduce pore volume and thus increase brine saturation. As for the lower waste panel, the reason for the selection of WRBRNSATT with a negative regression coefficient is not immediately apparent. For perspective, scanerplots for the top three variables in each of the regression analyses in Table 7 are shown in Fig. 25.

In addition to brine saturation, brine volume in the waste panels is also important because it influences the amount of dissolved, and hence mobile, radionuclides in the repository. Volume of brine in the upper waste panels tends to increase at very early times (i.e., in the first few hundred years) and then decrease monotonically (Fig. 26). In contrast, brine volume in the lower panel shows a more complex pattern of behavior, with brine volume tending to increase over the entire 10,000 yr period for some sample elements and displaying a pattern of early increase followed by monotonic decrease for other sample elements (Fig. 26).

The dominant variables with respect to brine volume in the upper panels identified by PRCCs are HALPOR, W'GRCOR and WASTWICK, with brine volume tending to increase as HALPOR increases and decrease as WGRCOR and WASTWICK increase (Fig. 26). These effects result because HALPOR influences the amount of brine that enters the reposirory due to drainage from the DRZ (Fig. 3, Table 2) and WGRCOR and WASTWICK influence the rate at which brine is consumed by corrosion (Fig. 13, Table 5, with fraction of steel remaining having a rank correlation of -1 with amount of brine consumed). The negative effect for SALPRES at early times is probably spurious and resuits from $H A L P O R$ having a PRCC ciose to 1 .

Regression analysis provides an alternative determination of variable imporance for volume of brine in upper panels (Table 8 ) and also identifies HALPOR, WGRCOR and WASTWICK as important variables with similar effects as in the analysis with PRCCs. In addition the analysis indicates that brine volume increases as $A N H P R M$ and HALPRM increase and decreases as WMICDFLG and WRBRNSAT increase. The effects of these variables have been previously discussed in the context of brine saruration. Indeed. the sensitivity analyses for brine saruration 
(Fig. 23, Table 7) and brine volume (Fig. 26, Table 8) are very similar due to the substantial correlations that exist between brine saturation and brine volume in the upper and lower waste panels (Fig. 27).

As for the upper waste panels, the sensitivity analyses for brine volume in the lower panel (Fig. 26, Table 8) are very similar to the corresponding results for brine saturation in the lower panel (Fig. 23, Table 7). In particular, brine volume tends to increase as $H A L P O R, A N H P R M$ and $H A L P R M$ increase and tends to decrease as WMICDFLG, WGRCOR, WRBRNSAT and WASTWICK increase, with these effects having been previously discussed in conjunction with brine saturation.

\section{Undisturbed Conditions: Brine and Gas Outflow}

The anhydrite marker beds provide a possible pathway by which brine can flow away from the repository (Fig. 28). However, the amount of brine that leaves the repository through the marker beds (i.e., at the boundary between the marker beds and the DRZ) tends to be smaller than the amount of brine that enters by this pathway (i.e., compare Figs. 1 and 28). Most sample elements result in no brine flow away from the repository in the marker beds (i.e., less than half of the sample elements result in nonzero cumulative brine flows in Fig. 28).

The largest brine flous anay from the repository take place in $M B 139$, with the next largest flows taking place in MB 138 and the smallest flows taking place in anhydrite layers A and B (Fig. 29). Further, the brine flows from the repository into the shaft tend to be intermediate in size between those into MB 139 and 138 (Fig. 29), although the largest flows into MB 138 are larger than the largest flows into the shaft.

The PRCCs in Fig 28 indicate that WMICDFLG and HALPOR are the two most important variables with respect to brine flow auzy from the repository, with this flow tending to increase as each of these variables increases. Increasing each of these variables increases gas generation and thus pressure in the repository, which in turn increases the pressure gradient into the marker beds. The scatterplots in Fig. 30 provide a summary of the effects of WMICDFLG and HALPOR at 10,000 yт.

The variables HMICDFLG and HALPOR are also the most important variables for brine movement into the individual marker beds (Table 9). In addition, small effects are indicated for several other variables. Increasing W'GRCOR and WASTHICK tends to increase brine movement into the marker beds due to their role in increasing pressure, and increasin S.ALPRES tends to decrease movement into the marker beds by increasing marker bed pressure. Positive effects are also indicated for ANHPRM and HALPRM. These two variables potentially play a dual role by initially increasing brine inflow to the repository and thus pressure due to gas generation by corrosion, and then by reducing resistance to brine flow away from the repository as pressure increases. The individual regression models tend to have relatively low $R^{2}$ values (i.e., 0.51 to 0.62 ) due to the large number of vectors in which no brine flow into the marker beds sakes place (Fig. 30 ). 
The last regression in Table 9 is for brine movement in the shaft away from the repository at the top of the DRZ. The size of the movements is small and typically around $10 \mathrm{~m}^{3}$ (Fig. 29). A number of variables are identified as affecting this movement but the final regression model has an $R^{2}$ of only 0.58 . The two most important variables are WMICDFLG and SHRGSSAT, with brine flow away from the repository tending to increase as each of these variables increases. Increasing WMICDFLG increases pressure in the repository and hence the movement of brine away from the repository. Increasing SHRGSSAT changes brine flow patterns in the vicinity of the shaft. For perspective, scatterplots for WMICDFLG and SHRGSSAT are presented in Fig. 31, with the positive effects indicated in the regression model apparent but weak.

Brine flow away from the repository in the marker beds provides a potential mechanism for radionuclide transport to the accessible environment. However, flows across the land withdrawal boundary (i.e., the subsurface boundary of the accessible environment) away from the repository are zero or very small for most sample elements (Figs. 32, 33). Generally, more flow crosses the land withdrawal boundary moving axay from the repository to the north than to the south (Fig. 33). However, it is a mistake to assume that the brine flows in Fig. 33 crossing the land withdrawal boundary originated in the repository. The pressurization of the marker beds can cause the movement actoss the land withdrawal boundary of brine that was initially present in the marker beds and has never had contact with the waste. For perspective, curnularive flows from the shaft into the Rustler Formation are also shown (Fig. 33). Again, it is a mistake to assurne that these flow's necessarily originated in the repository.

The dominant variable affecting brine flow in the marker beds across the land uithdrawal boundary away from the repository is $A N H P R M$, with this flow tending to increase as $A N H P R M$ increases due to reduced resistance to flow (Fig. 32, Table 10). The regressions for flow to the south (Table 10) have low $R^{2}$ values (i.e., 0.20 to 0.23 ) due to the large number of zero results (Fig. 33). However, the models for flow to the north and also for total flow are also rather poor with $R^{2}$ values of $0.80,0.59,0.33$ and 0.65 (Table 10) due to the large number of zero or very small flows (Fig. 34). However, when flow does occur, it takes place for larger values of ANHPRM and also tends to increase as ANHPRM increases (Fig. 34).

The last regression in Table 10 is for brine flow out of the shaft into the Culebra. Brine flow out of the shaft is much greater than brine flow into the shaft at the repository (Figs. 29, 33). Thus, most of the brine exiting the shaft into the Culebra did not enter the shaft directly from the repository. The variables SHPRMCLY and SHPRMHAL appear in the regression model with positive regression coefficients because increasing their values reduces resistance to flow. The variables H.ALPRM and SALPRES appear in the regression model with positive regression coefficients because increasing their values tends to increase brine movement from the Salado halite to the shaft. Finally. WMICDFLG also appears in the regression model with a positive coefficient because increasing its values tends 10 increase repository pressure and thus increase brine movement away from the repository. 
Gas flow can also take place in the anhydrite marker beds away from the repository, although little appreciable gas movement takes place for most sample elements (Fig. 35). Most gas movement in the individual marker beds tends to take place to the north (Fig. 36). In particular, MB 139 South experiences little gas inflow due to the tendency of brine to drain to its interface with the DRZ (Fig. 36).

The dominant variable in determining the amount of gas that moves away from the repository is WMICDFLG, with gas movement tending to increase as WMICDFLG increases due to increased repository pressure (Fig. 35, Table 11). In addition, gas movement tends to increase with increasing values for HALPOR, WGRCOR and $A N H P R M$, and to decrease with increasing values for $A N H B C V G P$ and SALPRES. Increasing HALPOR and $W G R C O R$ increases gas generation and hence pressure in the repository. Increasing $A N H P R M$ increases repository pressure by increasing gas generation due to corrosion and also reduces resistance to gas flow into the marker beds. In contrast, increasing SALPRES reduces gas flow into the marker beds by increasing the pressure within the marker beds. The negative effect for $A N H B C V G P$ indicates that gas is more likely to move into the marker beds when the Brooks-Corey model is in use. The very low $R^{2}$ value for gas movement into MB 139 South (i.e., 0.28 ) results from the large number of sample elements in which no gas movement takes place (Fig. 36). Scatterplots for the three most important variables with respect to gas movement away from the repository (i.e., WMICDFLG, HALPOR and $A N H B C V G P$ ) are given in Fig. 37, with the positive effects for WMICDFLG and HALPOR and the negative effect for $A N H B C V G P$ being discemible within these plots.

Very little gas movement takes place through the shaft to the Culebra (Fig. 36). Due to the large number of zero and very small (ie, probably numerical noise) results, the corresponding regression analysis (Table 11) produces rather poor results (i.e., $R^{2}=0.49$ ). However, examination of scatterplots shows the nonzero gas releases tend to be associated with small values for SHRGSSAT (Fig. 38).

The increased pressurization of the marker beds that results from gas generation in the repository can cause the marker beds to fracture and increase in pore volume (Fig. 39). However, pressure induced fracturing does not occur for most sample elements. Fracturing occurs almost equally to the north and south of the repository, with perhaps a slight tendency touards a greater increase in fracture-induced pore volume to the north (Fig. 40). Due to changes in pressure, the additional pore volume associated with fracturing can both increase and decrease with time (Fig. 39).

Due to its infuence on volume of gas generated and hence repository pressure, WMJCDFLG is the most important variable with respect to pore volume increase due to fracturing, with pore volume tending to increase as WMICDFLG increases (Fig. 39, Table 12). In addition, pore volume tends to increase as HALPOR and WGRCOR increase due to increased gas generation and to decrease as S.ALPRES increases due to reduced gas and brine inflow to the marker beds (Table 12). However, the $R^{2}$ values for the individual regression models tend to be low (i.e.. 0.31 to 0.49 in Table 12 ) due to the large number of observations that result in no increase in pore volume. Scatterplots 
for the effects of WMICDFLG, HALPOR, SALPRES and $W^{\prime} G R C O R$ on pore volume increase at $10,000 \mathrm{yr}$ are shown in Fig. 41 , with the two strongest trends involving WMICDFLG and HALPOR.

Fracturing is of concern because it can create zones of enhanced permeability between the repository and the boundary with the accessible environment (i.e., the land withdrawal boundary), which is $2.75 \mathrm{~km}$ from the repository. The longest observed fractures were approximately $2 \mathrm{~km}$ in length (Table 13) and thus did not reach the accessible environment. Further, most sample elements result in no fracturing of the marker beds (Table 13). As for fracture volume, fracture length can both increase and decrease with time due to changes in pressure (Fig. 42).

Fracture volume (Fig. 40) and length (Table 13) are highly correlated. Specifically, rank correlations of 0.9999 , $0.9994,0.9997,0.9996,0.9991$ and 0.9987 exist between fracture volume and length for MB 138 North, MB 138 South, Anhydrites a and $b$ North, Anhydrites $a$ and $b$ South, MB 139 North, and MB 139 South. Thus, the sensitivity analysis results obtained for fracture volume (Table 12, Fig. 41) also apply to fracture length.

\section{Discussion}

Lincerainty and sensitivity analysis procedures based on Latin hypercube sampling. examination of scanterplots, stepuise regression analysis, partial correlation analysis, and rank transformations were used to investigate brine inflow; gas generation, repository pressure, brine saturation, and brine and gas outflow in the vicinity of the repository under undisturbed conditions. Regression analyses and partial correlation analyses based on ranktransformed data generally performed better than analyses based on raw (i.e., untransformed) data. In some cases, nonlinear relationships between the input (i.e., sampled) and output (i.e., predicted) variables gave rise to poor results with rank-transformed data; in these cases, the examination of scatterplots was used to develop an understanding of the relationships between the input and output variables.

The sampled variables were assigned distributions that characterized subjective uncertainty. ${ }^{3}$ Thus, the presented uncertainty and sensitivity analysis results are showing the effects of subjective, or state of knowledge, uncentainty and result from an integration over the probability space $\left(\mathrm{S}_{s u}, \&_{s u}, p_{s u}\right)$ associated with subjective uncertainty (Sect. 5. Ref. 11). Further, all results are conditional on the existence of undisturbed conditions at the repository, which is equivalent to being conditional on the element $x_{s t .0}$ of the sample space $\mathrm{S}_{s t}$ associated with the probability space $\left(S_{s t} \&{ }_{s t} . p_{s s}\right)$ for stochastic uncerainty that corresponds to undisturbed conditions (Sect. 12. Ref. 4).

Of the results under study, repository pressure is potentially the most important due to its influence on spallings ${ }^{15.17}$ and direct brine ${ }^{16}$ releases. In particular, no spallings and direct brine releases are believed to have the potential to occur when repositor pressure is below $8 \mathrm{MPa}$, which is the pressure exerted by a column of drilling fiuid at the depth of the repositor. ${ }^{\text {is }}$ The uncertainty analysis showed that in the context of the assessed subjective 
uncertainty in the analysis, there is a significant likelihood (i.e., degree of belief) that pressure in the repository under undisturbed condirions will rise above $8 \mathrm{MPa}$ (Fig. 18). Further, this assessment was found to be quite stable over the three independent LHSs in use (Fig. 19). Sensitivity analysis showed that the uncertainty in repository pressure is dominated by the extent to which microbial degradation of cellulose takes place, the rate at which the corrosion of steel takes place, and the amount of brine that drains from the surrounding disturbed rock zone into the repository (Fig. 18, Table 6).

Brine sanuration can affect direct brine releases, with no direct brine releases taking place for saturations below approximately 0.4 (Figs. 8, 11, Ref. 16). Brine saturations were generally lower in the upper (i.e., updip) waste panels than in the lower (i.e., downdip) waste panel (Fig. 23). In both the upper and lower waste panels, the brine saturation was often too low to produce direct brine releases. The uncertainty in brine saturation was dominated by the amount of brine that drains from the surrounding disturbed rock zone into the repository, the rate at which the corrosion of steel takes place, the extent to which brine wicking into the waste occurs, and the extent to which microbial degradaion of cellulose occurs (Fig. 23, Table 7). Brine saturation was not used in the calculation of spaliings releases in the 1996 WIPP PA but may be an important input in future calculations of spallings releases. ${ }^{17.19}$

Another analysis outcome of importance is pressure-induced fracturing in the anhydrite marker beds in the vicinity of the repository and the subsequent movement of brine auray from the repository in these fracrures. Such brine movement is potentially important because it can transport radionuclides away from the repoštory. The uncertainty analysis showed limited fracnuring of the anhydrite marker beds, with none of the fractures reaching the boundary of the accessible environment at approximately $2.8 \mathrm{~km}$ from the repository (Fig. 42, Table 13). Further, little brine flow across the boundary with the accessible environment and away from the repository was observed (Fig. 33), with most of the flows having never been in contact with the waste.

Brine flow up or down the sealed shaft is also of potential importance. However, the shaft seals were found to be quite effective, with essentially no brine flow between the repository and the Culebra Dolomite taking place in the shafts (Figs. 6, 29, 33).

In addition to providing insights on the uncertainty in predictions of impontant variables and the input variables that give.rise to this uncerainty, the uncertainty and sensitivity analysis techniques in use provide a powerful tool for model verification in particular, the extensive sensitivity analysis results provide an opportunity to examine many anainsis outcomes for anomalous behavior that may be due to an error in the development of the underlying model or the implementation of the analysis. Forrunately, no such errors were found.

The development of two-phase flow modeling as part of the WIPP PA can be traced through a sequence of uncertainty and sensinivity analyses performed as part of the 1991 WIPP PA (Refs. 20-25). the 1992 WIPP PA 
(Vols. 4, 5, Ref. 26) and the applications of a systems prioritization methodology (Ref. 27). The general tendency through time has been toward more detailed representations of the geometry of the repository and the processes that take place in the vicinity of the repository. As more detailed modeling and more refined parameter values are used, the trend has been towards lower estimated repository pressures.

Although of interest by themselves, results contained in this presentation also constitute inputs to other parts of the 1996 WIPP PA. In particular, pressure results are used as input to the spallings calculations, ${ }^{15}$ pressure and brine sanuration results are used as input to the direct brine release calculations, ${ }^{16}$ and brine flow patterns are used as input to the radionuclide transport calculations. 28

\section{Acknowledgment}

Work performed for Sandia National Laboratories (SNL), which is a multiprogram laboratory operated by Sandia Corporation, a Lockheed Martin Company, for the United States Deparment of Energy under contract DE-AC04-94.AL85000. Review provided at SNL by M. Chavez, C. Crawford and M.S. Tierney. Editorial suppor provided by L. Harrison. T. Allen and H. Radke of Tech Reps, Inc.

\section{References}

1. Helton, J.C., Bean, J.E., Economy, K., Garner, J.W., MacKinnon, R.J., Miller, J., Schreiber, J.D., \& Kaughn, P. Uncertainty and Sensitivity Analysis for Two-Phase Flow in the Vicinity of the Repository in the 1996 Performance Assessment for the Waste Isolation Pilot Plant: Disturbed Conditions, Reliability Engineering and System Safety (in this issue).

2. Vaughn, P., Bean, J.E., Helton, J.C., Lord, M.E., MacKinnon, R.J., \& Schreiber, J.D. Representation of TwoPhase Flow in the Vicinity of the Repository in the 1996 Performance Assessment for the Waste Isolation Pilot Plant Reliabiliny Engineering and System Safery (in this issue).

3. Helton, J.C., Martell M.-A., \& Tiemey, M.S. Characterization of Subjective Uncertainty in the 1996 Performance Assessment for the Waste Isolation Pilot Plant, Reliability Engineering and System Safeny (in this issue).

4. Helion. J.C., Davis, F.J., \& Johnson J.D. Characterization of Stochastic Uncertainty in the 1996 Performance Assessment for the Waste Isolation Pilot Plant, Reliability Engineering and Sistem Safety (in this issue).

5. Helton J.C. 1993. "Lincertainty and Sensitivity Analysis Techniques for Lise in Performance Assessment for Radioactive Waste Disposal." Reliabiliț Engineering and Sistem Safern; 42 (2-3). 327-367.

6. Iman R.L.. \& Conover. W.J.. The Lise of the Rank Transform in Regression. Technometrics 1979, 21 (4), 499509. 
7. Iman, R.L., Davenport, J.M., Frost, E.L., \& Shortencarier, M.J., Stepwise Regression with PRESS and Rank Regression (Program Liser's Guide), SAND79-1472, Sandia National Laboratories, Albuquerque, NM. 1980.

8. WIPP PA (Performance Assessment), WIPP PA User's Manual STEPWISE, Version 2.20. Document Version 1.00, Sandia WIPP Central Files WPO $\$ 27768$, Sandia National Laboratories, Albuquerque, NM, 1995.

9. Iman, R.L., Shortencarier, M.J., \& Johnson, J.D. A FORTRAN 77 Program and User's Guide for the Calculation of Partial Correlation and Standardized Regression Coefficients. NUREG/CR-4122. SAND850044, Sandia National Laboratories, Albuquerque, NM, 1985.

10. WTPP PA (Performance Assessment), PCCSRC, Version 2.21, User's Manual,[Document Version 1.0], Sandia WIPP Central Files WPO \#27773, Sandia National Laboratories, Albuquerque, NM, 1995.

11. Helton, J.C., Anderson, D.R., Basabilvazo, G., Jow, H.-N., \& Marietta, M.G., Conceptual Structure of the 1996 Performance Assessment for the Waste Isolation Pilot Plant, Reliability Engineering and System Safety (in this issue).

12. U.S. Department of Energy, Title 40 CFR Par! 191 Compliance Certification Application for the Waste Isolation Pilot Piant, DOE/CAO-1996-2184, Volumes I-XXI. U.S. Department of Energy, Carlsbad Area Office, Carlsbad NM 1996.

13. Helton, J.C., Bean J.E., Berglund, J.W., Davis, F.J., Economy, K., Garner, J.W., Johnson, J.D., MacKinnon, R.J., Miller, J., O'Brien, D.G., Ramsey, J.L., Schreiber, J.D., Shinta, A., Smith, L.N., Stoelzel, D.M., Stockman, C., \& Vaughn, P., Uncertainn and Sensitivity Analysis Results Obtained in the 1996 Performance Assessment for the Waste Isolation Pilot Plant, S.AND98-0365, Sandia National Laboratories, Albuquerque, NM, 1998.

14. Iman, R.L., \& Conover, W.J., A Modern Approach to Statistics, John Wiley \& Sons, New York, NY, 1983.

15. Berglund, J.W., Gamer, J.W., Helton, J.C., Johnson, J.D., \& Smith, L.N. Direct Releases to the Surface and Associated Complementary Cumulative Distribution Functions in the 1996 Performance Assessment for the Waste Isolation Pilot Plant: Cuttings, Cavings and Spallings, Reliability Engineering and System Safety (in this issue).

16. Stoelzel, D.M.. O'Brien. D.G., Gamer, J.W., Helton. J.C., Johnson, J.D., \& Smith, L.N., Direct Releases to the Surface and Associated Complementary Cumulative Distribution Functions in the 1996 Performance Assessment for the Waste lsolation Pilot Plant: Direct Brine Release, Reliabiliti. Engineering and System Safery; (in this issue).

17. Knowles, M.K. Hansen, F.D., Thompson, T.W., Gross, M.B., \& Schatz, J.F., Review and Perspectives on Spallings Releases in the 1996 Performance Assessment for the Waste Isolation Pilot Plant, Reliabilin, Engineering and Sistem Safer. (in this issue).

18. Stoelzel, D.M.. \& O'Brien, D.G.. Analysis Package for the BRAGFLO Direct Relcase Calculations (Task 4) of the Performance Assessment Analyses Supporting the Compliance Certification Application. Sandia WIPP Central Files WPO $=40520$, Sandia National Laboratories, Albuquerque, NM. 1996. 
19. Hansen, F.D., Knowles, M.K., Thompson, T.W., Gross, M., McLennan, J.D., \& Schatz, J.F., Description and Evaluation of a Mechanistically Based Conceptual Model for Spall, SAND97-1369, Sandia National Laboratories, Albuquerque, NM, 1997.

20. Helton, J.C., Gamer, J.W., Rechard, R.P., Rudeen, D.K., \& Swif, P.N., Preliminary Comparison with 40 CFR Pant 191. Subpan B for the Waste isolation Pilot Plant, December 1991. Volume 4: Uncertainty and Sensitivity Analysis Results, SAND91-0893/4, Sandia National Laboratories, Albuquerque, NM, 1992.

21. WIPP PA (Performance Assessment), Long-Term Gas and Brine Migration at the Waste Isolation Pilot Plant: Preliminary Sensitivity Analyses for Post-Closure 40 CFR 268 (RCRA), May 1992, SAND92-1933, Sandia National Laboratories, Albuquerque, NM, 1992.

22. Helton, J.C., Bean, J.E., Butcher, B.M., Garner, J.W., Schreiber, J.D., Swif, P.N., \& Vaughn, P., Uncertainty and Sensizivity Analyses for Gas and Brine Migration at the Waste Isolation Pilot Plant, May 1992, SAND922013, Sandia National Laboratories, Albuquerque, NM, 1993.

23. Helton. J.C., Bean, J.E., Butcher, B.M., Garner, J.W., Schreiber, J.D., Swif, P.N., \& Vaughn, P., Uncertainty and Sensitivity Analysis for Gas and Brine Migration at the Waste Isolation Pilot Plant: Fully Consolidated Shaf. Nuclear Science and Engineering, 122 (1), 1-31, 1996.

24. Helton, J.C. Bean, J.E., Butcher, B.M., Garner, J.W., Schreiber, J.D., Swift, P.N., \& Vaughn, P., Uncertainty and Sensitivity Analysis for Gas and Brine Migration at the Waste Isolation Pilot Plant: Permeable Shaft with Panel Seals, Journal of Hazardous Materials, 45 (2-3), 107-139, 1996.

25. Helion, J.C., Bean, J.E., Butcher, B.M., Garner, J.W., Schreiber, J.D., Swift, P.N., \& Vaughn, P., Uncertainty and Sensirivity Analysis for Gas and Brine Migration at the Waste Isolation Pilot Plant: Pernteable Shaft without Panel Seals, Reliability Engineering and System Sajety, 57 (3), 299-316, 1997.

26. WIPP PA (Performance Assessment), Preliminary Performance Assessment for the Waste lsolation Pilot Plant. December 1992, Volumes 1-5, SAND92-0700/1-5, Sandia National Laboratories, Albuquerque, NM, 19921993.

27. Helton, J.C., Anderson, D.R., Baker, B.L., Bean, J.E., Berglund, J.W., Beyeler, W., Blaine, R., Economy, K., Gamer, J.W., Hora, S.C., Lincoln. R.C., Marietta, M.G., Mendenhall, F.T., Prindle, N.H., Rudeen, D.K., Schreiber, J.D., Shiver, A.W., Smith, L.N., Swift, P.N., \& Vaughn, P., Computational Implementation of a Systems Prioritization Methodology for the Waste Isolation Pilot Plant: A Preliminary Example, Reliabiliny Engineering and System Safen, 1997. 57(3), 223-266.

28. Stockman, C.T., Garner, J.W., Helton. J.C., Johnson, J. D., Shinta, A. \& Smith. L.N., Radionuclide Transport in the Vicinity of the Repository and Associated Complementary Cumulative Distribution Functions in the 1996 Performance Assessment for the Waste Isolation Pilot Plant, Reliabilin Engineering and Sistem Safeñ (in this issue). 
Figure Captions

Fig. 1. Cumulative brine flow into DRZ (BRAALIC) and into repository (BRNREPTC) under undisturbed conditions.

Fig. 2. Cumulative brine flow over 10,000 yr into DRZ (BRM38NIC, BRM38SIC, BRAABNIC, BRAABSIC, $B R M 39 N I C, B R M 39 S I C$, and $B R A A L I C)$ and into repository (BRNREPTC) under undisturbed conditions.

Fig. 3. Partial rank correlation coefficients for cumulative brine flow from marker beds (BRAALIC) and curnulative brine flow into repository (BRNREPTC) under undisturbed conditions with $A N H C O M P$ and HALCOMP excluded from calculation.

Fig. 4. Scatterplots for curmulative brine discharge from the marker beds (BRAALIC) over 10,000 yt under undisturbed conditions versus WMICDFLG and $A N H P R M$.

Fig. 5. Scatterplot for cumulative brine inflow to the repository (BRNREPTC) over $10,000 \mathrm{yr}$ under undisturbed conditions versus HALPOR.

Fig. 6. Cumulative brine flow down the shaft at the upper boundary of the DRZ (BRN_DNSH) under undisturbed conditions.

Fig. 7. Cumulative gas generation due to corrosion ( $\left.F E_{-} M O L E\right)$ and microbial degradation of cellulose (CELL_MOL) under undisturbed conditions.

Fig. 8. Time-dependent masses of steel $\left(F E_{-} K G\right)$ and cellulose (CELL_KG) in repository under undisturbed conditions.

Fig. 9. Cumulative gas generation due to microbial degradation of cellulose under inundated $\left(C E L L_{-} M_{-} I\right)$ and humid (CELL_M_H) conditions for undisturbed conditions.

Fig. 10. Cumulative gas generation due to both corrosion and microbial degradation of cellulose (GAS_MOLE) under undisturbed conditions.

Fig. 11. Partial rank correlation coefficients for cumulative gas generation due to corrosion of steel (FE_MOLE) and cumulative gas generation due to corrosion of steel and microbial degradation of cellulose ( $\left.\bar{G} . A S_{-} M O L E\right)$ under undisnurbed conditions with $A N H C O M P$ and $H A L C O M P$ excluded from calculation.

Fig. 12. Scatterplots for total gas generation over $10,000 \mathrm{yr}$ due to corrosion of steel and microbial degradation of cellulose (G.AS_MOLE) under undisturbed conditions versus WMICDFLG and HALPOR.

Fig. 13. Cumulative volume of brine consumed by corrosion ( $\left.B R N_{-} R M V\right)$ under undisturbed conditions.

Fig. 14. Scanerplot for amount of gas generated by corrosion ( $F E$ MOLE), amount of steel remaining in the repository (FE_KG) and amount of brine consumed by corrosion (BRN_RMV) at $10.000 \mathrm{yr}$ under undisturbed conditions. The scatterplot for amount of brine removed should actually be a straight line. with the resolution at uiich computational results were stored introducing the scatter in the plot.

Fig. 15. Uncertaint and sensitivity analysis results for fraction of steel remaining in upper waste panels (FEREM_R) (upper frames) and lower waste panel (FEREM_ $W$ ) (lower frames) under undisturbed conditions. 
Fig. 16. Scanterplots for fraction of steel remaining in upper waste panels ( $F E R E M_{-} R$ ) (left frames) and lower panel (FEREM_W) (right frames) for undisturbed conditions at 10,000 yт versus HALPOR, WGRCOR and WMICDFLG.

Fig. 17. Uncertainty and sensitivity analysis results for cumulative gas generation due to corrosion and microbial degradation in upper waste panels (GASMOL_R) (upper frames) and lower waste panel (GASMOL_W) (lower frames) for undisturbed conditions.

Fig. 18. Uncertainty and sensitivity analysis results for pressure in lower waste panel (WAS PRES) under undisturbed conditions.

Fig. 19. Mean and percentile curves for three replicated LHSs for pressure in lower waste panel (WAS_PRES) under undisturbed conditions.

Fig. 20. Scatterplots at 2,000 and 10,000 yr for cumulative gas generated by corrosion and microbial degradation (GAS_MOLE) under undisturbed conditions versus pressure in repository (WAS_PRES).

Fig. 21. Total pore volume in repository $\left(P O R V O L_{-} I\right)$ under undisturbed conditions.

Fig. 22. Scanerplots of pressure in repository (WAS_PRES) at 10.000 yr under undisturbed conditions versus total pore volume in repository ( $P O R V O L_{-} T$ ).

Fig. 23. Lincertainty and sensitivity analysis results for brine saturation in upper waste panels (REP_SATB) (upper frames) and lower waste panel (WAS_SATB) (lower frames) under undisturbed conditions.

Fig. 24. Percentile curves for three replicated LHSs for brine saturation in the lower (WAS_SATB) and upper waste paneis (REP_SATB) under undisturbed conditions.

Fig. 25. Scatterplots for brine saturation in upper waste panels (REP_SATB) (left frames) and lower waste panel (WAS_SATB) (right frames) for undisturbed conditions at 10,000 yr versus $H A L P O R$, WGRCOR, WASTWTCK, WMICDFLG and ANHPRM.

Fig. 26. Uncertainty and sensitivity analysis results for brine volume in upper waste panels (BRNVOL_R) (upper frames) and lower waste panel (BRNWOL $W$ ) (lower frames) under undisturbed conditions.

Fig. 27. Scatterplots for brine saturation and brine volume in upper (BRNVOL_R, REP_SATB) and lower (BRNVOL_W,WAS_SATB) waste panels under undisturbed conditions at $10,000 \mathrm{yr}$.

Fig. 28. Uncertainty and sensitivity analysis results for cumulative brine flow into marker beds away from repository (BRAALOC) under undisturbed conditions.

Fig. 29. Curmulative brine flow over 10,000 yr away from repository in marker beds (BRM38NOC, BRM38SOC, $B R A A B N O C, B R A A B S O C, B R M 39 N O C, B R M 39 S O C, B R A A L O C)$ and up shaft (BSCL8AOC) under undisturbed conditions.

Fig. 30. Scanerplots for cumulative brine flow away from the repository over $10.000 \mathrm{yt}$ in marker beds (BRAALOC) under undisturbed conditions versus WMICDFLG and HALPOR.

Fig. 31. Scatterplots for cumulative brine flow in shaft at boundary of DRZ and intact halite (BSCL8AOC) over 10.000 YT under undisnurbed conditions versus WMICDFLG and SHRGSSAT.

Fig. :2. Lincenaintr and sensitivity analysis results for cumulative brine flow in marker beds across land withdrawal boundary away from repository (BRA.ALLWC) under undisturbed conditions. 
Fig. 33. Cumulative brine flow over $10,000 \mathrm{yr}$ away from repository in individual marker beds at land withdrawal boundary ( $B R M 38 N L W, B R M 38 S L W, B R A A B N L W, B R A A B S L W, B R M 39 N L W, B R M 39 S L W, B R A A L L W C$ ) and in shaft at boundary with Rustler Formation (BRNSHUC) under undisturbed conditions.

Fig. 34. Scatterplots for cumulative brine flow in marker beds across land withdrawal boundary away from repository over 10,000 yr for MB 139 North (BRM39NLW) (left frames) and all marker beds (BRAALLWC) (right frames) versus (ANHPRM), (HALPOR) and (WMICDFLG).

Fig. 35. Uncertainty and sensitivity analysis results for cumulative gas flow into marker beds away from repository (GSAALOM) under undisturbed conditions.

Fig. 36. Cumulative gas flow's over 10,000 yr away from repository in individual marker beds (GSM38NOC, GSM38SOC, GSAABNOC, GSAABSOC, GSM39NOC, GSM39SOC, GSAALOM) and in shaft at boundary with Rustier Formation (GSMSHUPC) under undisturbed conditions.

Fig. 37. Scatterplots for cumulative gas flow in marker beds away from repository (GSAALOM) under undisturbed conditions over 10,000 yr versus WMICDFLG, HALPOR and $A N H B C V G P$.

Fig. 38. Scatterplors for cumulative gas flow in shaft away from repository at boundary with Rustler Formation (GSMSHL:PC) under undisnurbed conditions over 10,000 yr versus SHRGSSAT.

Fig. 39. Uncertainty and sensitivity analysis results for total pore volume increase in marker beds (PVOLI $\Pi$ under undisturbed conditions.

Fig. 40. Pore volume increase due to fracturing in individual marker beds (PVOLI38N, PVOLI38S, PVOLIABN, PVOLIABS, PVOLI39N, PVOLI39S, PVOLI $T$ ) at 10.000 yr under undisturbed conditions.

Fig. 41. Scatterplots for total pore volume increase due to fracturing in marker beds (PVOLI_T) at 10,000 yr under undisturbed conditions versus WMICDFLG, HALPOR, SALPRES and WGRCOR.

Fig. 42. Uncertainty and sensitivity analysis results for length of fracture zone in north MB 139 (FRACX39M) under undisturbed conditions. 

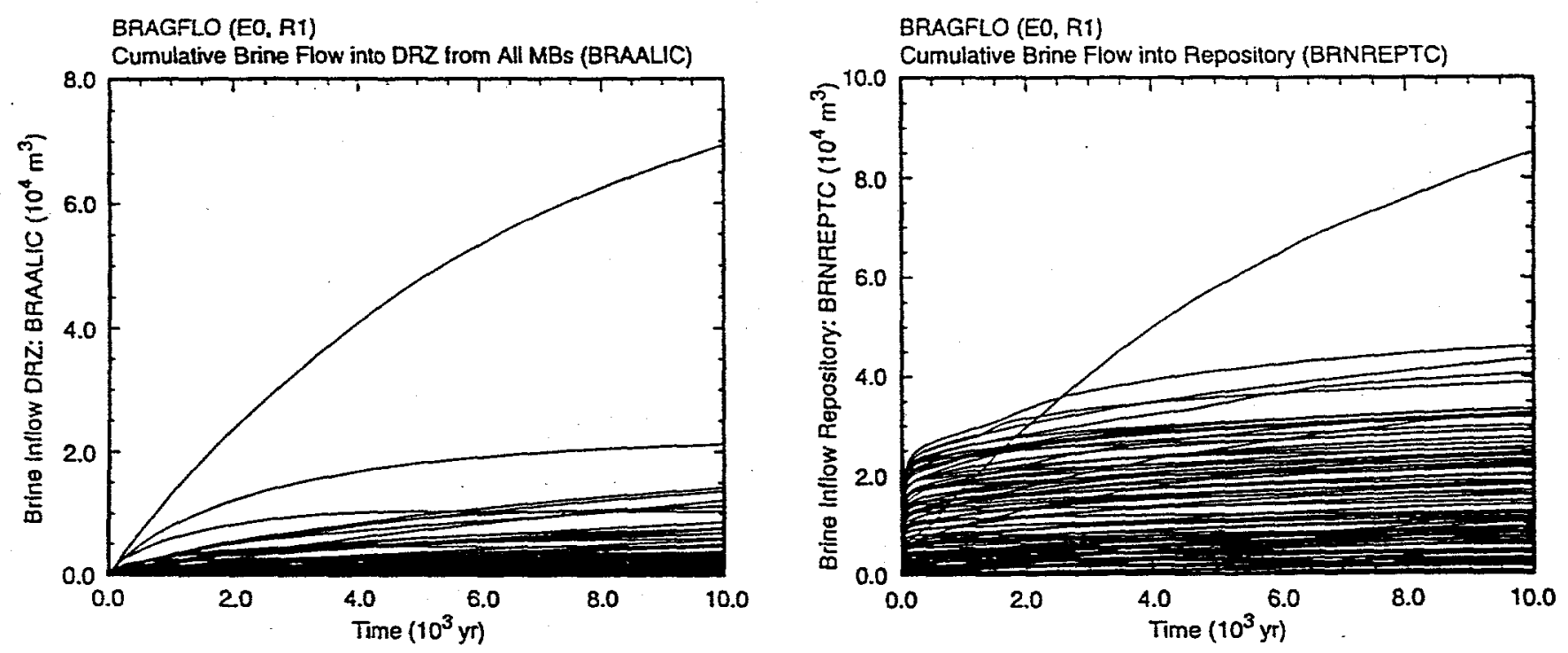

TRi $6342-51390$

Fig. 1. Cumulative brine flow into DRZ (BRAALIC) and into repository (BRNREPTC) under undisturbed conditions.
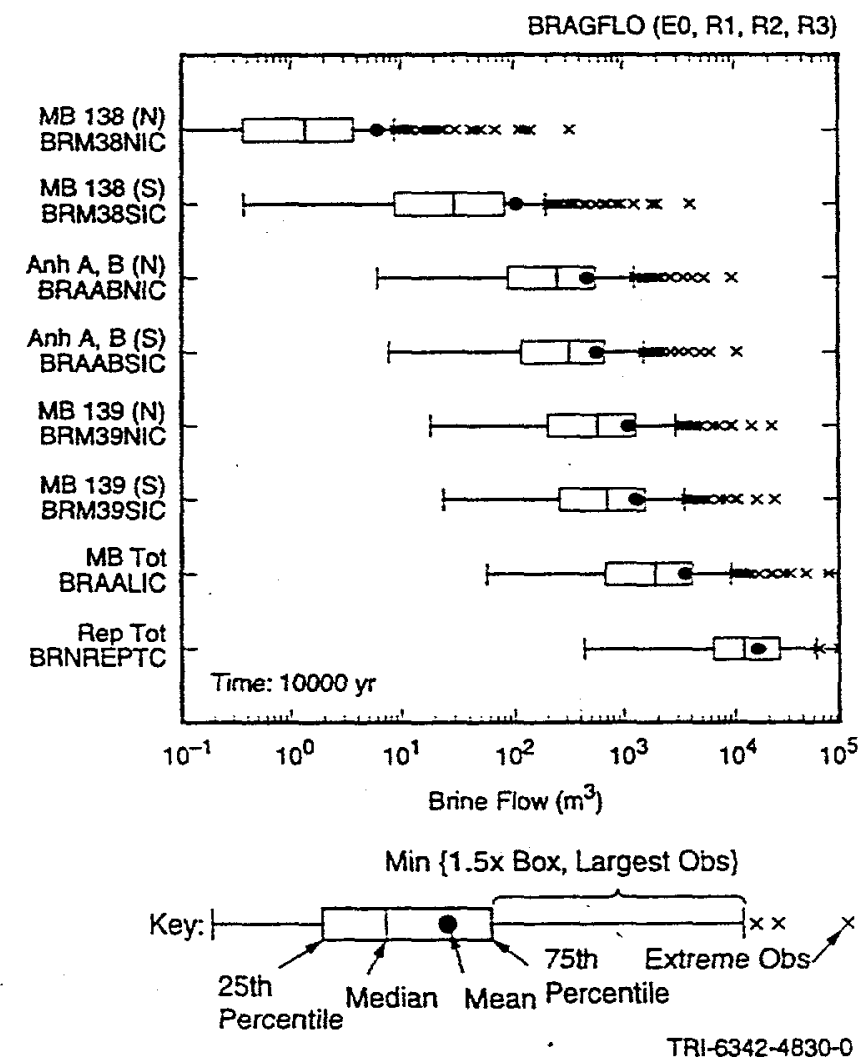

Fig. 2. Cumulative brine flow over $10,000 \mathrm{yr}$ into DRZ (BRM38NIC, BRM38SIC, BRAABNIC, BRAABSIC, $B R M 39 N I C, B R M 39 S I C$, and $B R A A L I C)$ and into repository (BRNREPTC) under undisturbed conditions. 
Cumulative Brine Flow into DRZ from All MBs (BRAALIC)

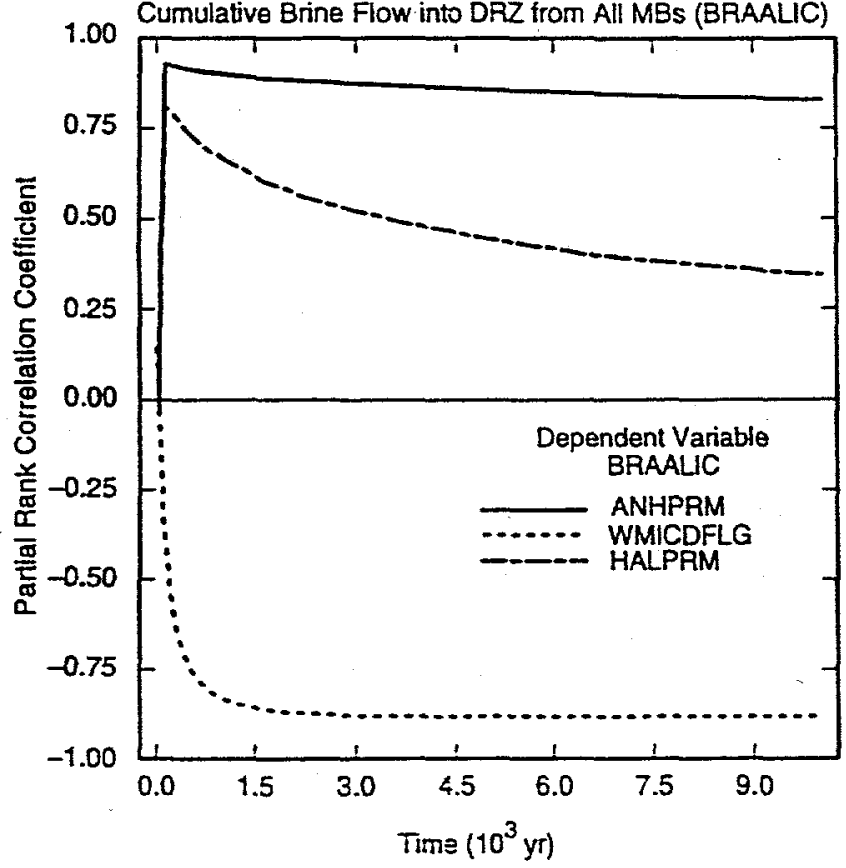

BRAGFLO (EO, R1, R2, R3)

Cumulative Brine Flow into Repository (BRNREPTC)

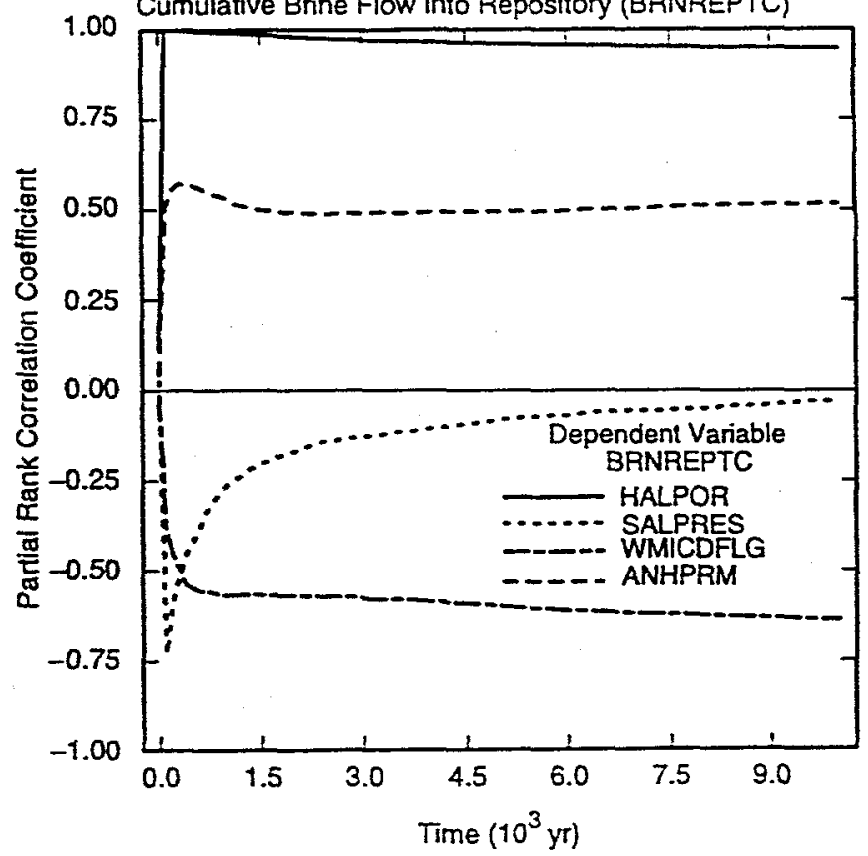

TRI-6342-4901-0

Fig. 3. Partial rank correlation coefficients for cumulative brine flow from marker beds (BRAALIC) and cumulative brine flow into repository (BRNREPTC) under undisturbed conditions with ANHCOMP and HALCOMP excluded from calculation.
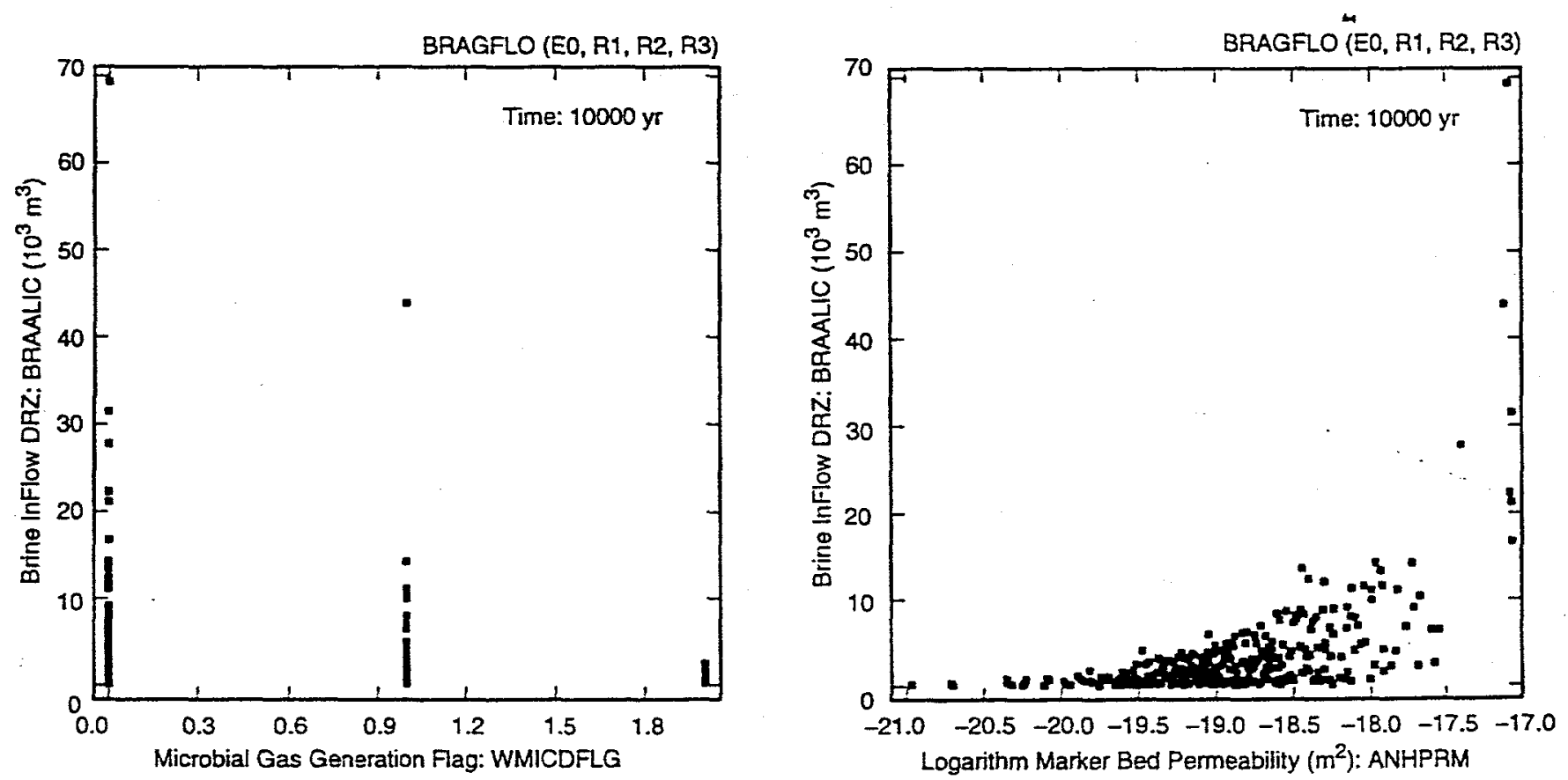

TR1-6342-4902-0

Fig. 4. Scatterplots for cumulative brine discharge from the marker beds (BRAALIC) over 10,000 yr under undisturbed conditions versus WMICDFLG and ANHPRM. 

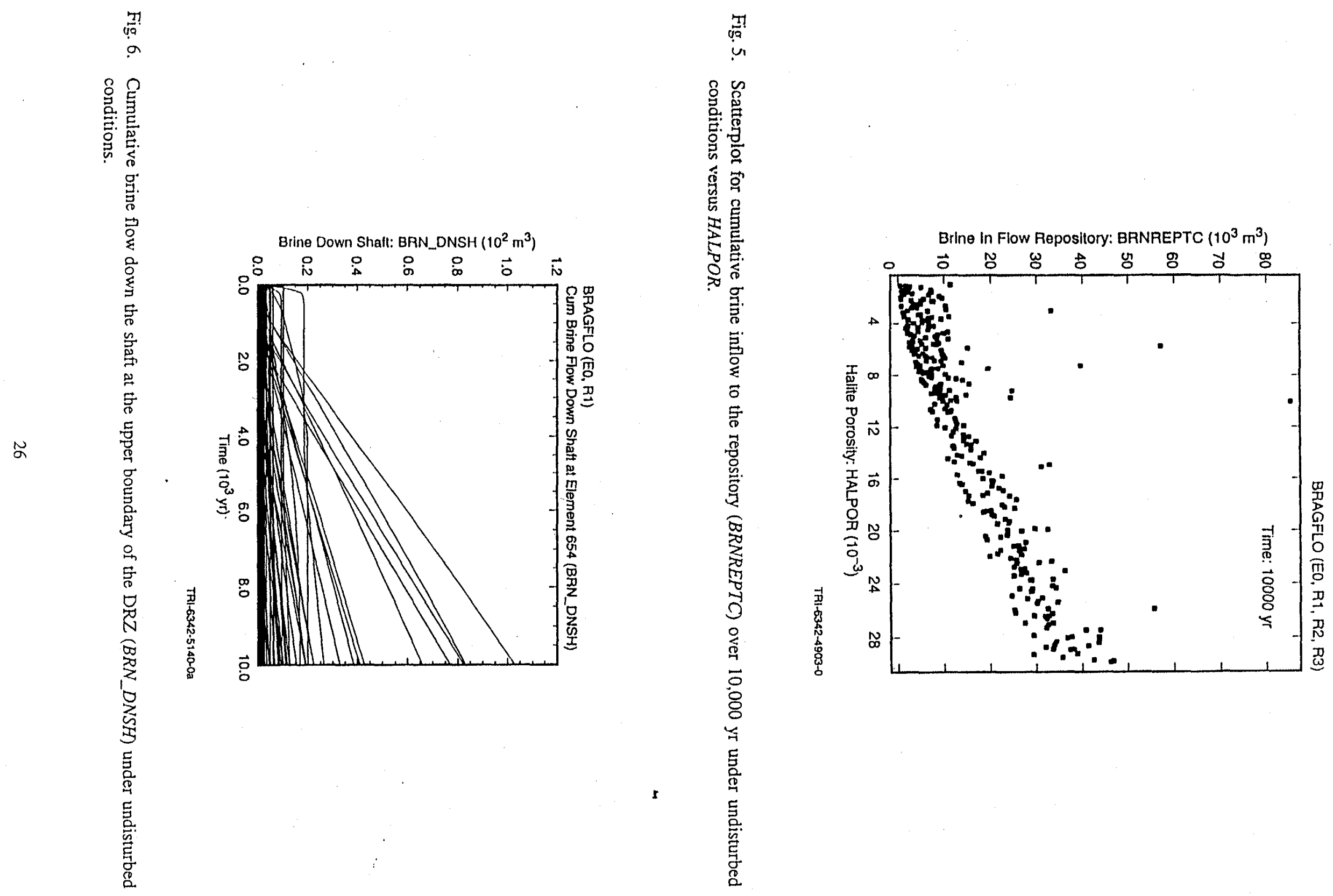

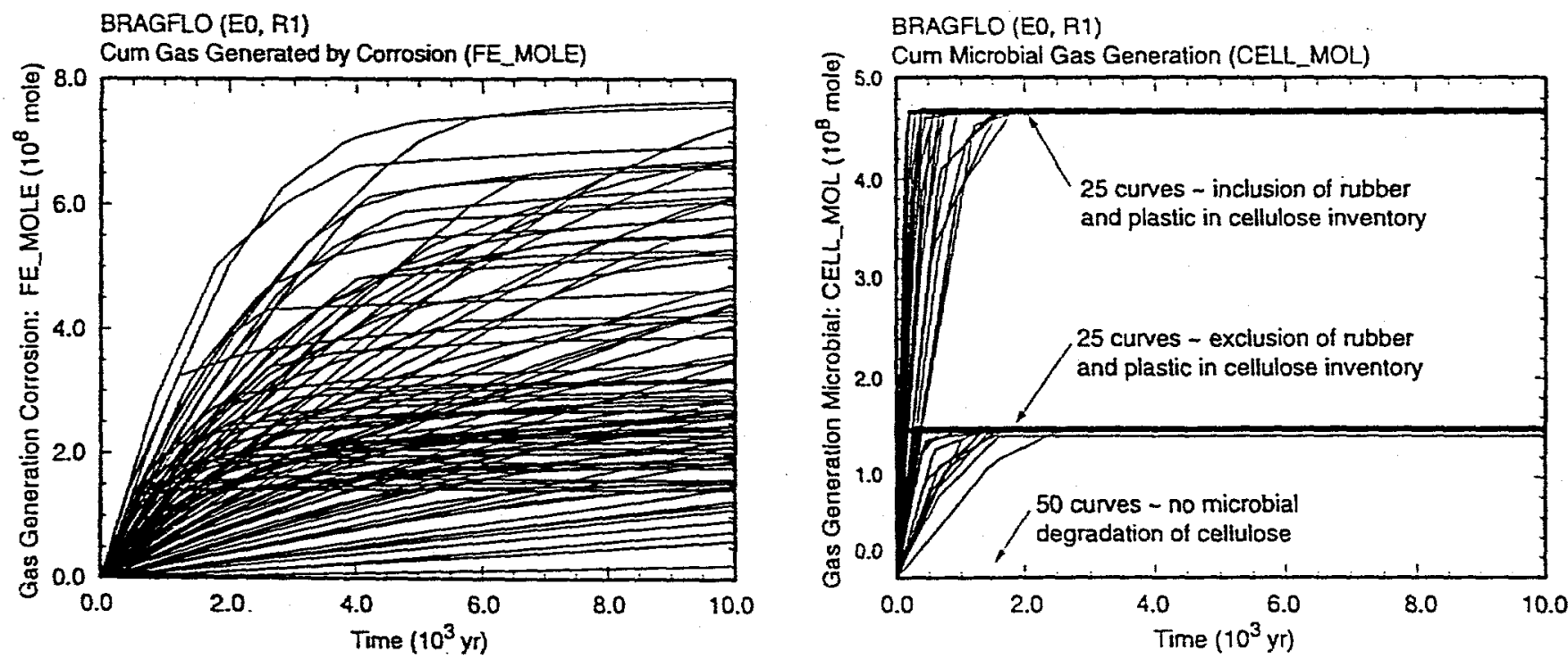

TRI-6342-4904-0

Fig. 7. Cumulative gas generation due to corrosion (FE_MOLE) and microbial degradation of cellulose (CELL_MOL) under undisturbed conditions.
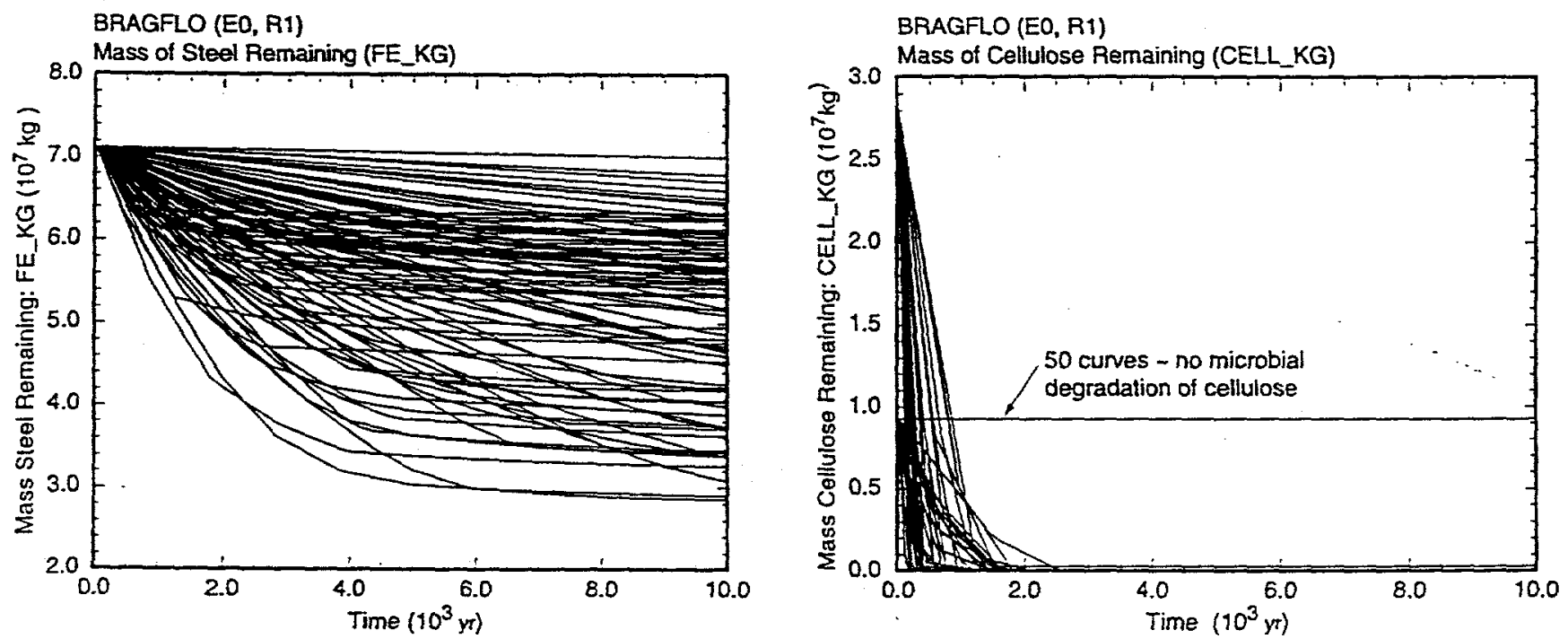

TRI- $6342-4905-0$

Fig. 8. Time-dependent masses of steel $\left(F E_{-} K G\right)$ and cellulose (CELL_KG) in repository under undisturbed conditions. 
BRAGFLO (EO, R1)

Cum Gas Generated by Inundated Microbial Action (CELL_M_l)

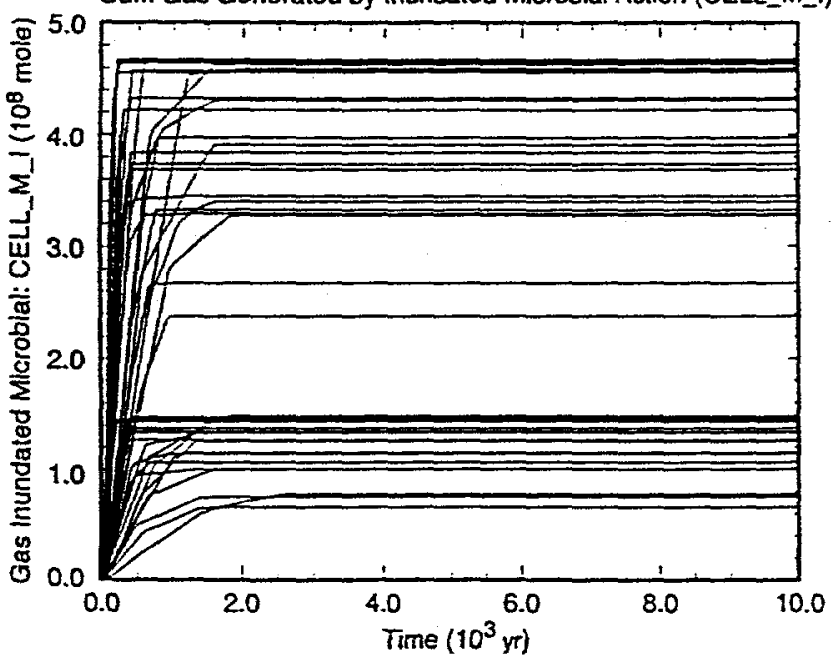

BRAGFLO (EO. R1)

Cum Gas Generated by Humid Microbial Action (CELL $M$ H)

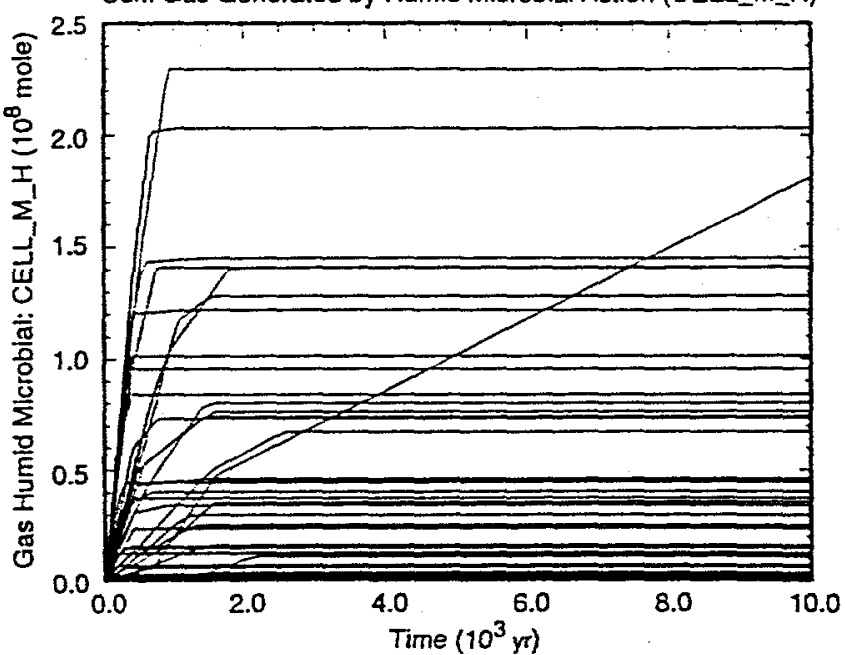

TRi-6342-4906-0

Fig. 9. Cumulative gas generation due to microbial degradation of cellulose under inundated ( $C E L L_{-} M_{-} D$ ) and humid $\left(C E L L_{-} M_{-} H\right)$ conditions for undisturbed conditions.

BRAGRLO (EO, R1)

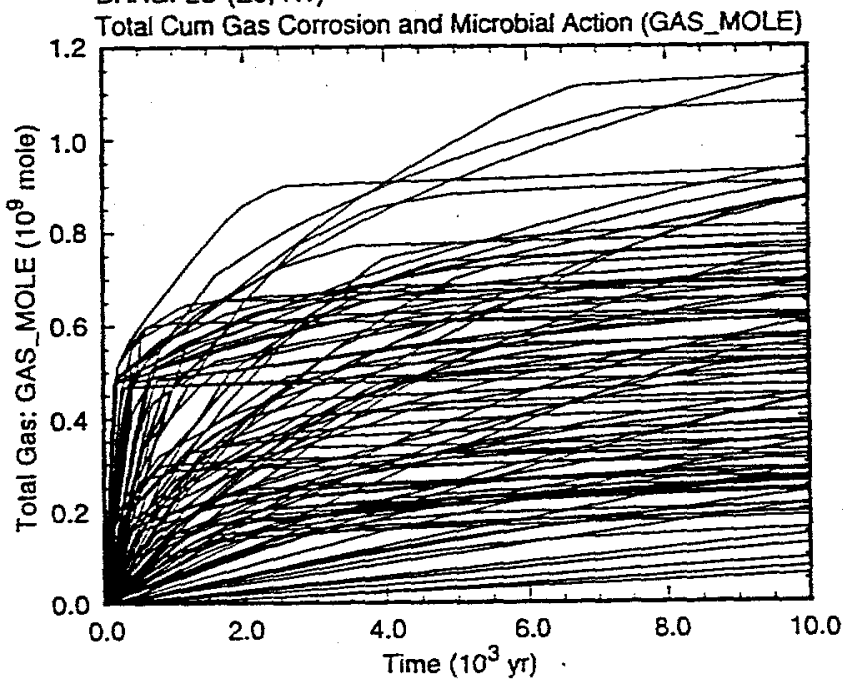

TRI-6342-5141-0a

Fig. 10. Cumulative gas generation due to both corrosion and microbial degradation of cellulose (GAS_MOLE) under undisturbed conditions. 

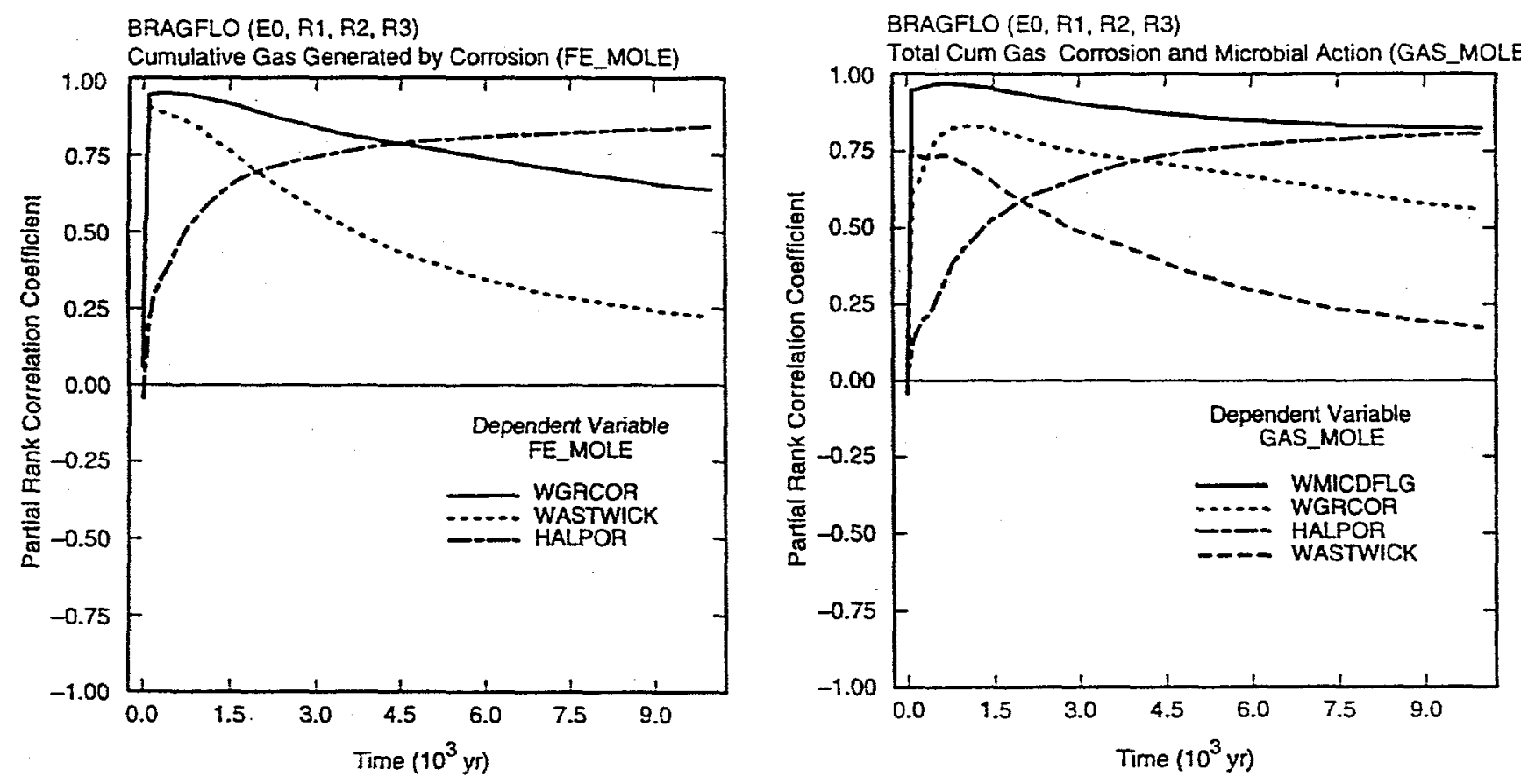

TRi-6342-4907-0

Fig. 11. Partial rank correlation coefficients for cumulative gas generation due to corrosion of steel (FE_MOLE) and cumulative gas generation due to corrosion of steel and microbial degradation of cellulose (GAS_MOLE) under undisturbed conditions with ANHCOMP and HALCOMP excluded from calculation.
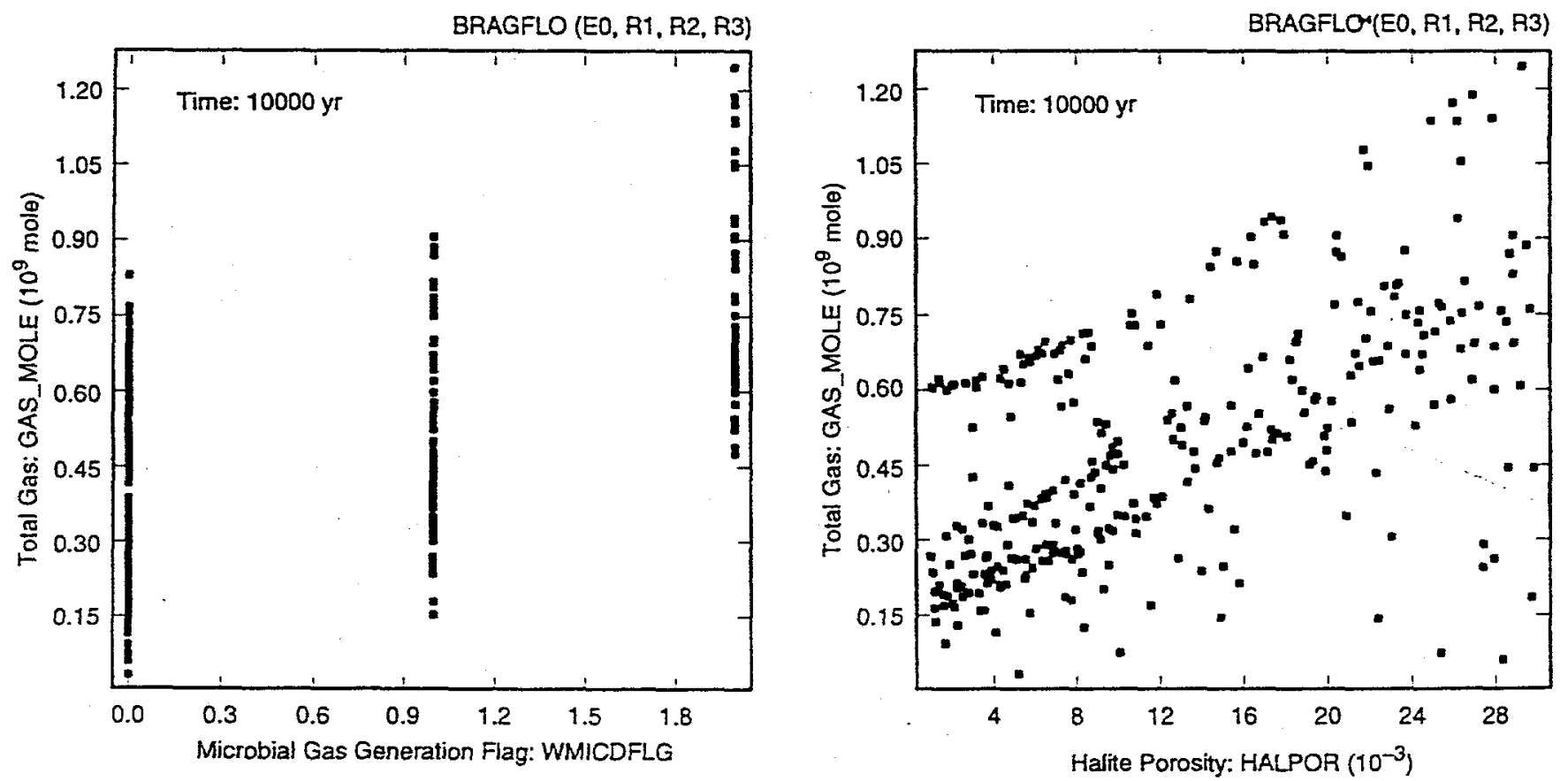

TR1-6342-4906-0

Fig. 12. Scatterplots for total gas generation over $10,000 \mathrm{yr}$ due to corrosion of steel and microbial degradation of cellulose (GAS_MOLE) under undisturbed conditions versus WMICDFLG and HALPOR. 


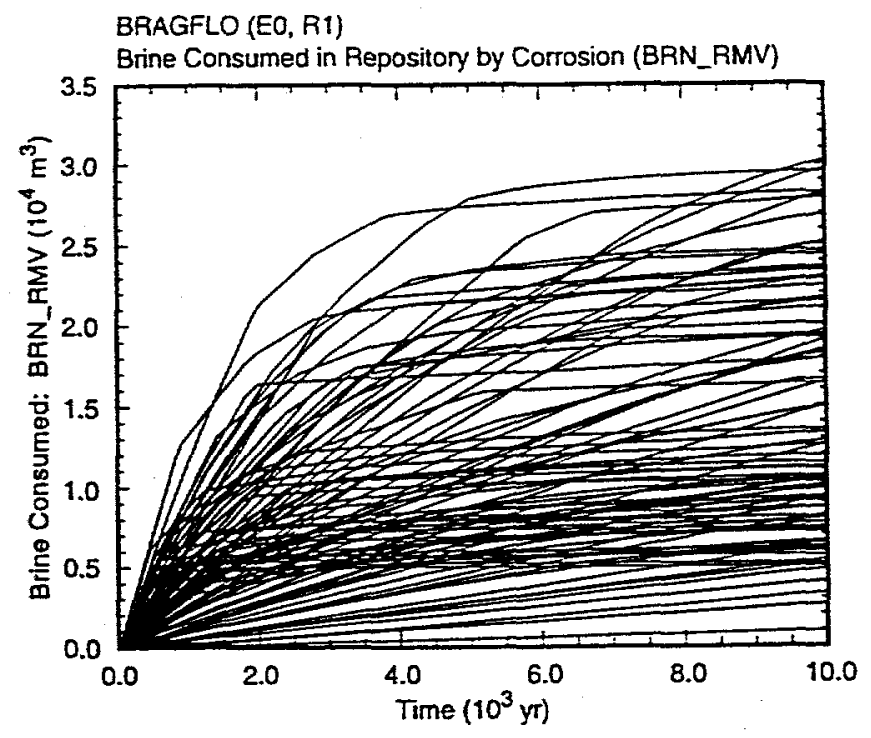

Tht-6342-5142-0

Fig. 13. Curnulative volume of brine consumed by corrosion ( $\left.B R N_{-} R M V\right)$ under undisturbed conditions.
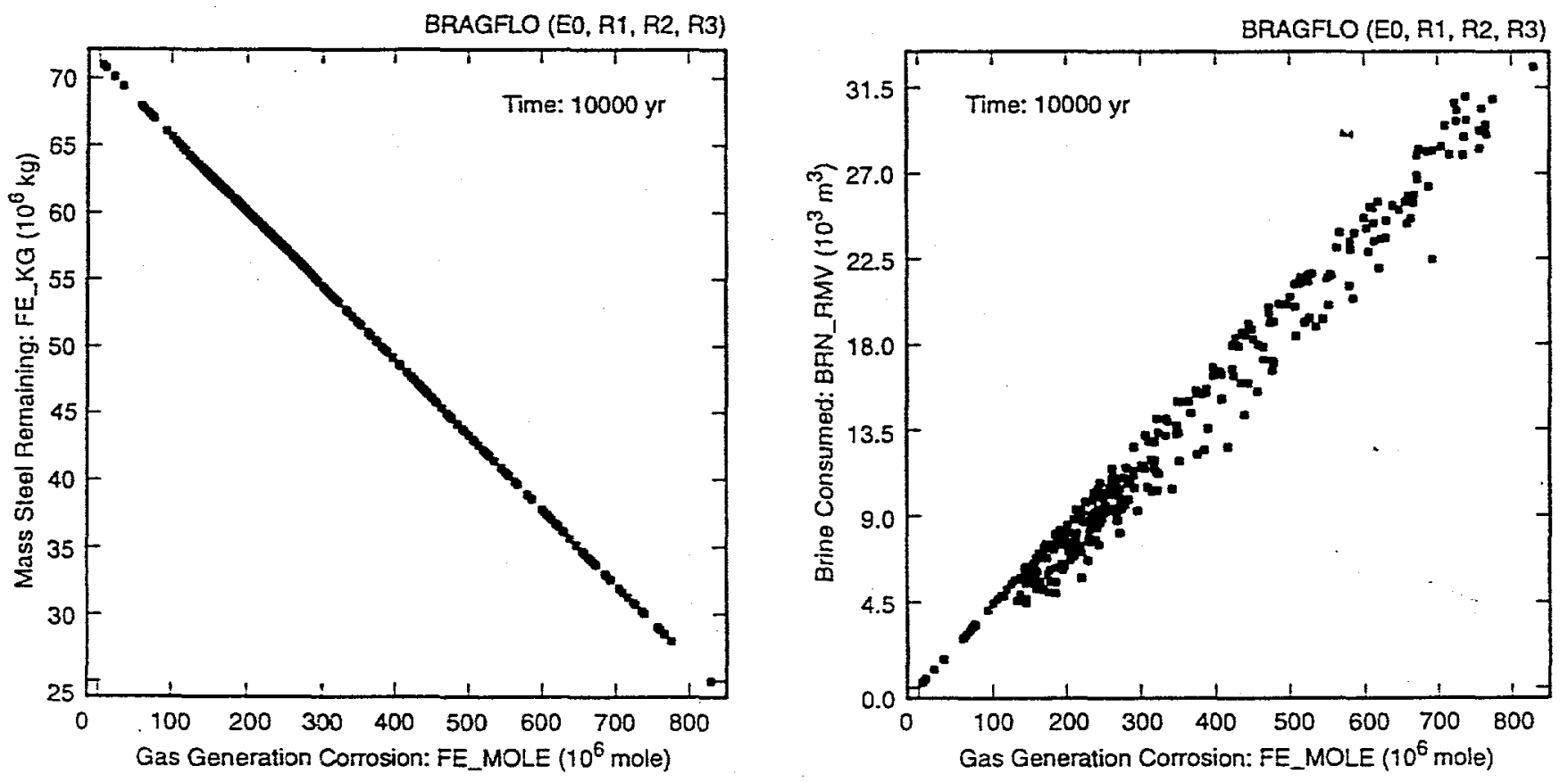

TRI-6342-4909-0

Fig. 14. Scatterplot for amount of gas generated by corrosion ( $F E_{-} M O L E$ ), amount of steel remaining in the repository $\left(F E_{-} K G\right)$ and amount of brine consumed by corrosion ( $B R N_{-} R M V$ ) at 10,000 yr under undisturbed conditions. The scatterplot for amount of brine removed should actually be a straight line, with the resolution at which computational results were stored introducing the scatter in the plot. 

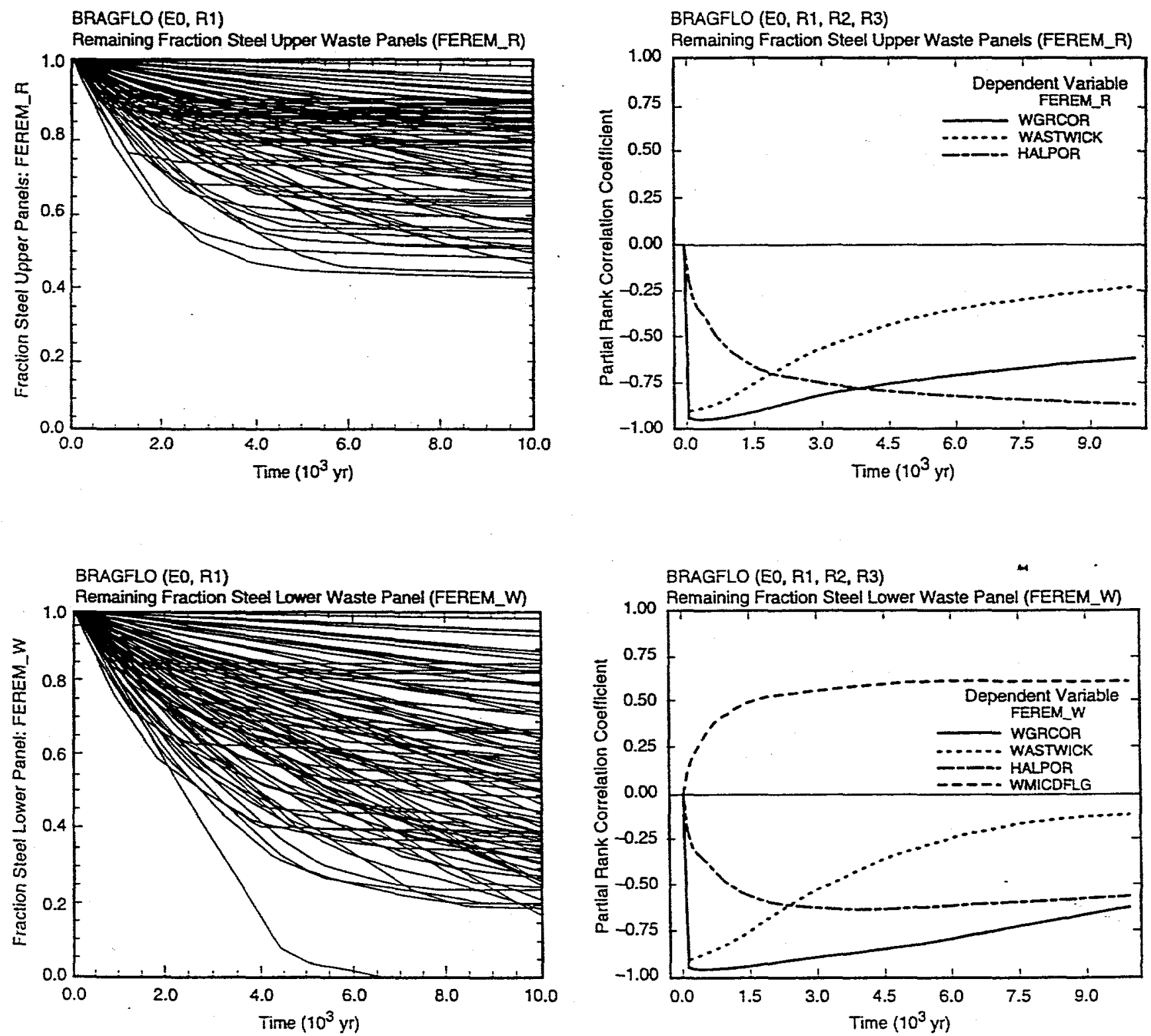

$\operatorname{TR} 1-63 \times 2-4910-0$

Fig. 15. Uncertainty and sensitivity analysis results for fraction of steel remaining in upper waste panels $\left(F E R E M_{-} R\right.$ ) (upper frames) and lower waste panel (FEREM_W) (lower frames) under undisturbed conditions. 

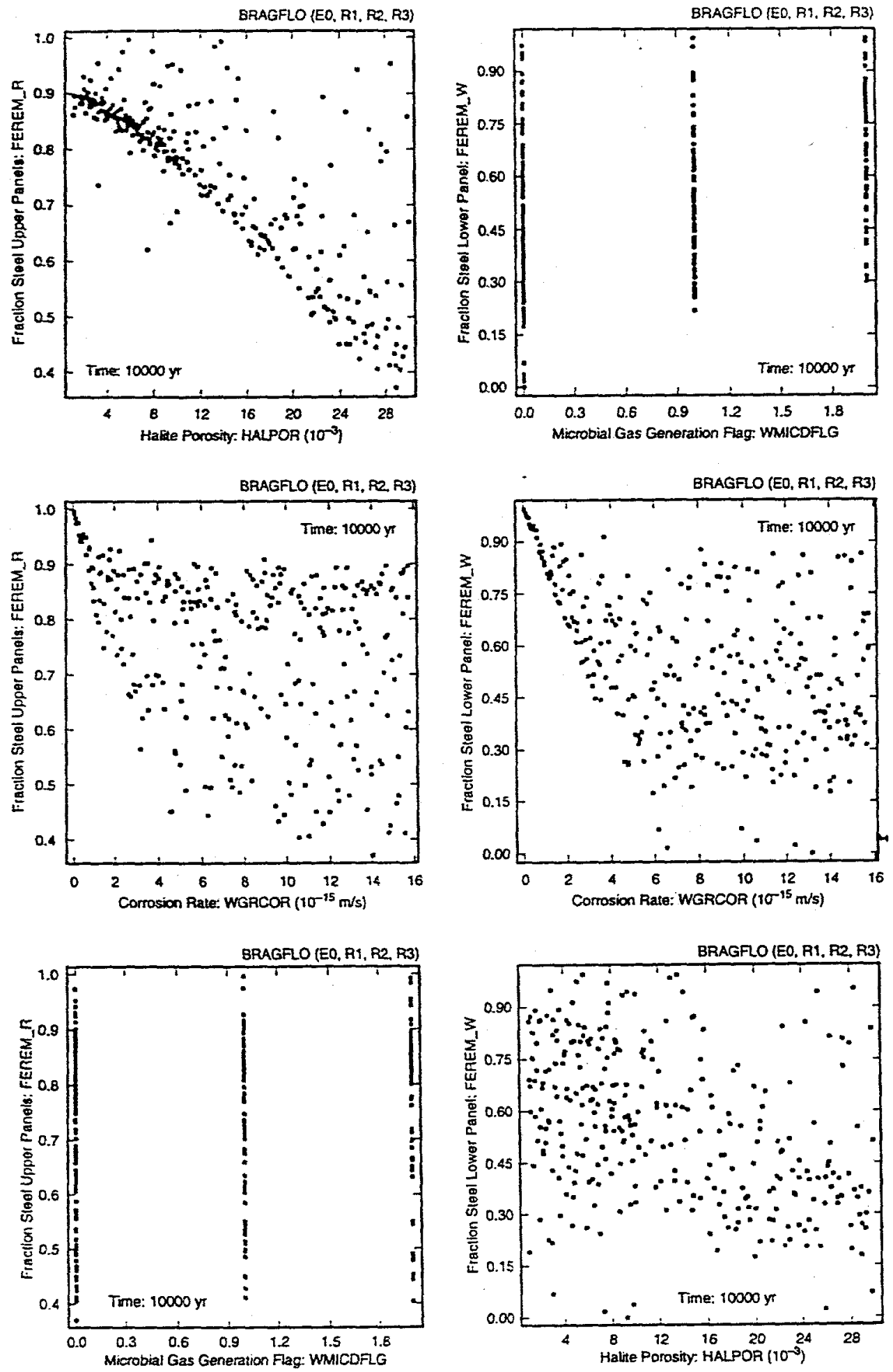

TRI-6342-4917-0

Fig. 16. Scatterplots for fraction of steel remaining in upper waste panels (FEREM_R) (left frames) and lower panel (FEREM_W) (right frames) for undisturbed conditions at 10,000 yr versus HALPOR, WGRCOR and WMICDFLLG. 
BRAGFL (ED, Ri)

Total Cum Gas Generated Upper Panels (GASMOL_R)

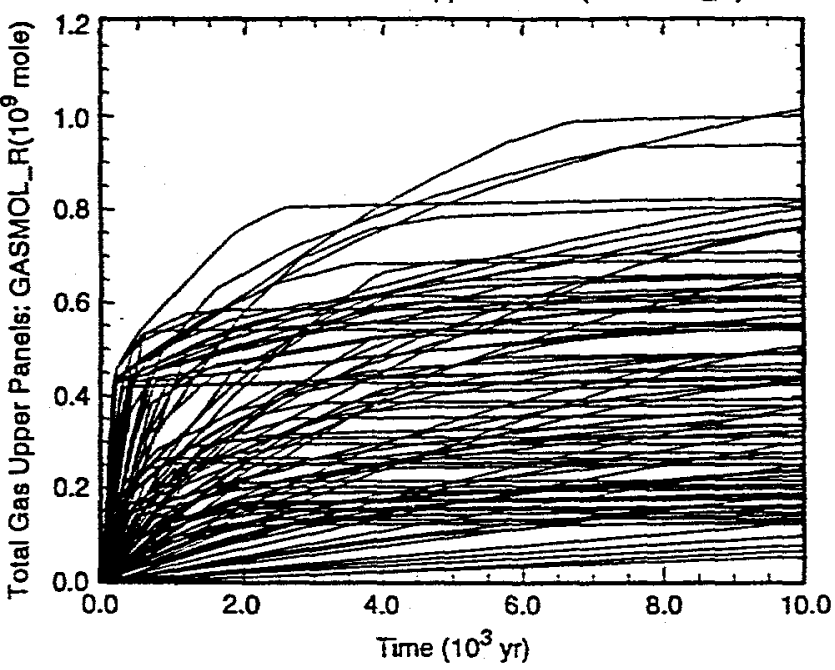

BRAGFLO (EO, R1)

Total Cum Gas Generated Lower Panel (GASMOL_W)

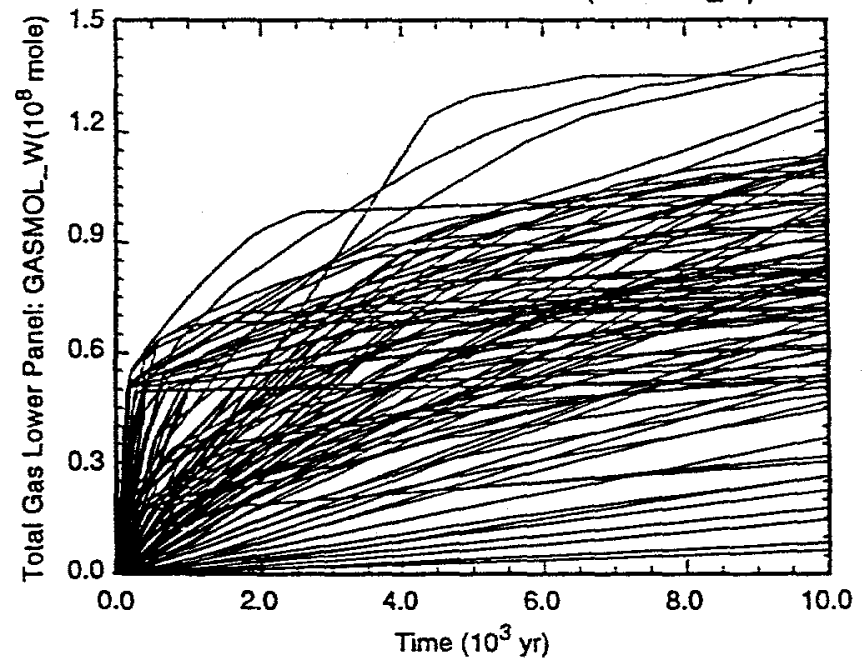

BRAGFLO (EO, R1, R2, R3)

Total Cum Gas Generated Upper Panels (GASMOL_R)

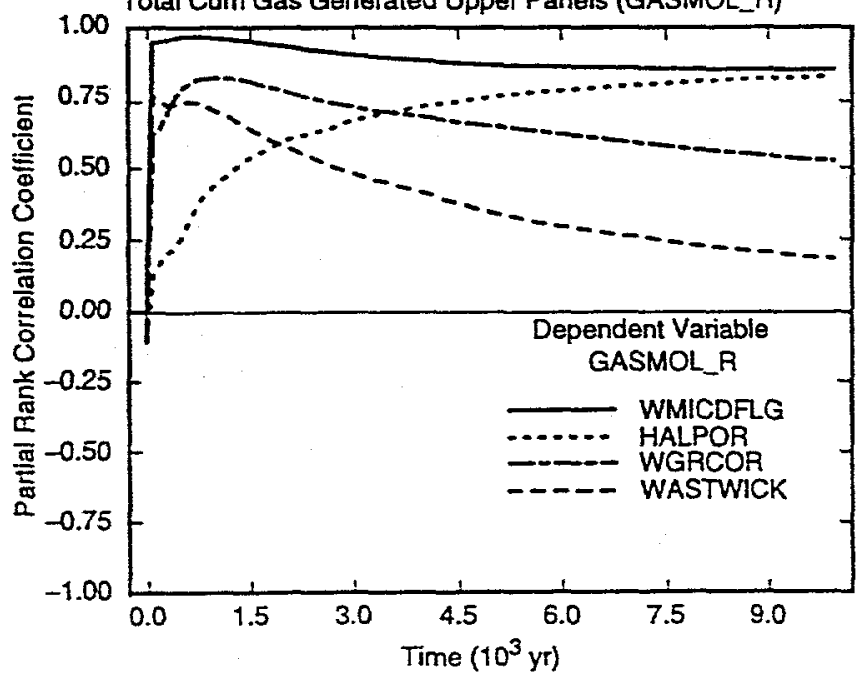

BRAGFLO (EO, R1, R2, R3)

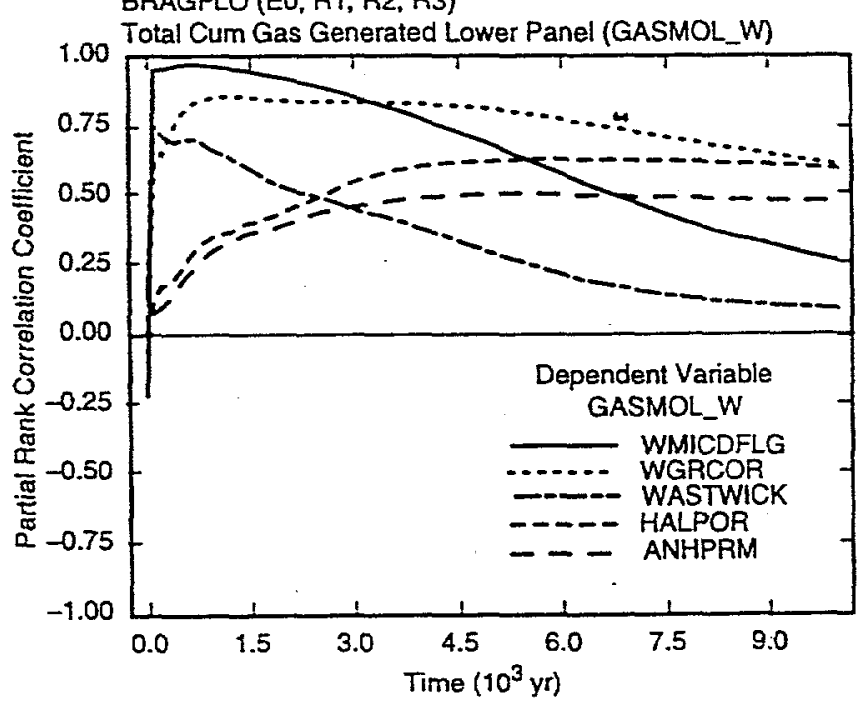

TRI-6342-49:2-0

Fig. 17. Uncertainty and sensitivity analysis results for cumulative gas generation due to corrosion and microbial degradation in upper waste panels $\left(G A S M O L_{-} R\right.$ ) (upper frames) and lower waste panel (GASMOL_W) (lower frames) for undisturbed conditions. 

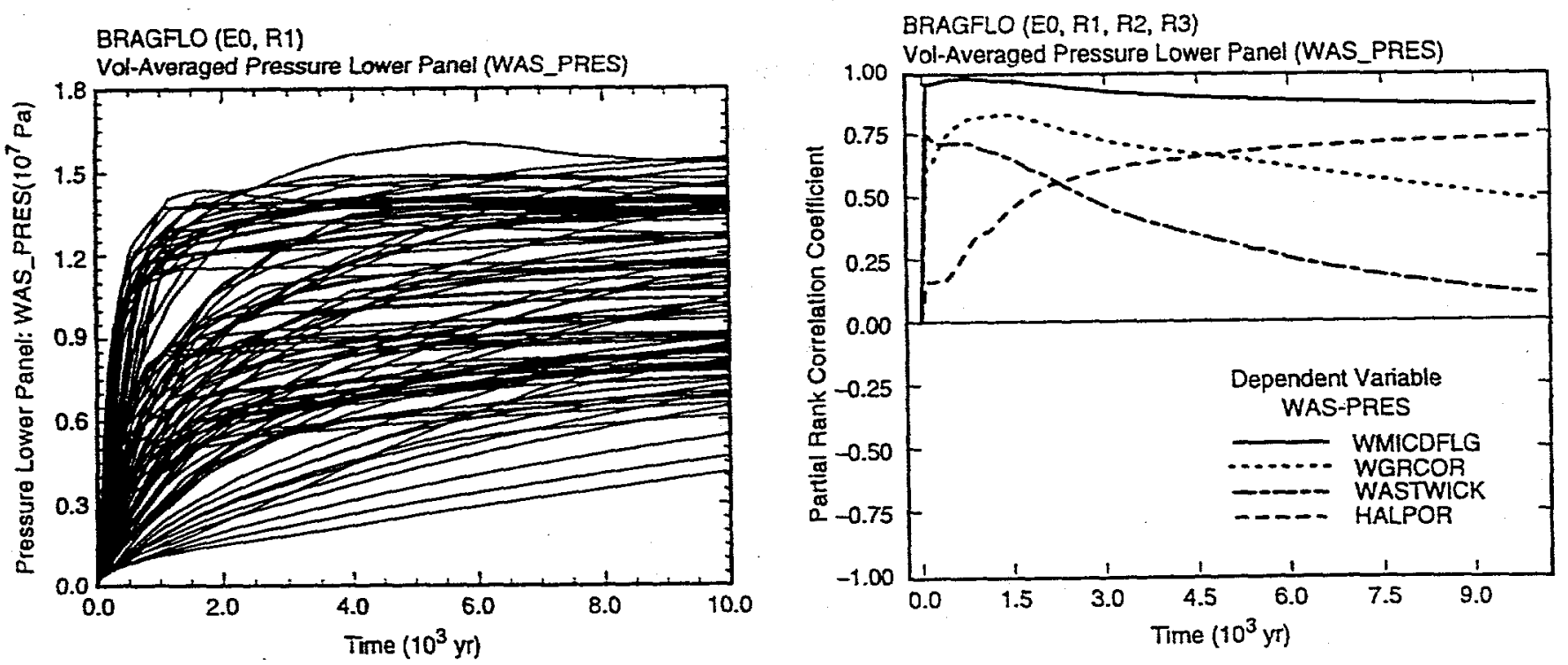

TRI-6342-49 13-0

Fig. 18. Uncertainty and sensitivity analysis results for pressure in lower waste panel (WAS_PRES) under undisturbed conditions.

BRAGFLO (EO, R1, R2, R3)

Vol-Averaged Pressure Lower Panel (WAS_PRES)

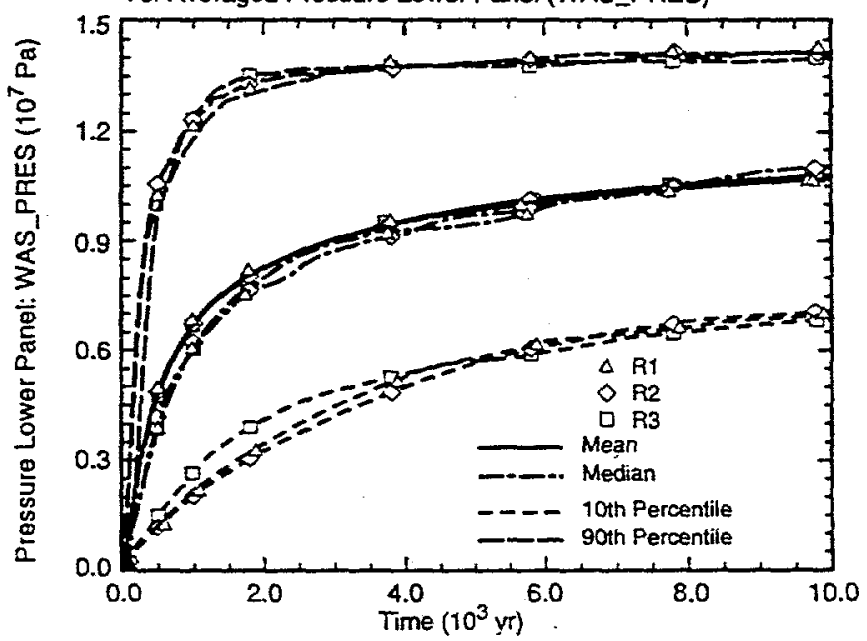

TR1-6342-4914-0

Fig. 19. Mean and percentile curves for three replicated LHSs for pressure in lower waste panel (WAS_PRES) under undisturbed conditions. 

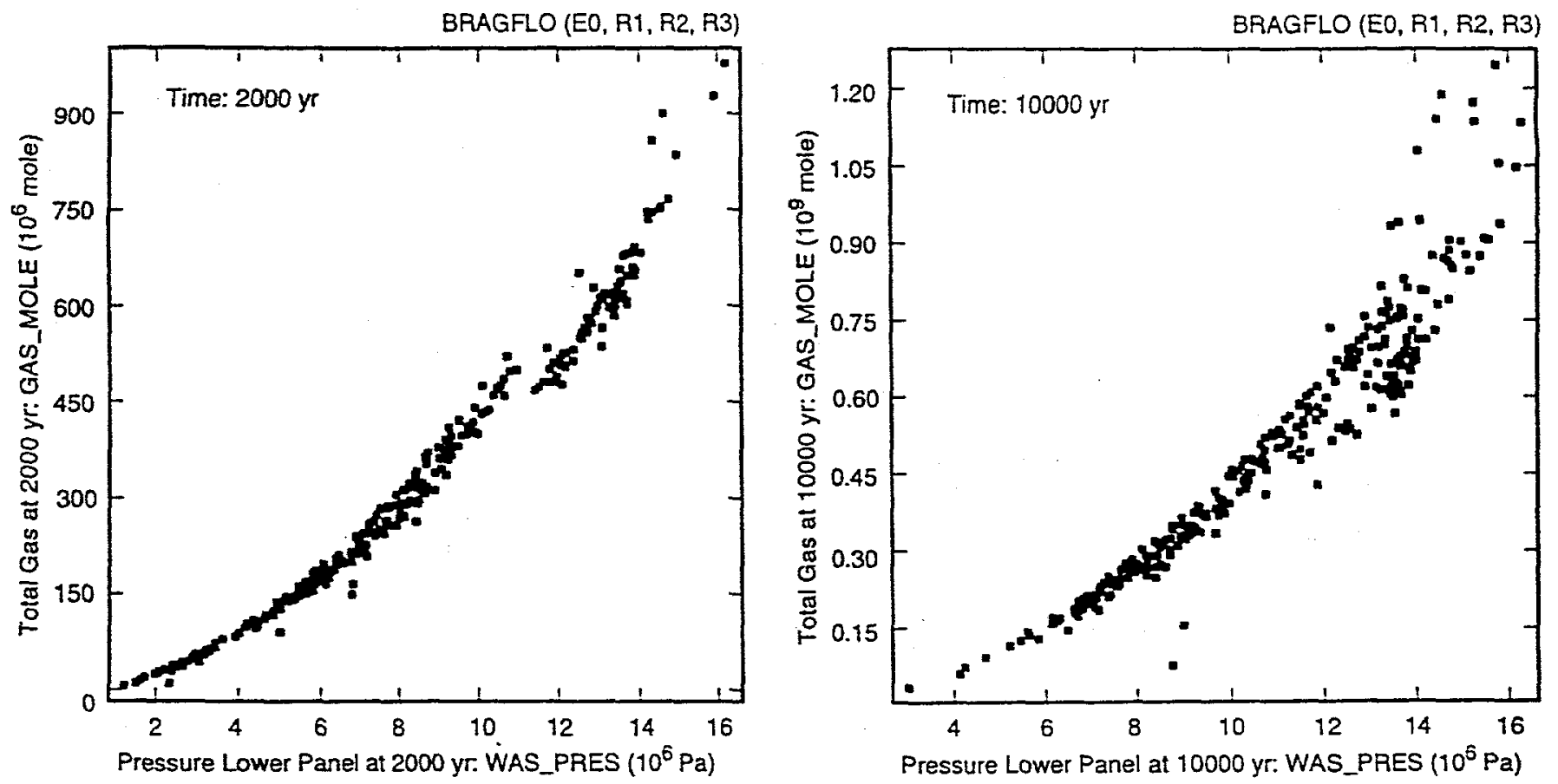

TR1-6342-4915-0

Fig. 20. Scatterplots at 2,000 and 10,000 yr for cumulative gas generated by corrosion and microbial degradation (GAS_MOLE) under undisturbed conditions versus pressure in repository (WAS_PRES).

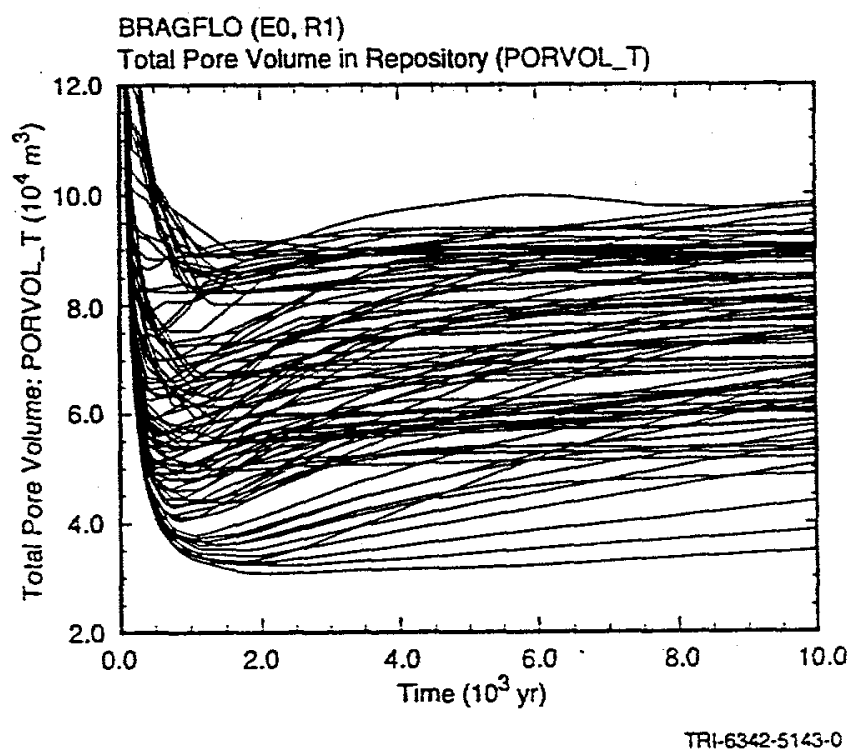

Fig. 21. Total pore volume in repository $\left(P O R V O L_{-} T\right)$ under undisturbed conditions. 


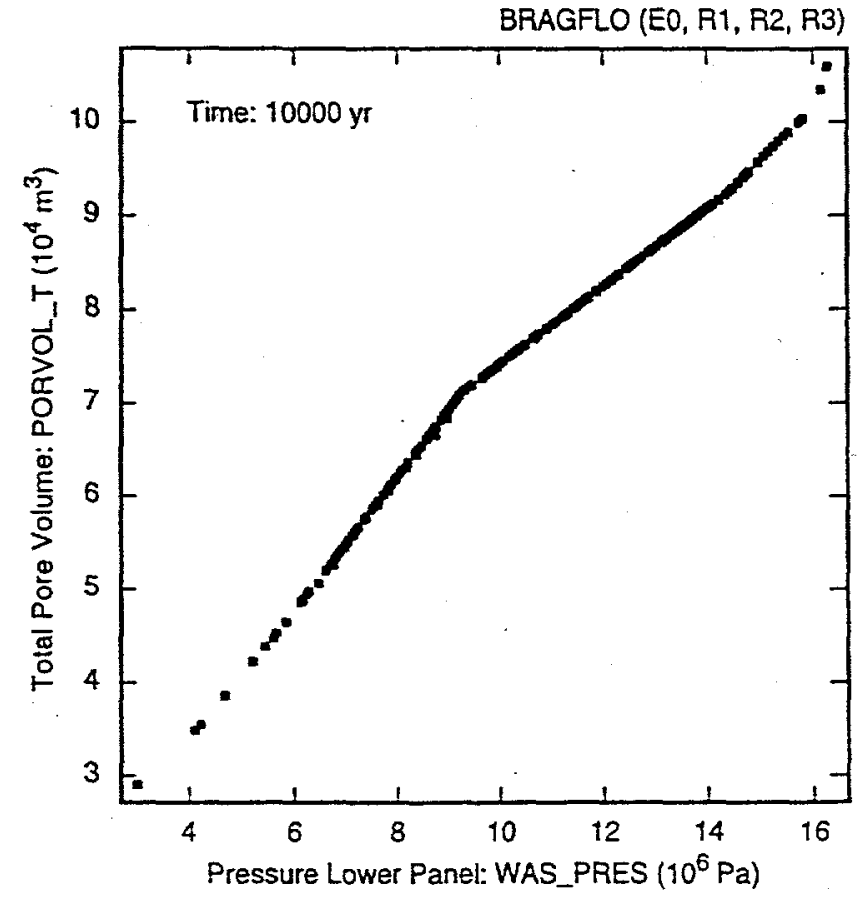

TR1-6342-5144-0

Fig. 22. Scatterplots of pressure in repository (WAS_PRES) at $10,000 \mathrm{yr}$ under undisturbed conditions versus total pore volume in repository (PORVOL_T). 

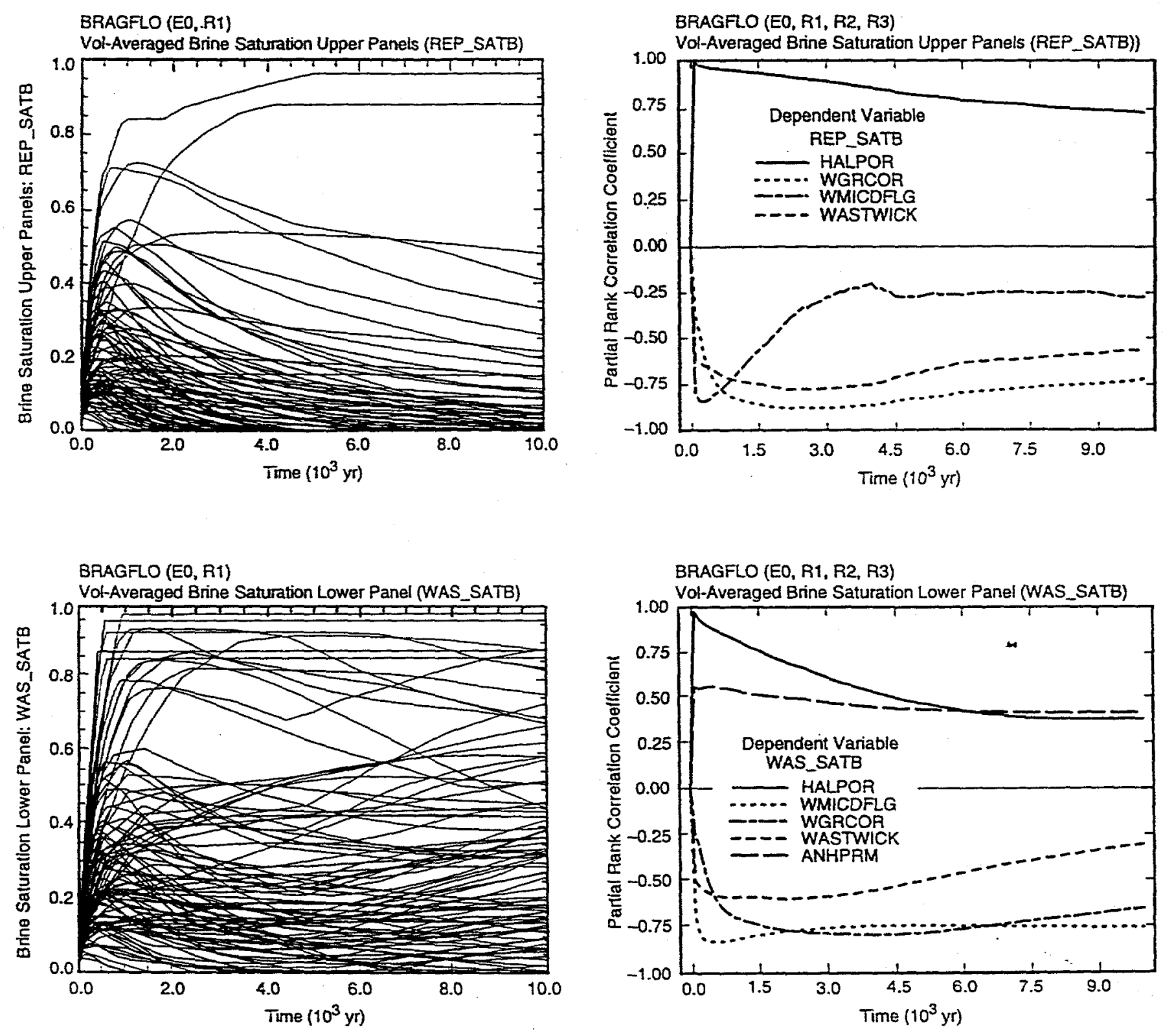

TRl-6342-4916-0

Fig. 23. Uncertainty and sensitivity analysis results for brine saturation in upper waste panels (REP_SATB) (upper frames) and lower waste panel (WAS_SATB) (lower frames) under undisturbed conditions. 

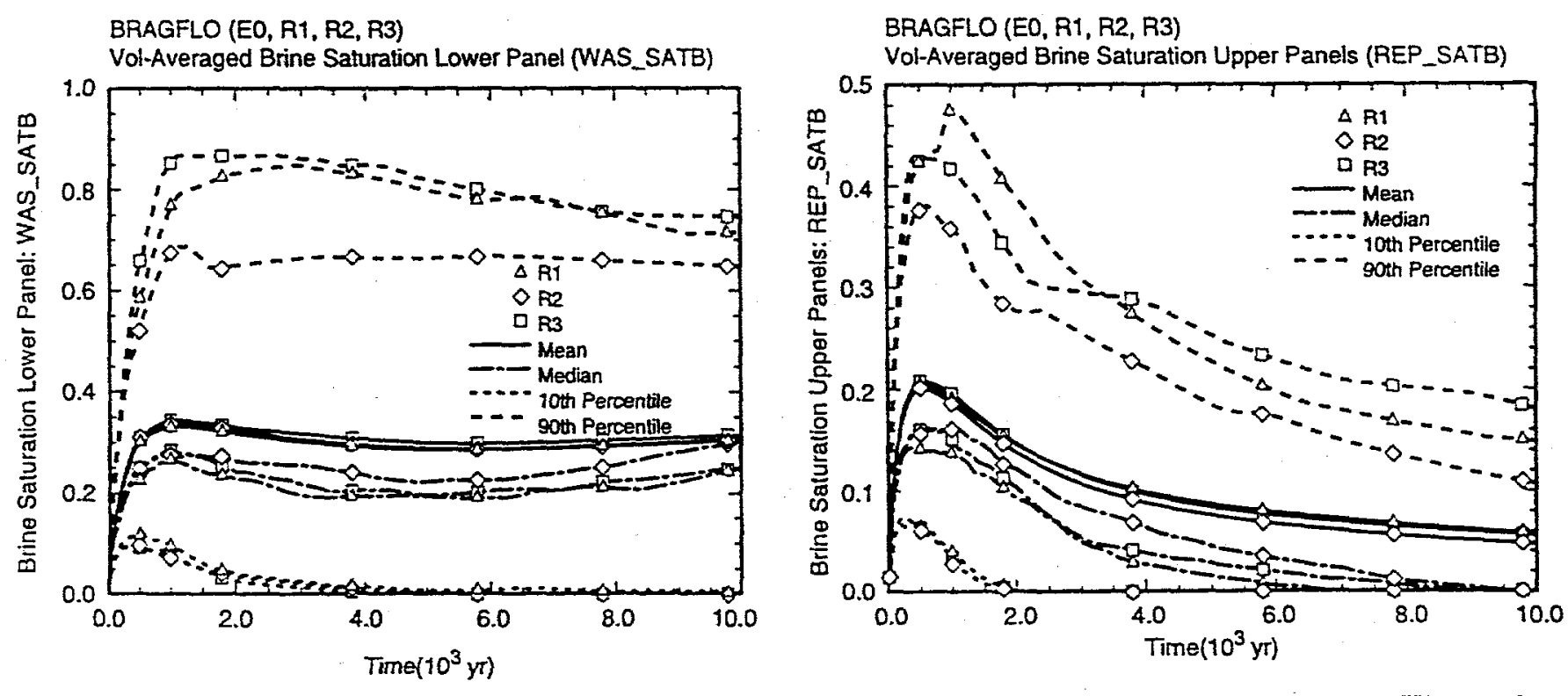

TRI-6342-5145-0

Fig. 24. Percentile curves for three replicated LHSs for brine saturation in the lower (WAS_SATB) and upper waste panels (REP_SATB) under undisturbed conditions. 

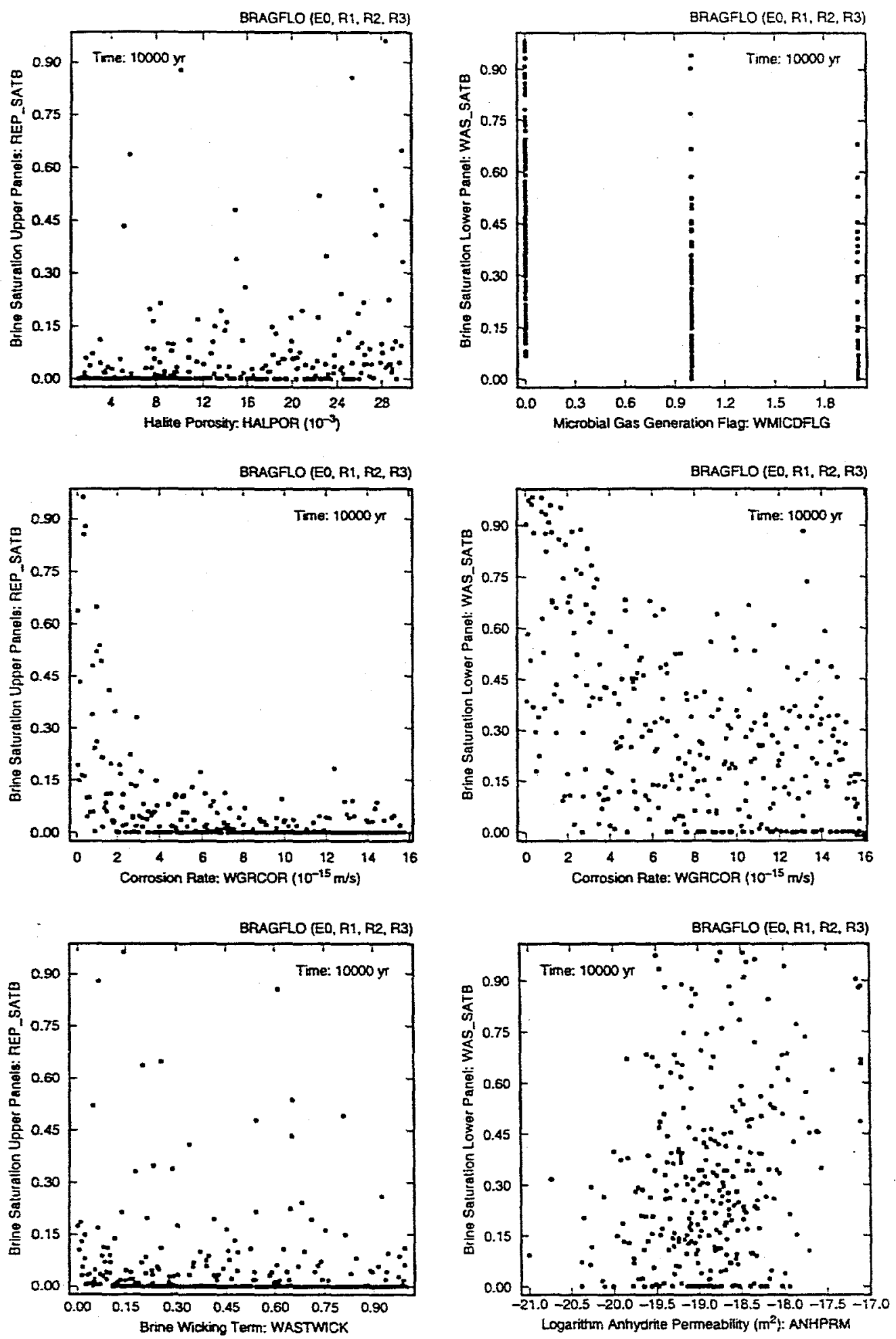

TRi- $6342-4911-0$

Fig. 25. Scatterplots for brine saturation in upper waste panels (REP_SATB) (left frames) and lower waste panel (WAS_SATB) (right frames) for undisturbed conditions at 10,000 yr versus HALPOR, WGRCOR, WASTKICK, WMICDFLG and ANHPRM. 

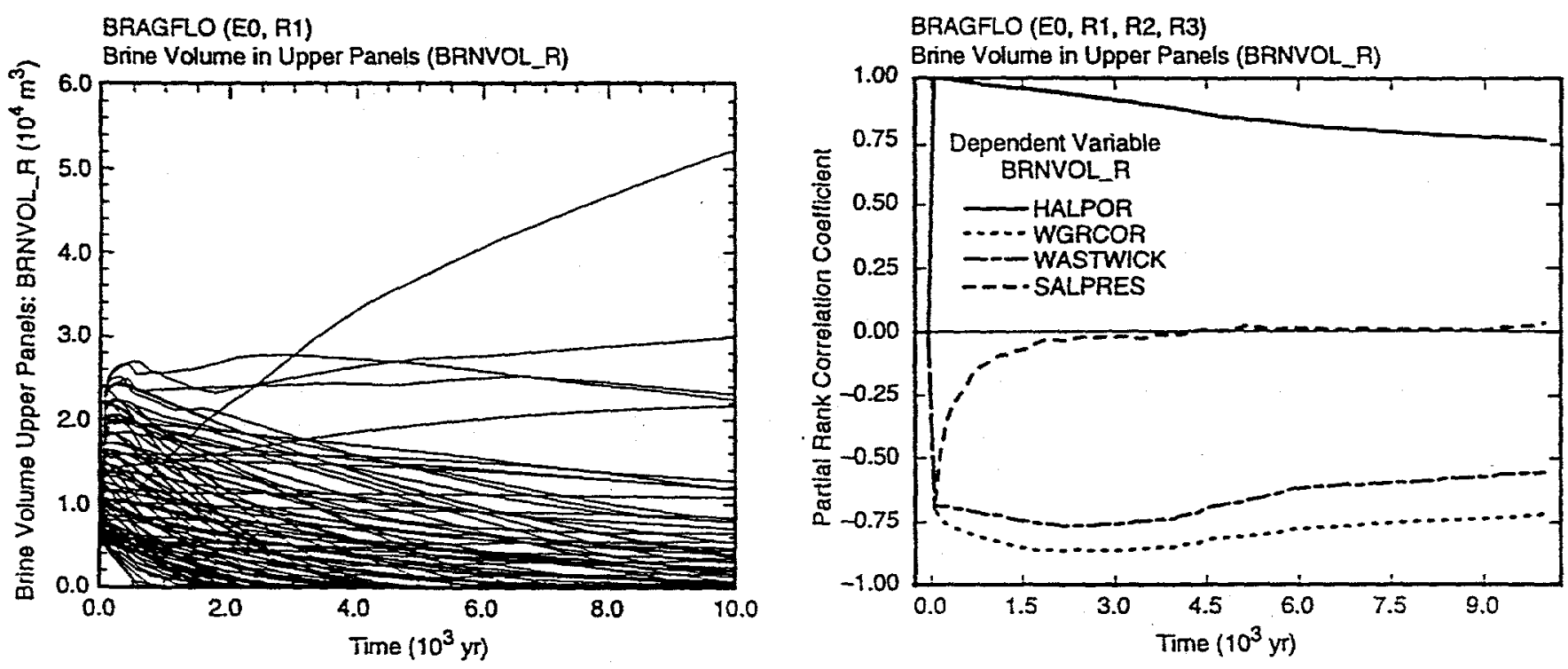

BRAGFLO (EO, R1)

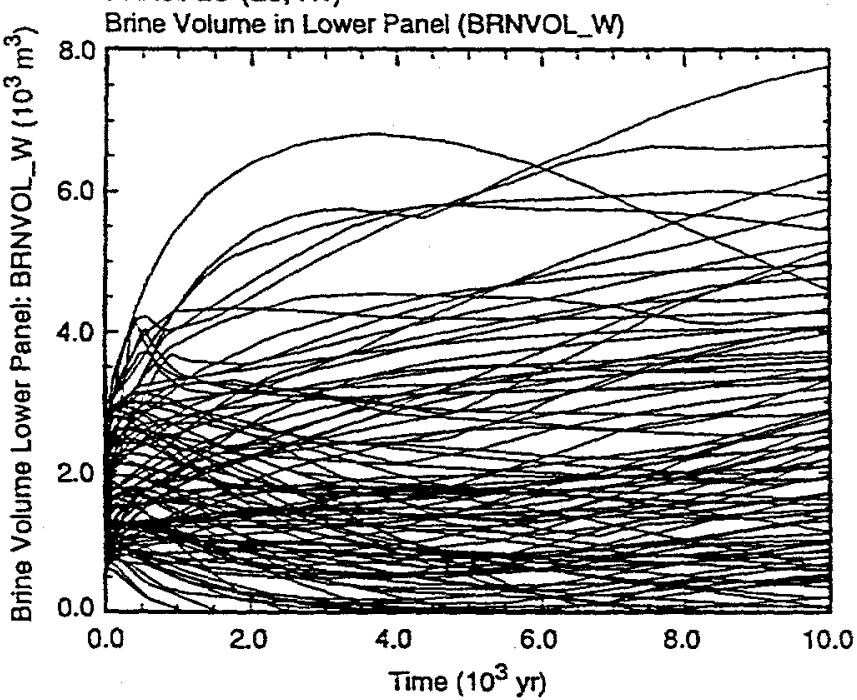

BRAGFLO (EO, R1, R2, R3)

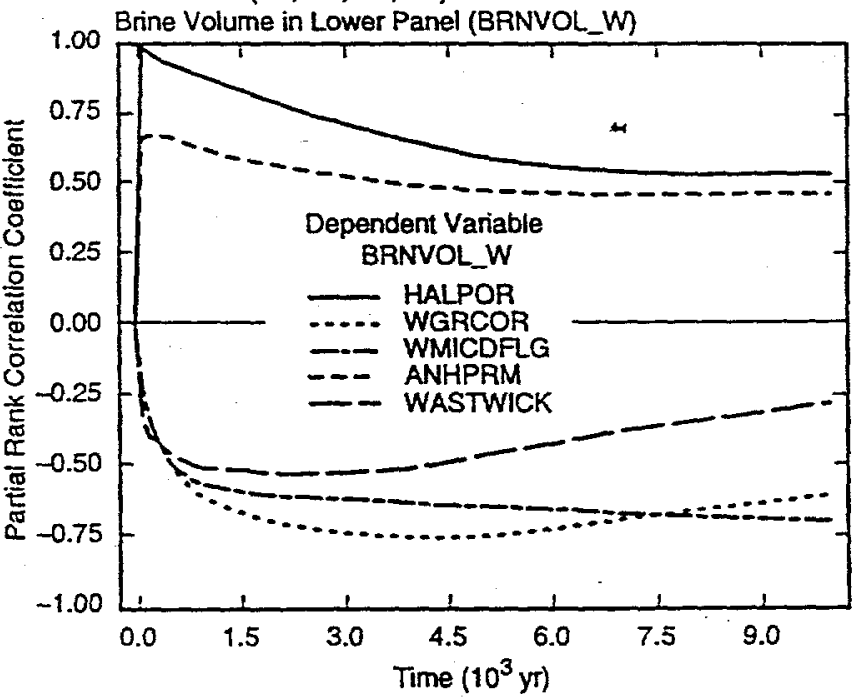

TRI-6342-4918-0

Fig. 26. Uncertainty and sensitivity analysis results for brine volume in upper waste panels (BRNVOL_R) (upper frames) and lower waste panel (BRNWOL_W) (lower frames) under undisturbed conditions. 

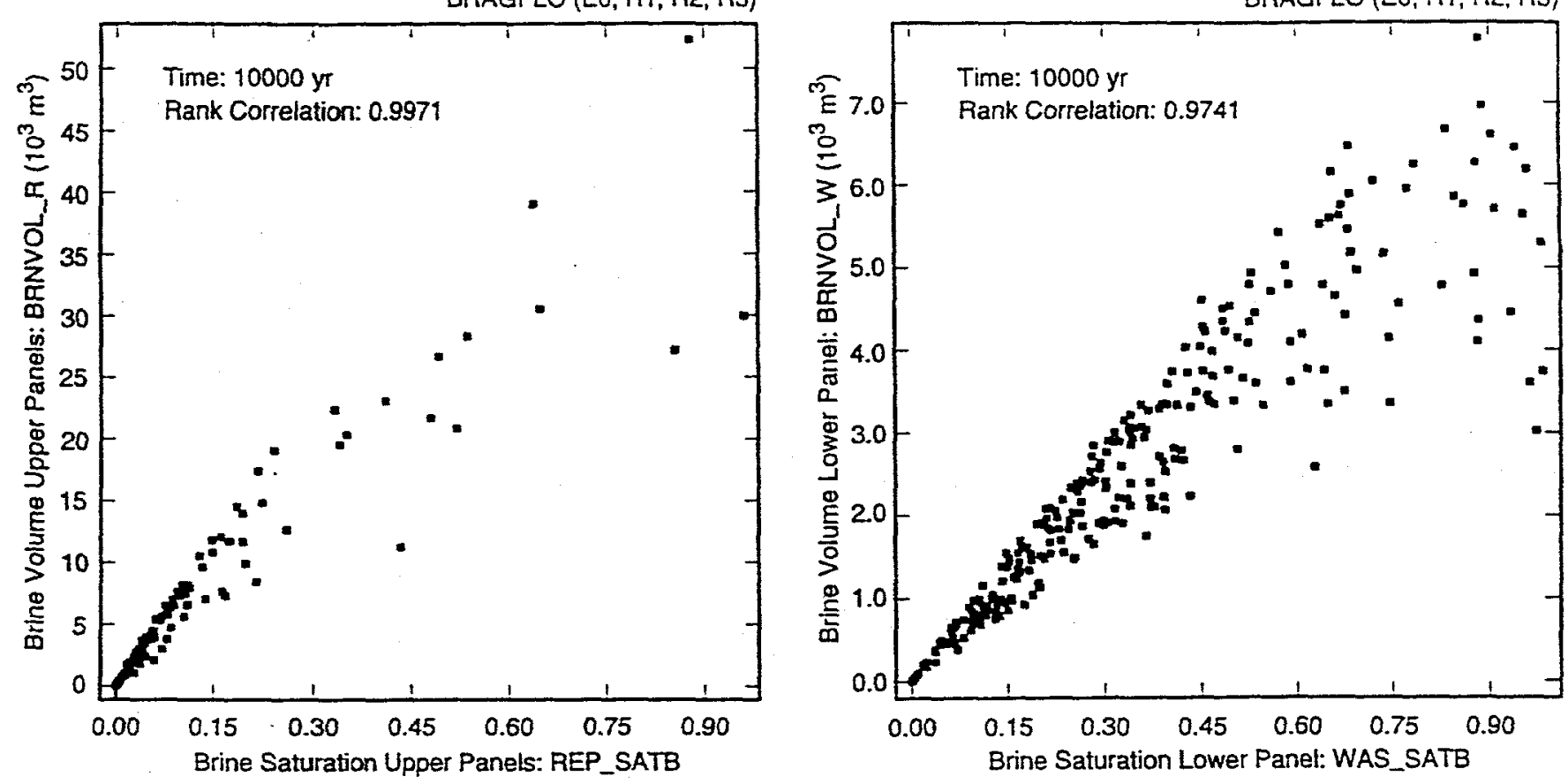

$\operatorname{TRI}-6362-4919-0$

Fig. 27. Scatterplots for brine saturation and brine volume in upper (BRNVOL_R, REP_SATB) and lower (BRNVOL_W, WAS_SATB) waste panels under undisturbed conditions at 10,000 yr.

BRAGRLO (EO, R1)

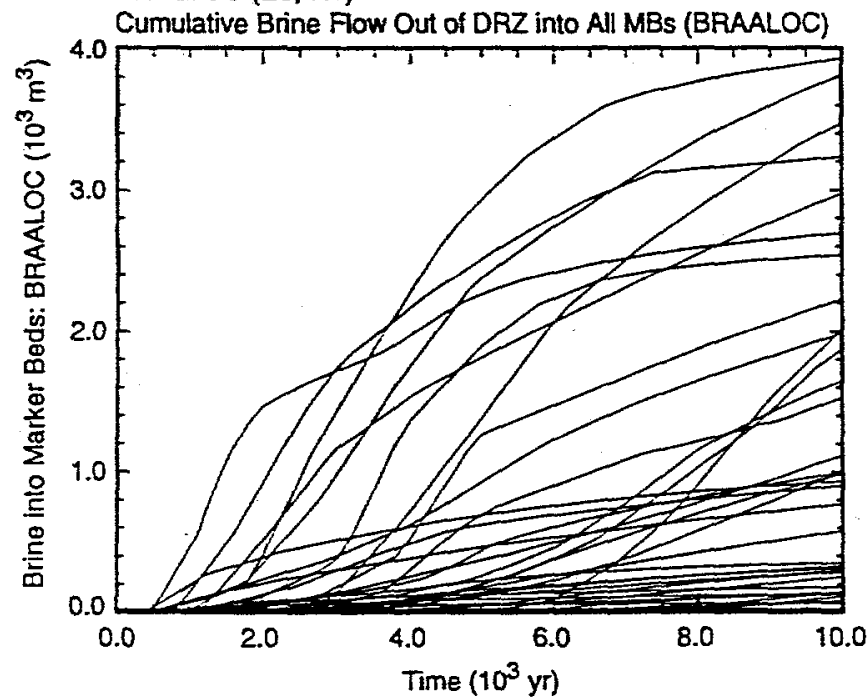

BRAGFLO (EO, R1, R2, R3)

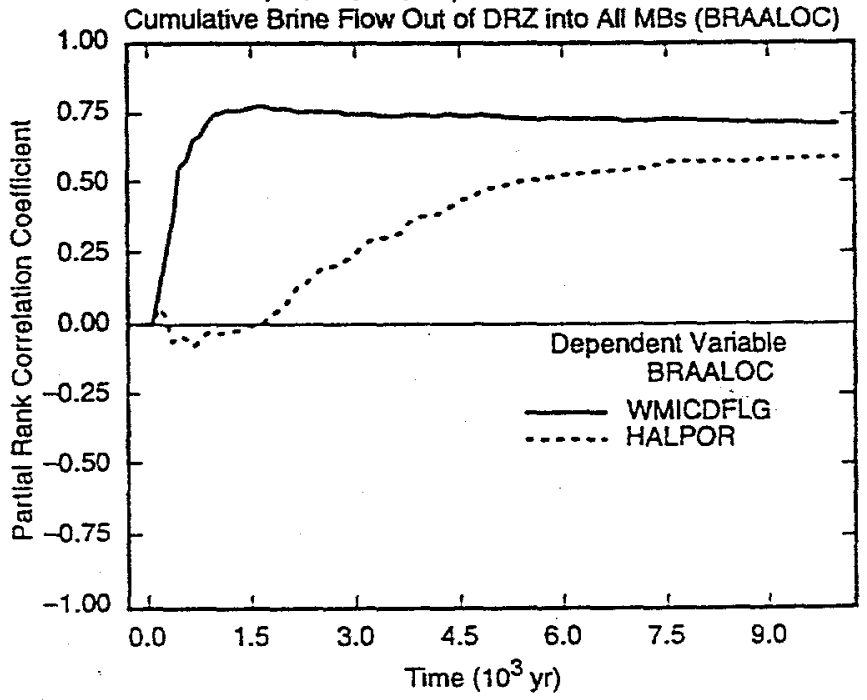

TA1-6342-4920-0

Fig. 28. Uncertainty and sensitivity analysis results for cumulative brine flow into marker beds away from repository (BRAALOC) under undisturbed conditions. 


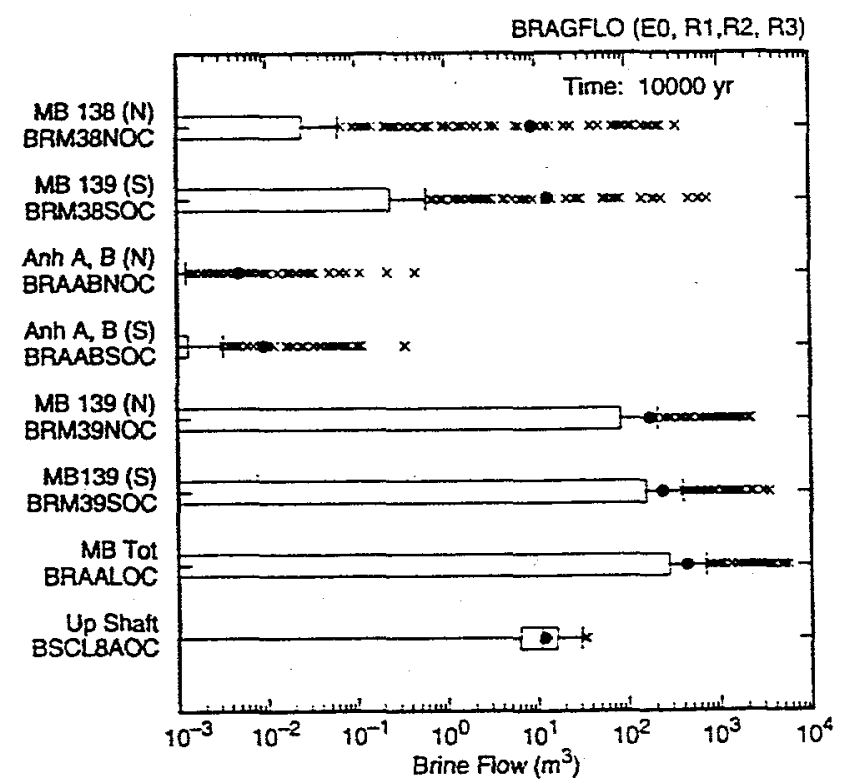

TRI-6342-492i-1

Fig. 29. Cumulative brine flow over $10,000 \mathrm{yt}$ away from repository in marker beds (BRM38NOC, BRM38SOC, $B R A A B N O C, B R A A B S O C, B R M 39 N O C, B R M 39 S O C, B R A A L O C)$ and up shaft (BSCLSAOC). under undisturbed conditions.

BRAGFLO (EO, R1, R2, R3)
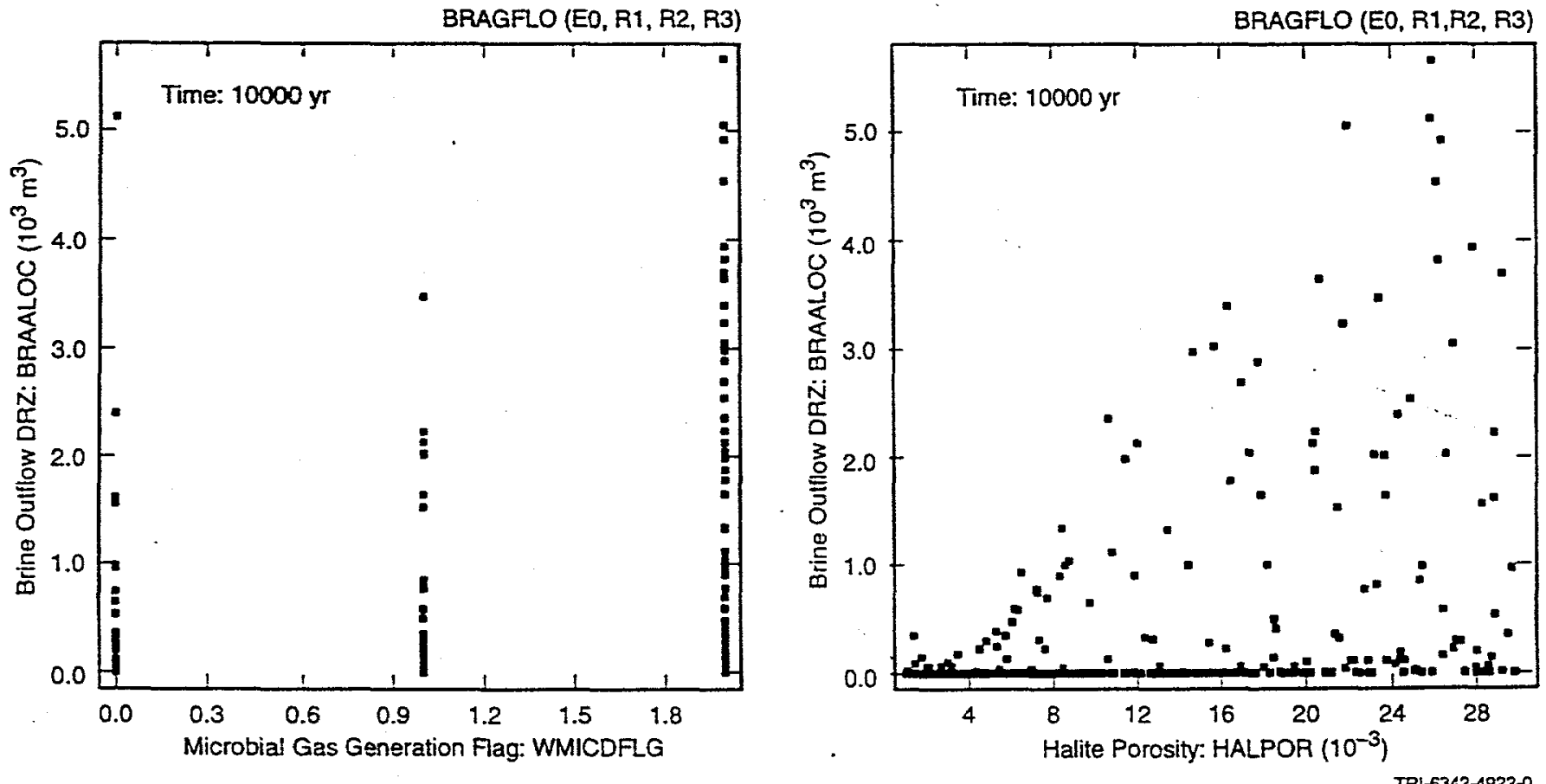

Fig. 30. Scatterplots for cumulative brine flow' away from the repository over $10,000 \mathrm{yr}$ in marker beds (BRAALOC) under undisturbed conditions versus WMICDFLG and HALPOR. 
BRAGFLO (EO, R1, R2, R3)

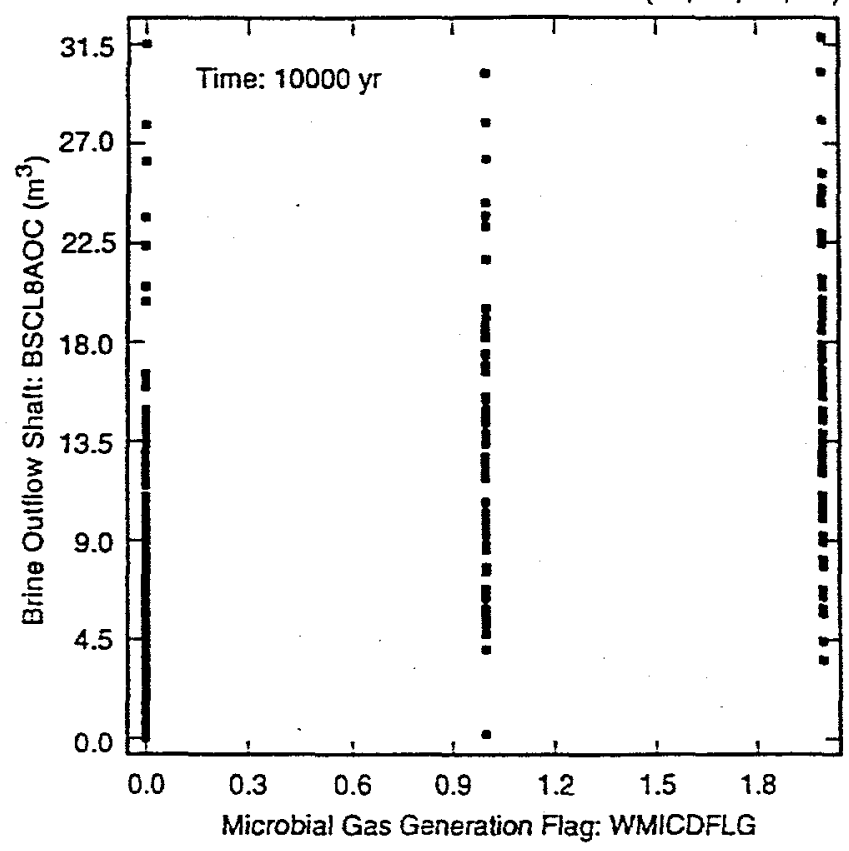

BRAGFLO (EO, R1, R2, R3)

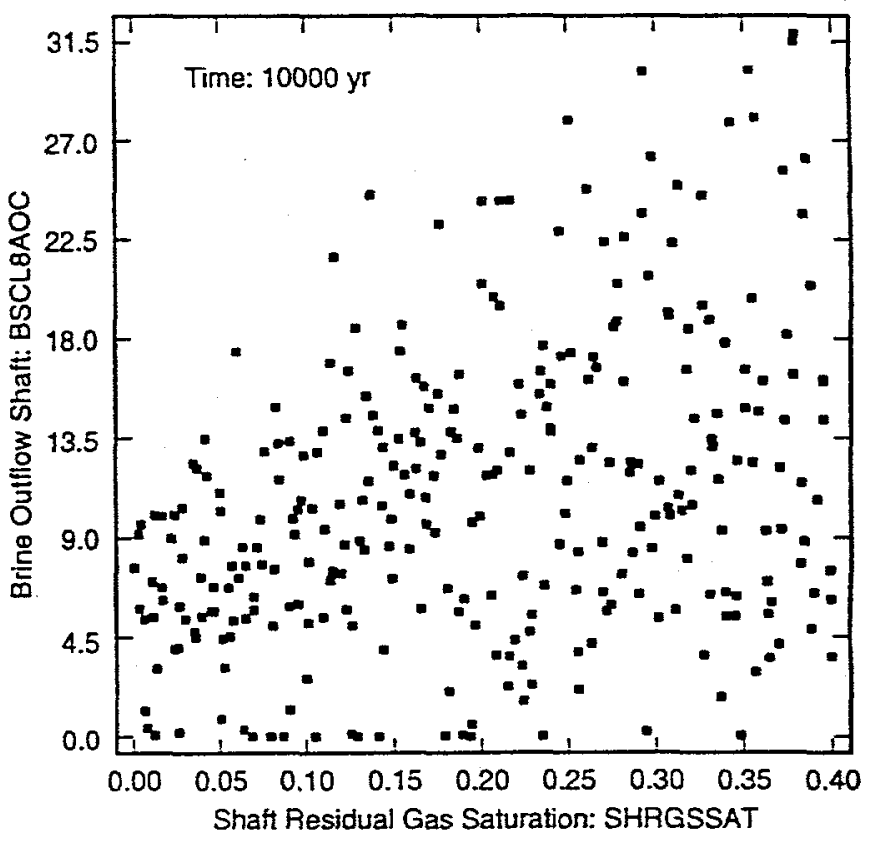

TRt $-6342-4923-0$

Fig. 31. Scatterplots for cumulative brine flow in shaft at boundary of DRZ and intact halite (BSCLSAOC) over $10,000 \mathrm{yr}$ under undisturbed conditions versus WMICDFLG and SHRGSSAT.
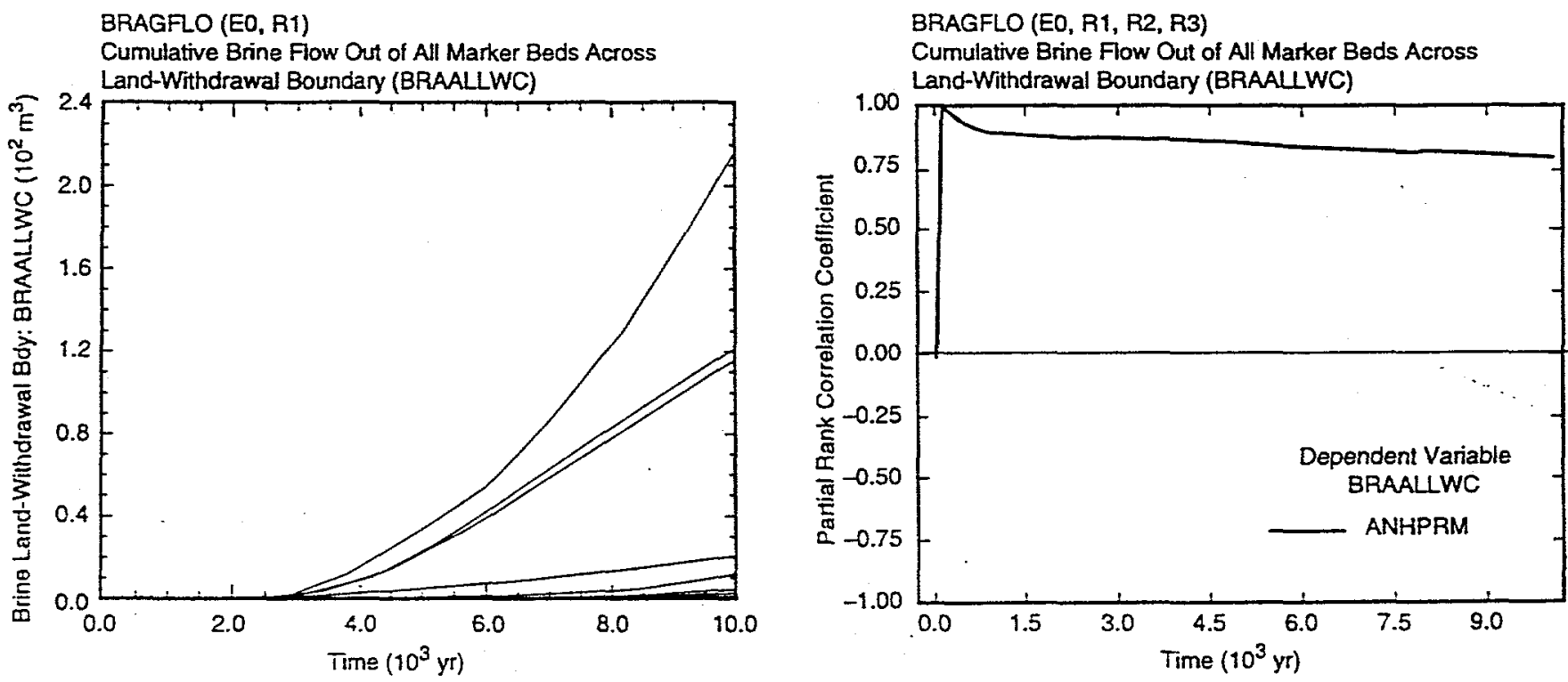

Th1-6342-4924-0

Fig. 32. Uncertainty and sensitivity analysis results for cumulative brine flow in marker beds across land withdrawal boundary away from repository (BRAALLWC) under undisturbed conditions. 


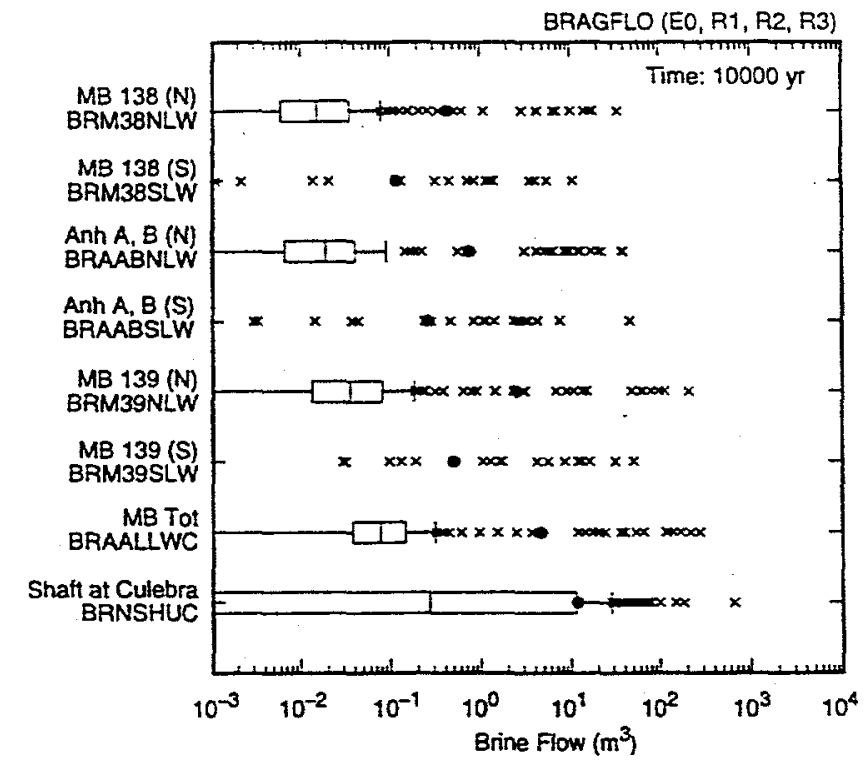

TRI-6342-483i-0

Fig. 33. Cumulative brine flow over 10,000 yr away from repository in individual marker beds at land withdrawal boundary (BRM38NLW, BRM38SLW, BRAABNLW, BRAABSLW, BRM39NLW, BRM39SLW, BRAALLWC) and in shaft at boundary with Rustler Formation (BRNSHUC) under undisturbed conditions. 

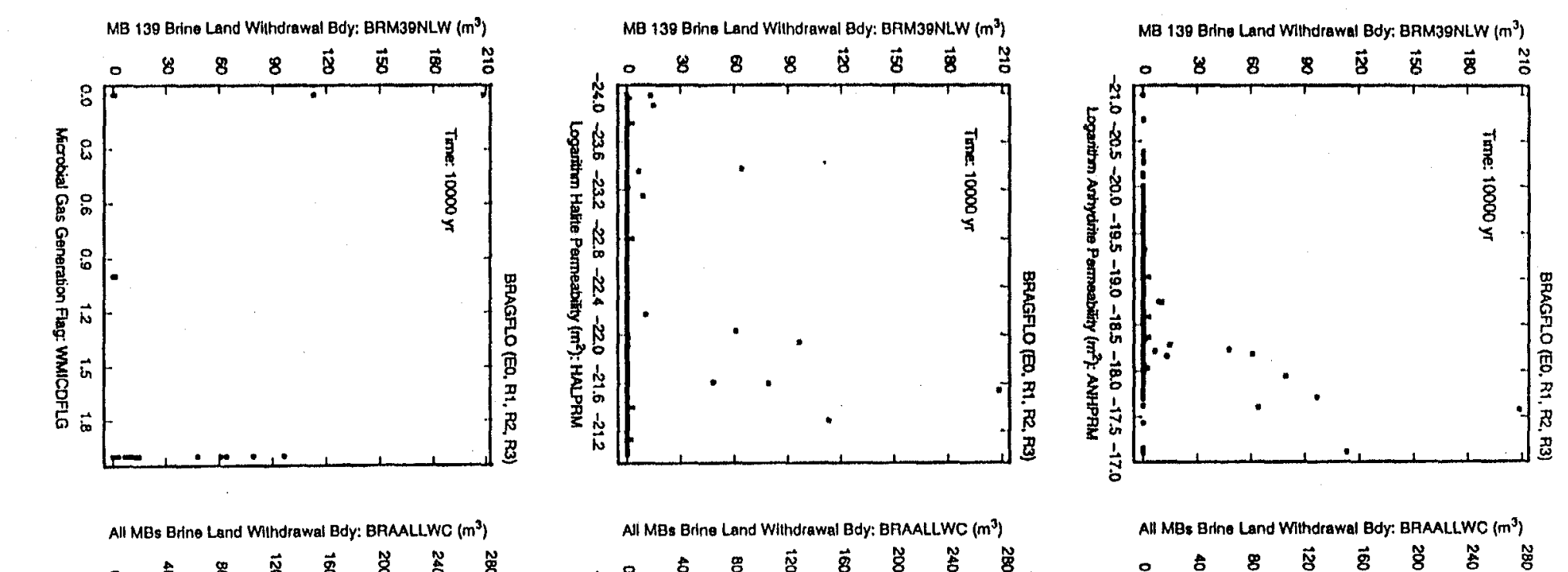

All MEs Brine Land Withdrawal Bdy: BRAALLWC $\left(\mathrm{m}^{3}\right)$
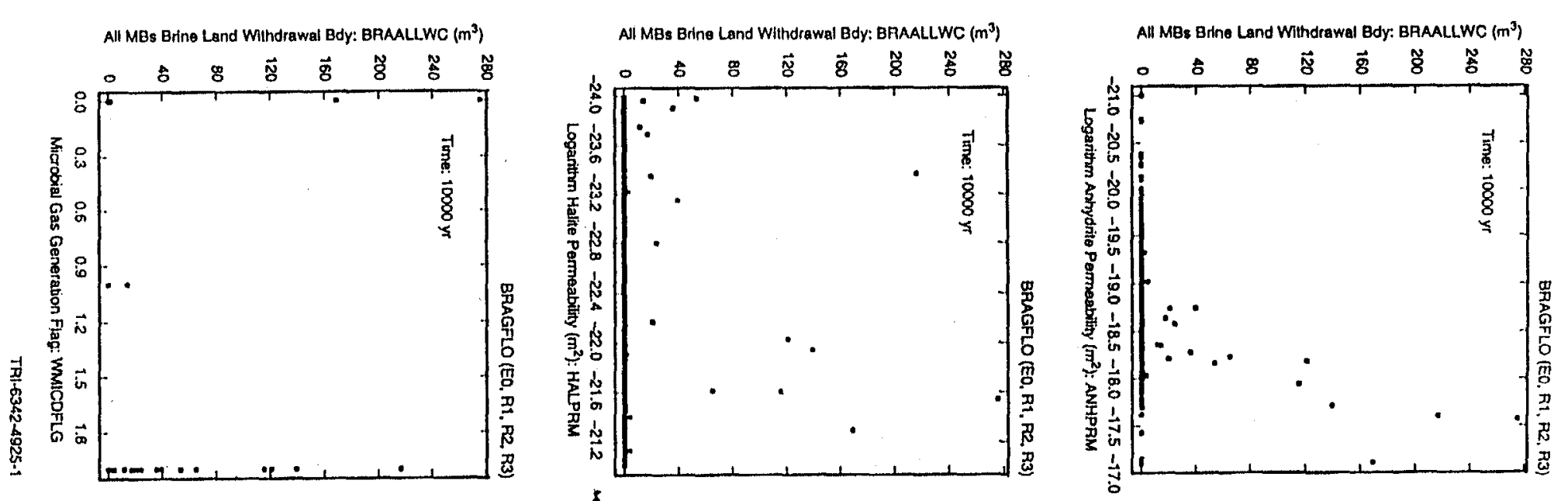
BRAGFLO (EO, R1)

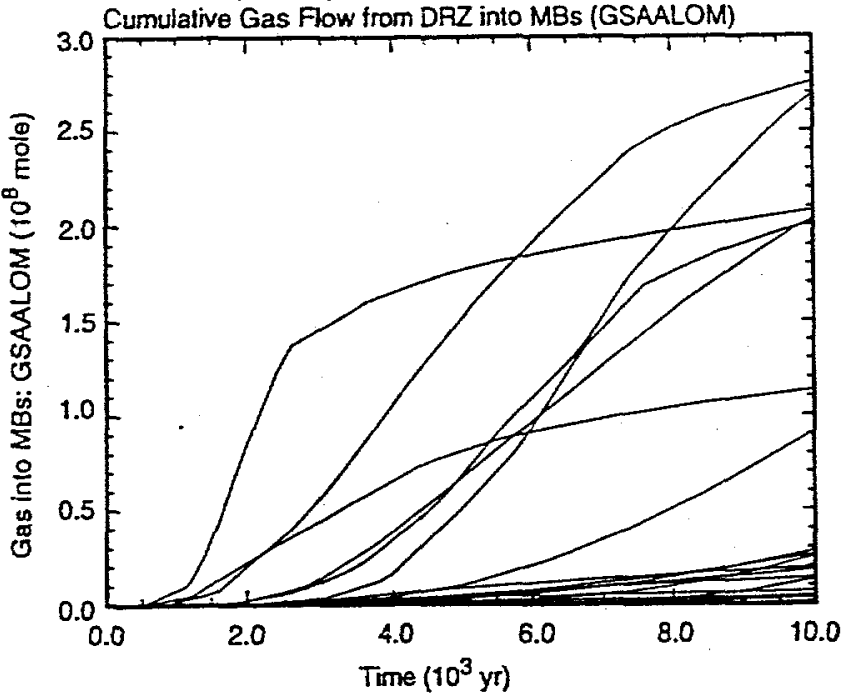

BRAGFLO (EO, R1, R2, R3)

Cumulative Gas Flow from DRZ into MBs (GSAALOM)

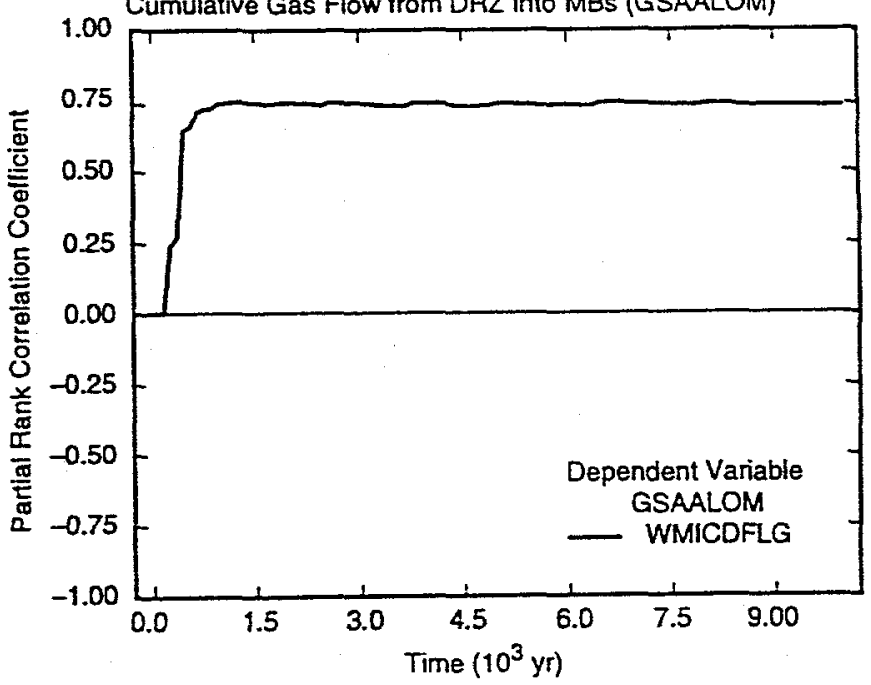

TR1-6342-4926-0

Fig. 35. Uncertainty and sensitivity analysis results for cumulative gas flow into marker beds away from repository (GSAALOM) under undisturbed conditions.

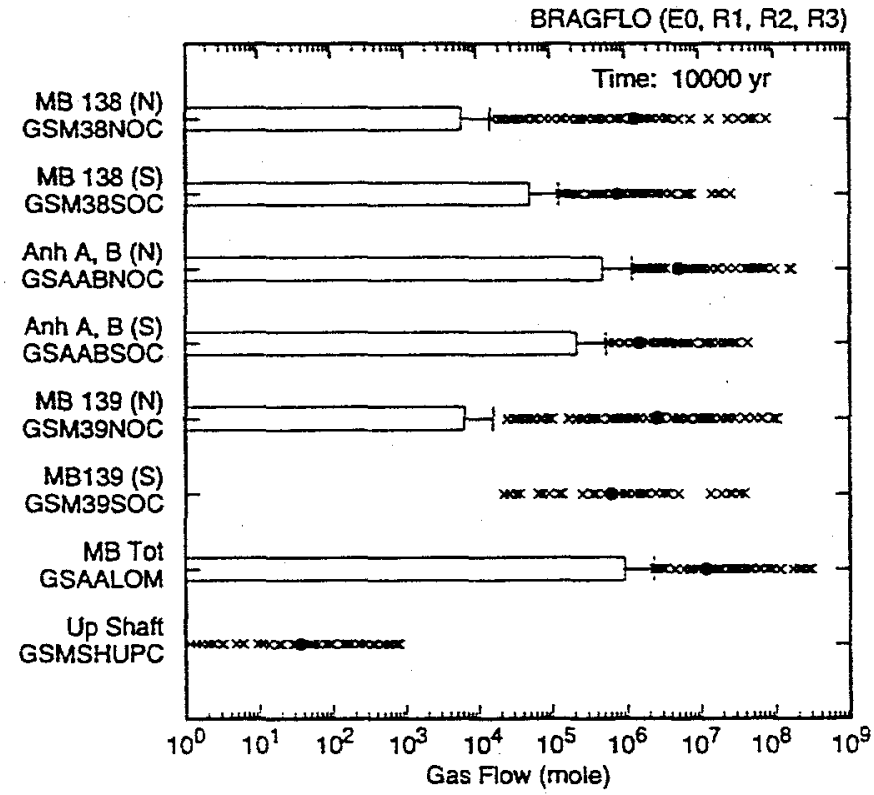

TR1-6342-4927-1

Fig. 36. Cumulative gas flows over $10,000 \mathrm{yr}$ away from repository in individual marker beds (GSM38NOC, GSM38SOC, GSAABNOC, GSAABSOC, GSM39NOC, GSM39SOC, GSAALOM) and in shaft at boundary with Rustler Formation (GSMSHUPC) under undisturbed conditions. 
BRAGFLO (EO, R1, R2, R3)

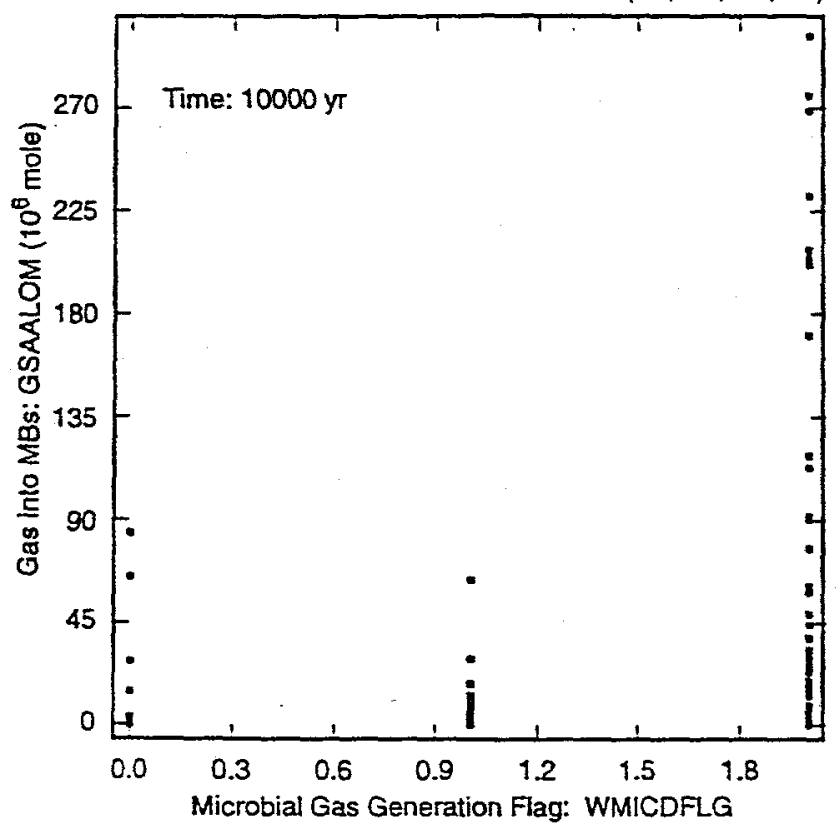

BRAGFLO (EO, R1, R2, R3)

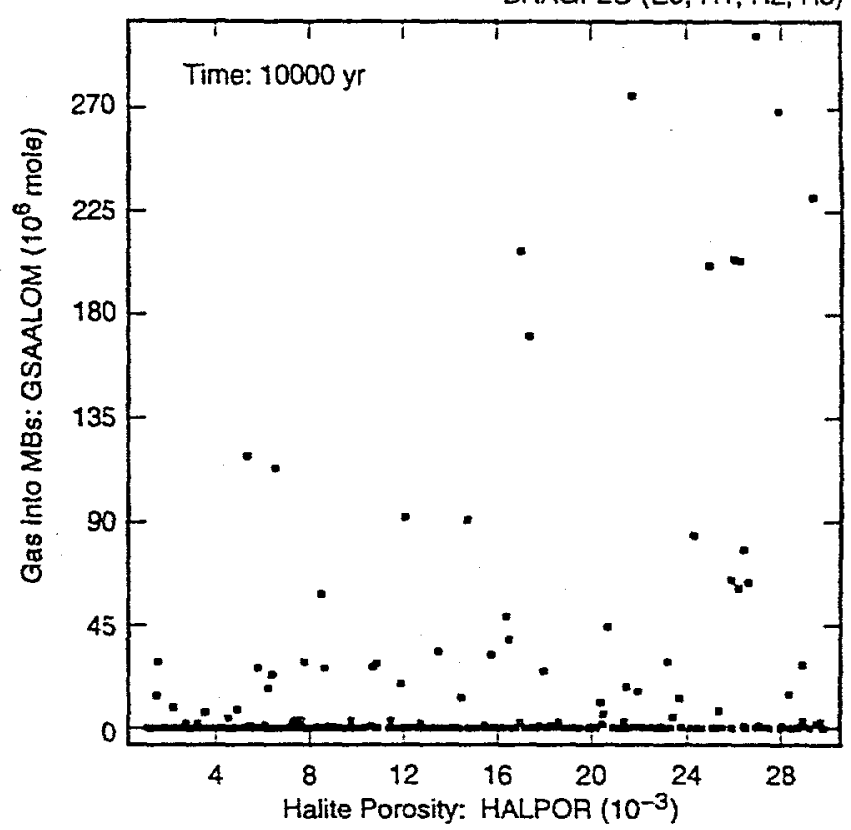

BRAGFLO (EO, A1, R2, R3)

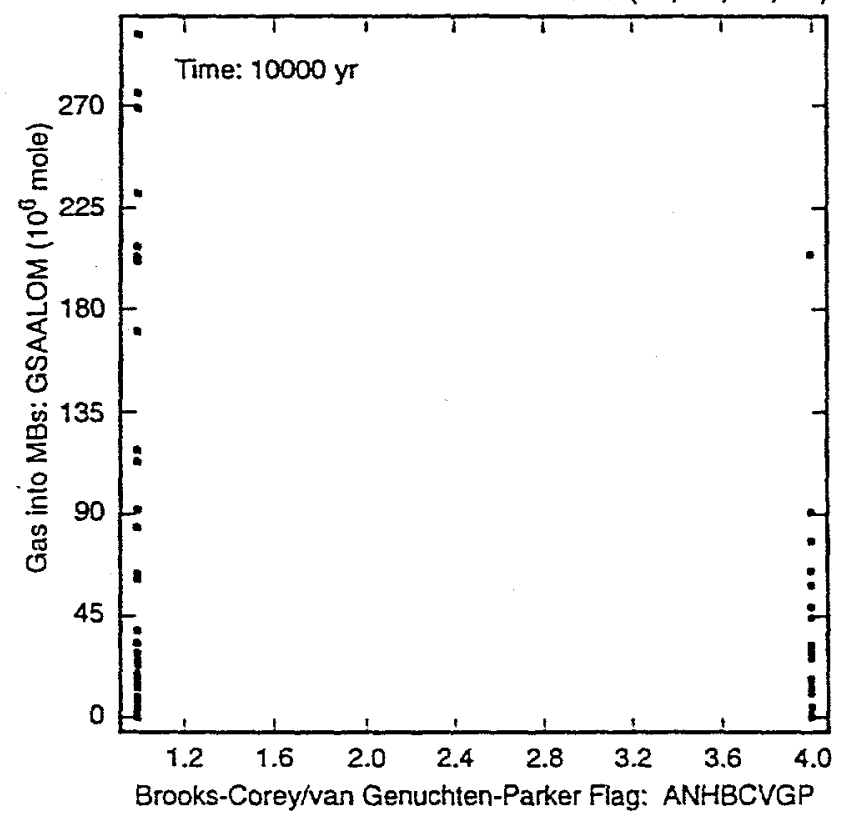

TRI-6342-5162-0

Fig. 37. Scatterplots for cumulative gas flow in marker beds away from repository (GSAALOM) under undisturbed conditions over 10,000 yr versus WMICDFLG, HALPOR and ANHBCVGP. 


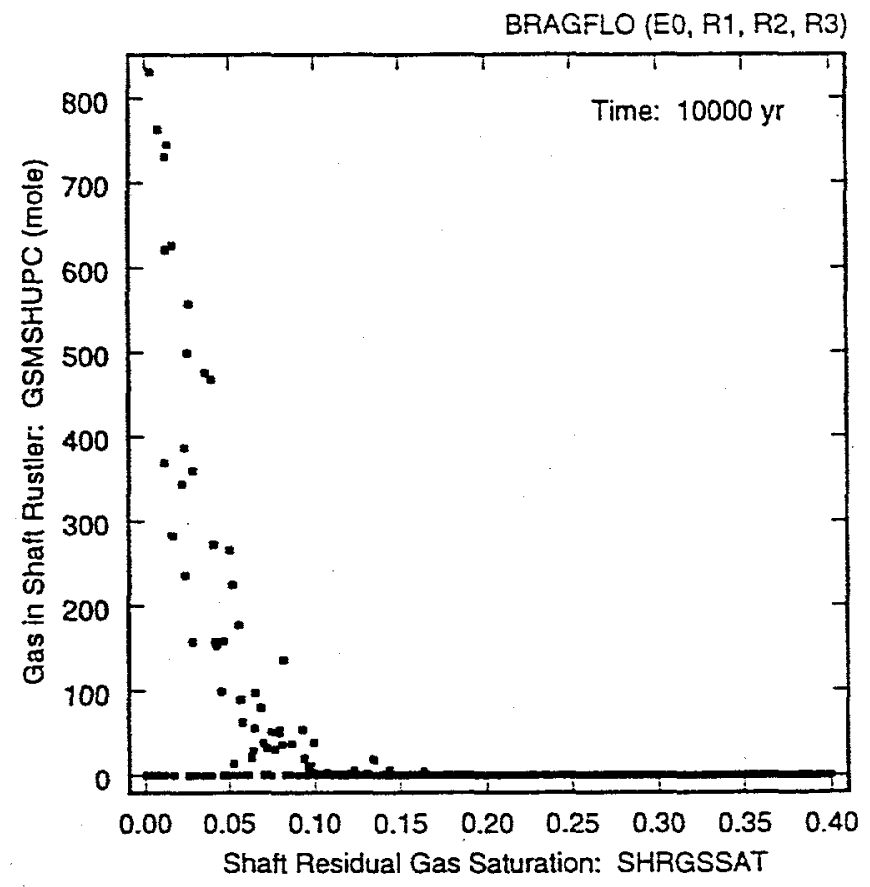

TR1-6342-5146-0

Fig. 38. Scatterplots for cumulative gas flow in shaft away from repository at boundary with Rustler Formation (GSMSHUPC) under undisturbed conditions over 10,000 yr versus SHRGSSAT.
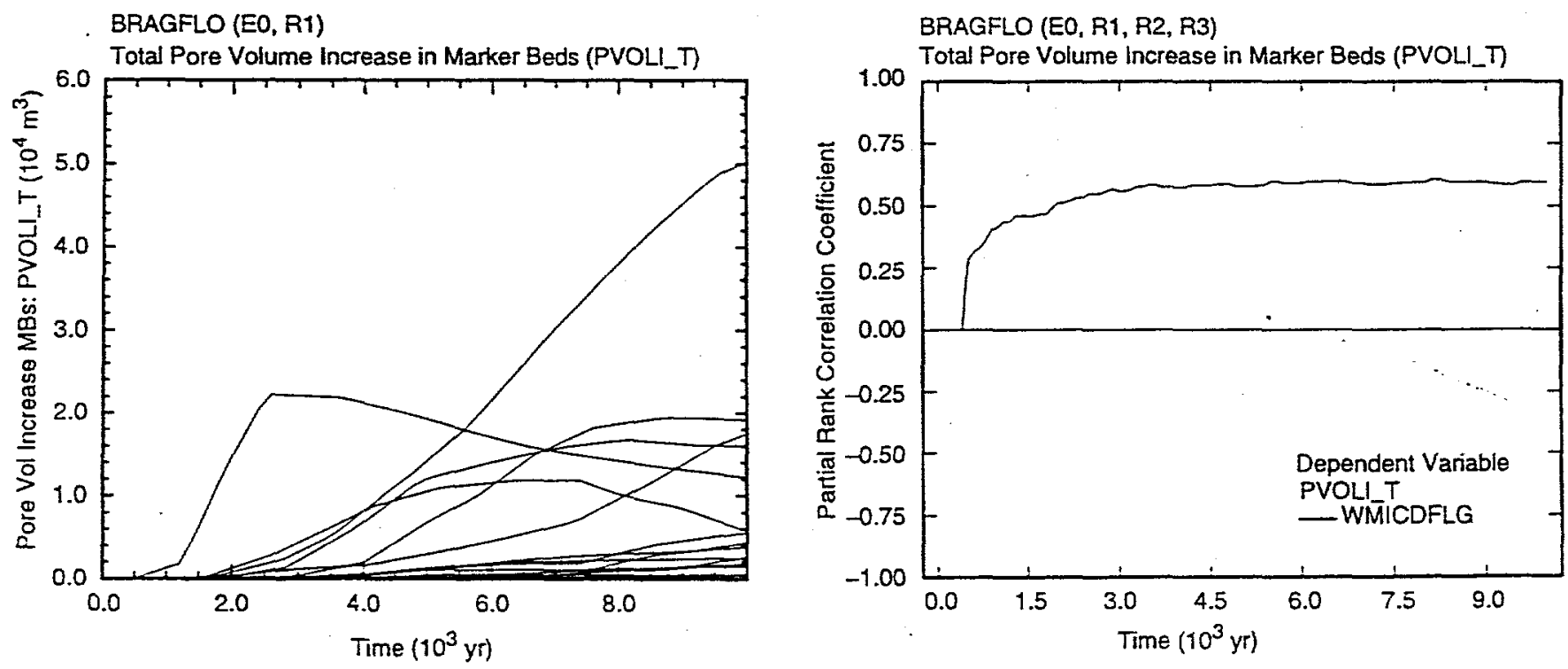

TA!-6342-5147-0

Fig. 39. Uncertainty and sensitivity analysis results for total pore volume increase in marker beds (PVOLI_T) under undisturbed conditions. 


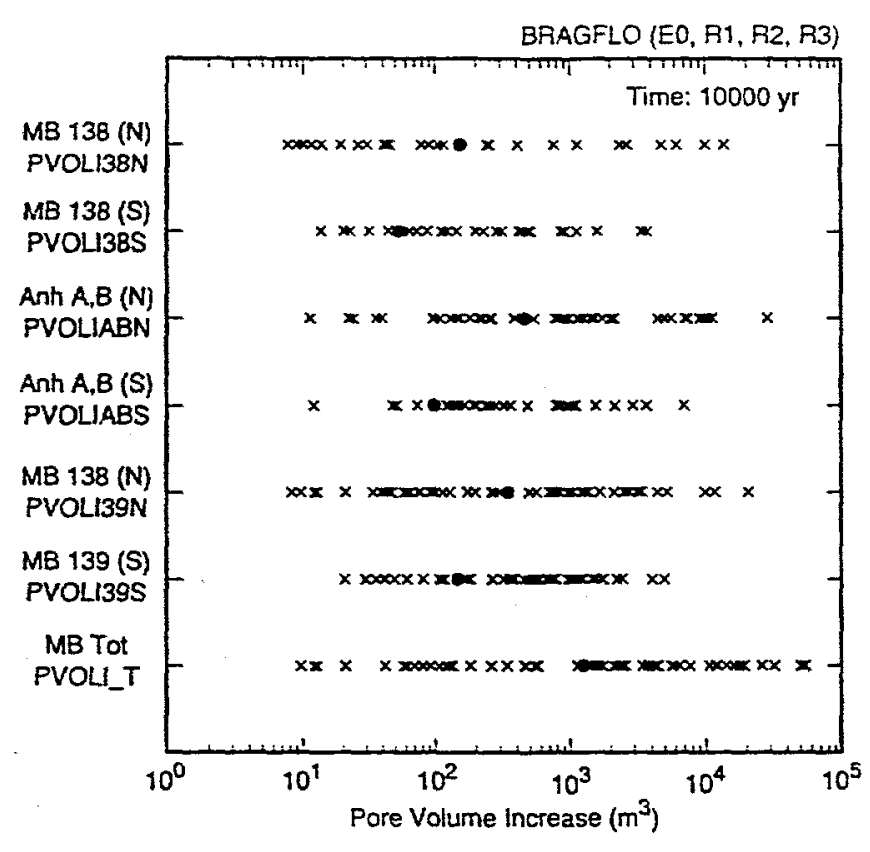

TRI-6342-4832-0

Fig. 40. Pore volume increase due to fracturing in individual marker beds (PVOLI38N, PVOLI38S, PVOLIABN, PVOLIABS, PVOLI39N, PVOLI39S, PVOLI_T) at 10,000 yr under undisturbed conditions. 

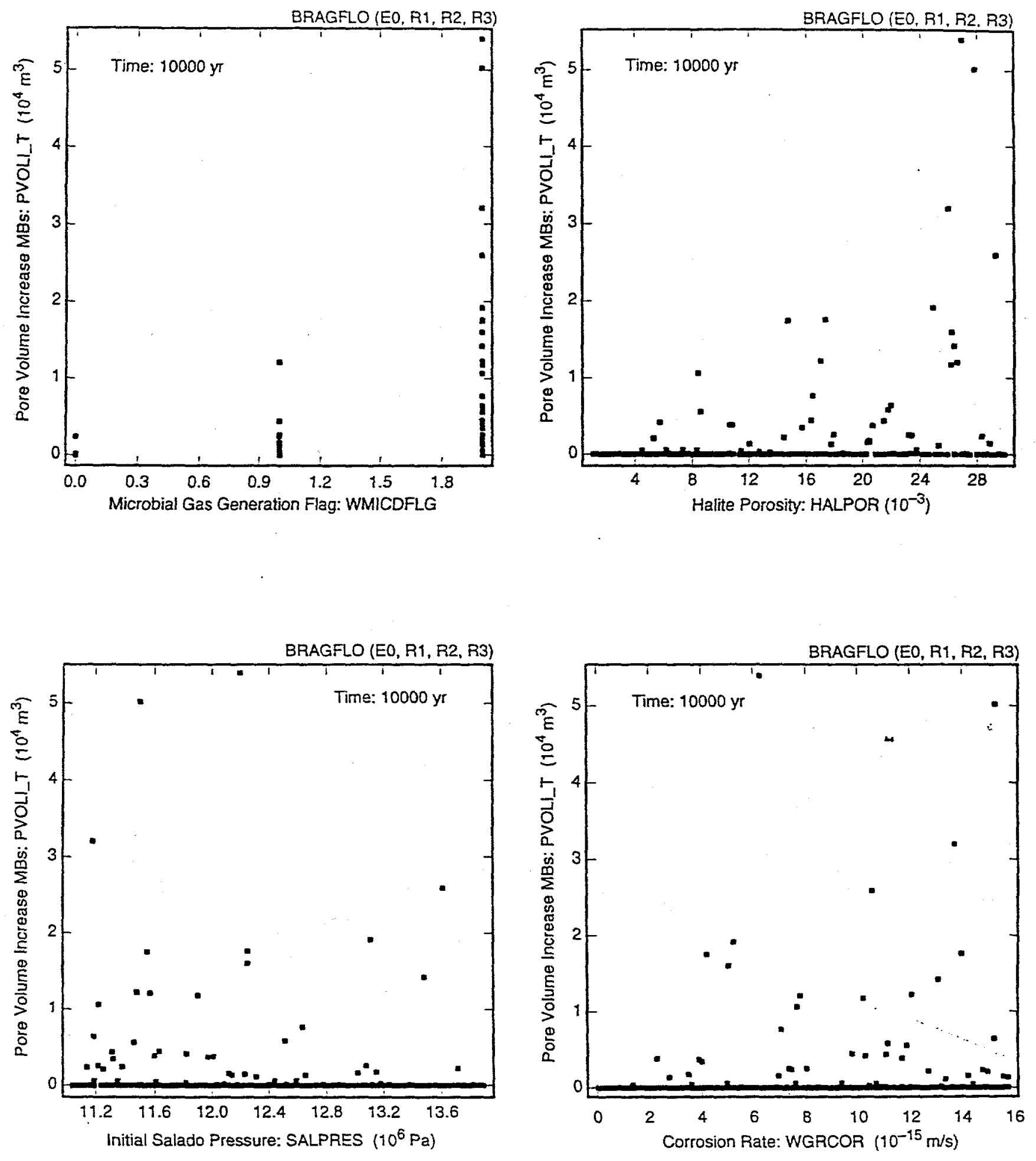

TRI-6342-4929-1

Fig. 41. Scatterplots for total pore volume increase due to fracturing in marker beds ( $P V O L J_{-} T$ ) at $10,000 \mathrm{yr}$ under undisturbed conditions versus WMICDFLG, HALPOR, SALPRES and WGRCOR. 
BRAGFLO (EO, R1)

Length of Fractured Zone in North MB139 (FRACX39N)

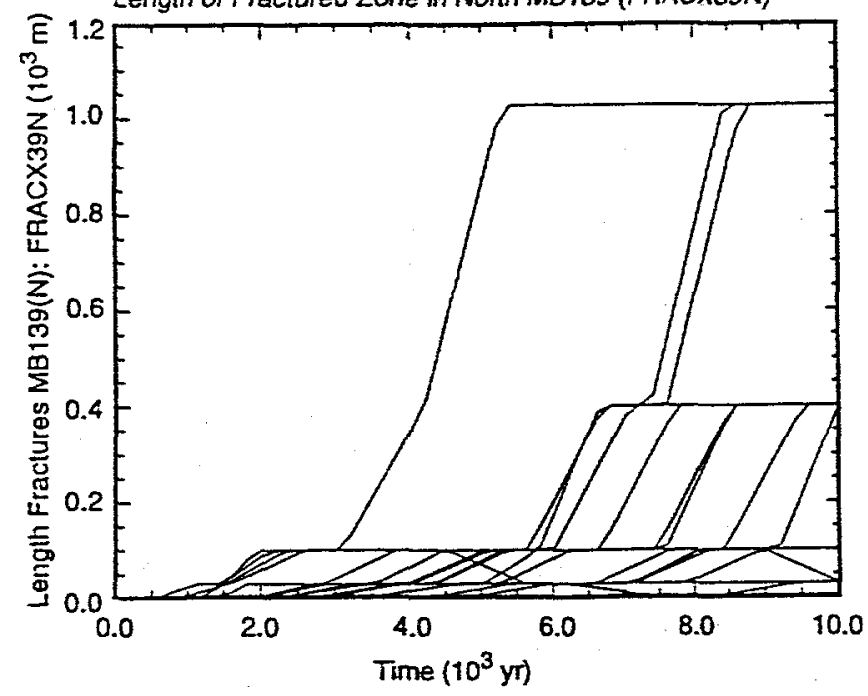

BRAGFLO (EO, R1, R2, R3)

Length of Fractured Zone in North MB139 (FRACX39N)

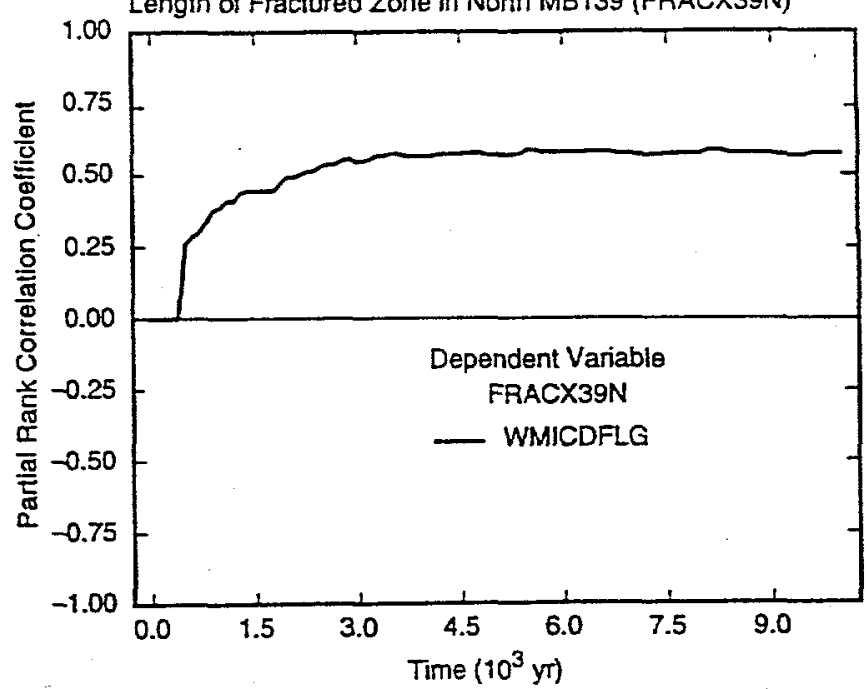

TRI-6342-4930-0

Fig. 42. Uncertainty and sensitivity analysis results for length of fracture zone in north MB 139 (FRACX39N) under undisturbed conditions. 
Table 1. Results Calculated by BRAGFLO Considered in Uncertainty and Sensitivity Analyses for Fluid Flow in the Vicinity of the Repository under Undisturbed (i.e., EO) Conditions

$B R A A B N I C$ - Cumulative brine flow $\left(\mathrm{m}^{3}\right)$ out of north anhydrites $\mathrm{A}$ and $\mathrm{B}$ into disturbed rock zone (DRZ) (i.e., from Cell 556 to Cell 527 in Fig. 3, Ref. 2)

$B R A A B N L W$ - Curmulative brine flow $\left(\mathrm{m}^{3}\right)$ in north anhydrites $\mathrm{A}$ and $\mathrm{B}$ across land withdrawal boundary (i.e., from Cell 561 to Cell 562 in Fig. 3, Ref. 2)

$B R A A B N O C$ - Cumulative brine flow $\left(\mathrm{m}^{3}\right)$ out of $\mathrm{DRZ}$ into north anhydrites $\mathrm{A}$ and $\mathrm{B}$ (i.e., from Cell 527 to Cell 556 in Fig. 3, Ref. 2)

$B R A A B S L W-$ Cumulative brine flow $\left(\mathrm{m}^{3}\right)$ in south anhydrites $\mathrm{A}$ and $\mathrm{B}$ across land withdrawal boundary (i.e., from Cell 550 to Cell 549 in Fig. 3, Ref. 2)

$B R A A B S O C$-Cumulative brine flow $\left(\mathrm{m}^{3}\right)$ out of $\mathrm{DRZ}$ into south anhydrites $\mathrm{A}$ and $\mathrm{B}$ (i.e., from Cell 482 to Cell 555 in Fig. 3, Ref. 2)

$B R A A L L W$ - Curmulative brine flow $\left(\mathrm{m}^{3}\right)$ in all MBs across land withdrawal boundary (i.e., $B R M 38 N L W \div$ $B R A A B N L W+B R M 39 N L W+B R M 38 S N L W \div B R A A B N L W+B R M 39 S L W)$

$B R A A L O C$ - Cumulative brine flow $\left(\mathrm{m}^{3}\right)$ out of $D R Z$ into all MBs (i.e., BRM38NOC $\div$ BRAABNOC $\div$ $B R M 39 N O C+B R M 38 S N O C \div B R A .4 B N O C+B R M 39 S O C$ )

$B R M 38 N L W$-Cumulative brine flow $\left(\mathrm{m}^{3}\right)$ in north MB138 across land withdrawal boundary (i.e., from Cell 593 to Cell 594 in Fig. 3, Ref. 2)

BRM38NOC-Cumulative brine flow $\left(\mathrm{m}^{3}\right)$ out of DRZ into north MB138 (i.e., from Cell 587 to Cell 588 in Fig. 3, Ref. 2)

BRM38SIC - Cumulative brine flow $\left(\mathrm{m}^{3}\right)$ out of south MB138 into DRZ (i.e., from Cell 571 to Cell $5 / 2$ in Fig. 3, Ref. 2)

BRM38SLW-Cumulative brine flow $\left(\mathrm{m}^{3}\right)$ in south MB138 across land withdrawal boundary (i.e., from Cell 566 to Cell 565 in Fig. 3, Ref. 2)

BRM38SOC-Cumulative brine flow $\left(\mathrm{m}^{3}\right)$ out of DRZ into south MB138 (i.e., from Cell 572 to Cell 571 in Fig. 3, Ref. 2)

BRM39NIC-Cumulative brine flow $\left(\mathrm{m}^{3}\right)$ out of north MBI39 into DRZ (i.e., from Cell 540 to Cell 465 in Fig. 3, Ref. 2)

$B R M 39 N L W$-Cumulative brine flow $\left(\mathrm{m}^{3}\right)$ in north $\mathrm{MB} 139$ across land withdrawal boundary (i.e., from Cell 545 to Cell 546 in Fig. 3, Ref. 2)

BRM39NOC - Cumulative brine flow $\left(\mathrm{m}^{3}\right)$ out of $\mathrm{DRZ}$ into north MB139 (i.e., from Cell 465 to Cell 540 in Fig. 3, Ref. 2)

BRM39SIC-Cumulative brine flow $\left(\mathrm{m}^{3}\right)$ out of south MB139 into DRZ (i.e., from Cell 539 to Cell 436 in Fig. 3, Ref. 2)

BRM39SLW-Cumulative brine flow $\left(\mathrm{m}^{3}\right)$ in south MB139 across land withdrawal boundary (i.e., from Cell 534 to Cell 533 in Fig. 3, Ref. 2)

BRM39SOC-Cumulative brine flow ( $\mathrm{m}^{3}$ ) out of DRZ into south MB139 (i.e.. from Cell 436 to Cell 539 in Fig. 3. Ref. 2) 
Table 1. Results Calculated by BRAGFLO Considered in Uncertainty and Sensitivity Analyses for Fluid Flow in the Vicinity of the Repository under Undisturbed (i.e., E0) Conditions (continued)

$B R N$ DNSH - Cumulative brine flow $\left(\mathrm{m}^{3}\right.$ ) down shaft at upper boundary of DRZ (i.e., from Cell 654 to Cell 653 in Fig. 3, Ref. 2)

$B R N \_R M V$-Cumulative brine $\left(\mathrm{m}^{3}\right)$ consumed in repository by corrosion (i.e., in Cells 596-625 in Fig. 3, Ref. 2)

$B R N V O L_{-} R-$ Brine volume $\left(\mathrm{m}^{3}\right)$ in upper waste panels (i.e., in Cells 617-625 in Fig. 3, Ref. 2)

BRNVOL_W-Brine volume $\left(\mathrm{m}^{3}\right)$ in lower waste panels (i.e., in Cells 596-616 in Fig. 3, Ref. 2)

BRNREPTC - Cumblative brine flow $\left(\mathrm{m}^{3}\right)$ into repository (i.e., into region corresponding to Cells 596-625, $638-640$ in Fig. 3, Ref. 2)

BRNSHUC - Cumulative brine flow $\left(\mathrm{m}^{3}\right)$ up shaft at boundary berween Salado and Rustler Formations (i.e., from Cell 660 to Cell 661 in Fig. 3, Ref. 2)

BSCL8AOC-Cumulative brine flow $\left(\mathrm{m}^{3}\right)$ up shaft at boundary of DRZ and intact halite (i.e., from Cell 653 to Cell 654)

CELL_KG—Mass of cellulose (kg) in repository (i.e., in Cells 596-625 in Fig. 3, Ref. 2)

CELL_ $M_{-} H-$ Cumblative gas generation (mol) in repository due to microbial degradation of cellulose under inundated conditions (i.e., in Cells 596-625 in Fig. 3, Ref. 2)

$C E L L_{-} M_{-} /$-Cumulative gas generation (mol) in repository due to microbial degradation of cellulose under inundated conditions (i.e., in Cells 596-625 in Fig. 3, Ref. 2)

CELL_MOL_Cumulative gas generation (mol) in repository due to microbial degradation of cellulose (i.e., $\left.C E L L_{-} M_{-} H \div C E L L_{-} M_{-}\right)$

$F E \_K G-$ Mass of steel (kg) in repository (i.e., in Cells 596-625 in Fig. 3, Ref. 2)

FE_MOLE_Cumulative gas generation (mol) in repository due to corrosion (i.e., in Cells 596-625 in Fig. 3, Ref. 2)

FEREM_R-Fraction of steel remaining in upper waste panels (i.e., in Cells 617-625 in Fig. 3, Ref. 2)

FEREM_W-Fraction of steel remaining in lower waste panel (i.e., in Cells 596-616 in Fig. 3, Ref. 2)

FRACXABN-Length $(\mathrm{m})$ of fractured zone in north anhydrites A and B (i.e., in Cells 556-563 in Fig. 3 , Ref. 2)

FRACXABS - Length (m) of fractured zone in south anhydrites A and B (i.e., in Cells 548-555 in Fig. 3 , Ref. 2)

FRACX38N-Lengti (m) of fractured zone in north MB 138 (i.e., in Cells $588-595$ in Fig. 3, Ref. 2)

FRACX385-Lengih (m) of fractured zone in south MB 138 (i.e.. in Cells 564-571 in Fig. 3, Ref. 2)

FRACX39N-Lengh (m) of fractured zone in north MB 139 (i.e.. in Cells 540-547 in Fig. 3, Ref. 2)

FR4CX395-Lengti (m) of fractured zone in south MB 139 (i.e.. in Cells 532-539 in Fig. 3, Ref. 2) 
Table 1. Results Calculated by BRAGFLO Considered in Uncertainty and Sensitivity Analyses for Fluid Flow in the Vicinity of the Repository under Undisturbed (i.e., EO) Conditions (continued)

$G A S \_M O L E-T o t a l$ cumulative gas generation in repository (i.e., $F E_{-} M O L E+C E L L_{-} M O L$ )

$G A S M O L$ _ $R$-Cumulative gas generation (mol) in upper waste panels due to corrosion and microbial degradation (i.e., in Cells 617-625 in Fig. 3, Ref. 2)

GASMOL_W-Cumulative gas generation (mol) in lower waste panel due to corrosion and microbial degradation (i.e., in Cells 596-616 in Fig. 3, Ref. 2)

GSAABNIM-Curmulative gas flow (mol) out of north anhydrites A and B into DRZ (i.e., from Cell 556 to Cell 527 in Fig. 3, Ref. 2)

GSAABNOC-Cumblative gas flow (mol) out of DRZ into north anhydrites A and B (i.e., from Cell 527 to Cell 556 in Fig. 3, Ref. 2)

GSAABSIM-Cumulative gas flow (mol) out of south anhydrites A and B into DRZ (i.e., from Cell 555 to Cell 482 in Fig. 3, Ref. 2)

GSAABSOC-Cumulative gas flow (mol) out of DRZ into south anhydrites A and B (i.e., from Cell 482 to Cell 555 in Fig. 3, Ref. 2)

GSAALIM-Cumulative gas flow (mol) out of all MBs into DRZ (i.e., GSM38NIM + GSAABNIM + GSM39NIM + GSM38SNIM + GS.A.4BNIM + GSM39SIM)

GSAALOM-Cumulative gas flow (mol) out of DRZ into all MBs (i.e., GSM38NOC + GSAABNOC + GSM39NOC + GSM38SNOC + GSAABNOC + GSM39SOC)

GSM38NIM-Cumulative gas flow (mol) out of north MB138 into DRZ (i.e., from Cell 588 to Cell 587 in Fig. 3, Ref. 2)

GSM38NOC-Cumulative gas flow (mol) out of DRZ into north MB138 (i.e., from Cell 587 to Cell 588 in Fig. 3, Ref. 2)

GSM38SIM-Cumulative gas flow (mol) out of south MB138 into DRZ (i.e., from Cell 571 to Cell 572 in Fig. 3, Ref. 2)

GSM38SOC - Cumulative gas flow (mol) out of DRZ into south MB138 (i.e., from Cell 572 to Cell 571 in Fig. 3, Ref. 2)

GSM39NIM-Cumulative gas flow (mol) out of north MB139 into DRZ (i.e., from Cell 540 to Cell 465 in Fig. 3, Ref. 2)

GSM39NOC-Cumulative gas flow (mol) out of DRZ into north MB139 (i.e.. from Cell 465 to Cell 540 in Fig. 3, Ref. 2)

GSM39SIM-Cumulative gas flow (mol) out of south MB139 into DRZ (i.e., from Cell 539 to Cell 436 in Fig. 3, Ref. 2)

GSM39SOC-Cumularive gas flow (mol) out of DRZ into south MB139 (i.e., from Cell 436 to Cell 539 in Fig. 3. Ref. 2)

GSMSHUPC - Cumuiative gas flow (mol) up shafi at boundary between Salado and Rustler Formations (i.e., from Cell 660 to Cell 661 in Fis. 3. Ref. 2) 
Table 1. Results Calculated by BRAGFLO Considered in Uncertainty and Sensitivity Analyses for Fluid Flow in the Vicinity of the Repository under Undisturbed (i.e., E0) Conditions (continued)

PORVOL_R-Pore volume $\left(\mathrm{m}^{3}\right)$ in upper waste panels (i.e., in Cells 617-625 in Fig. 3, Ref. 2)

PORVOL_T-Total pore volume $\left(\mathrm{m}^{3}\right)$ in repository (i.e., in Cells 596-625 in Fig. 3, Ref. 2)

PORVOL_W-Pore vohume $\left(\mathrm{m}^{3}\right)$ in lower waste panels (i.e., in Cells 596-616 in Fig. 3, Ref. 2)

PVOLI_T-Pore volume increase $\left(\mathrm{m}^{3}\right)$ due to fracturing in all MBs (i.e., PVOLI38N + PVOLIABN + PVOLI39N $\div$ PVOLI38S + PVOLIABS + PVOLI39S)

PVOLIABN Pore volume increase $\left(\mathrm{m}^{3}\right)$ due to fracturing in north anhydrites $\mathrm{A}$ and $\mathrm{B}$ (i.e., in Cells $556-563$ in Fig. 3, Ref. 2)

PVOLIABS - Pore volume increase $\left(\mathrm{m}^{3}\right)$ due to fracturing in south anhydrites $A$ and $B$ (i.e., in Cells $548-555$ in Fig. 3, Ref. 2)

PVOLI38N-Pore volume increase $\left(\mathrm{m}^{3}\right)$ due to fracturing in north MB138 (i.e., in Cells $588-595$ in Fig. 3, Ref. 2)

PVOLI38S-Pore volume increase $\left(\mathrm{m}^{3}\right)$ due to fracturing in south MB138 (i.e., in Cells $564-571$ in Fig. 3 , Ref. 2)

PVOL139N-Pore volume increase $\left(\mathrm{m}^{3}\right)$ due to fracturing in north $\mathrm{MB139}$ (i.e., in Cells $540-547$ in Fig. 3 , Ref. 2)

PVOLI39S Pore volume increase $\left(\mathrm{m}^{3}\right)$ due to fracturing in south MB139 (i.e., in Cells 532-539 in Fig. 3 , Ref. 2)

REP_PRES_Pressure $(\mathrm{Pa})$ in upper waste panels (i.e., average pressure calculated over Cells 617-625 in Fig. $\overline{3}$, Ref. 2)

REP_SATB-Brine saturation in upper waste panels (i.e., average brine saturation calculated over Cells 617625 in Fig. 3, Ref. 2)

WAS_PRES Pressure $(\mathrm{Pa})$ in lower waste panel (i.e., average pressure calculated over Cells 596-616 in Fig. $\overline{3}$, Ref. 2)

WAS_SATB-Brine saturation in lower waste panel (i.e., average brine saruration calculated over Cells 596616 in Fig. 3, Ref. 2) 
Table 2. Stepwise Regression Analyses with Rank-Transformed Data for Cumulative Brine Flow over 10,000 yt into DRZ (BRM38NIC, BRM38SIC, BRAABNIC, BRAABSIC, BRM39NIC, $B R M 29 S I C, B R A A L I C)$ and into repository (BRNREPTC) under Undisturbed Conditions

\begin{tabular}{|c|c|c|c|c|c|c|c|c|c|c|c|c|}
\hline \multirow[b]{2}{*}{ Step ${ }^{2}$} & \multicolumn{3}{|c|}{ MB 138 North: BRM 38 NIC } & \multicolumn{3}{|c|}{ MB 138 South: BRM38SIC } & \multicolumn{3}{|c|}{ Anh $\mathrm{a}$ and $\mathrm{b}$ Nonth: $B R A A B N I C$} & \multicolumn{3}{|c|}{ Anh $\mathrm{a}$ and $\mathrm{b}$ South: $B R A A B S / C$} \\
\hline & Variable $^{b}$ & SRRC & $R^{2 d}$ & Variable & SRRC & $R^{2}$ & Variable & SRRC & $R^{2}$ & Variable & SRRC & $R^{2}$ \\
\hline 1 & ANHPRM & 0.75 & 0.54 & ANHPRM & 0.73 & 0.51 & WMICDFLG & -0.72 & 0.43 & WMICDFLG & -0.66 & 0.43 \\
\hline 2 & WMICDFLG & -0.52 & 0.80 & WMICDFLG & -0.55 & 0.80 & ANHPRM & 0.60 & 0.79 & ANHPRM & 0.59 & 0.77 \\
\hline 3 & HALPRM & -0.20 & 0.84 & HALPRM & -0.18 & 0.83 & HALPOR & -0.15 & 0.81 & HALPOR & -0.16 & 0.80 \\
\hline 4 & HALPOR & -0.12 & 0.86 & WGRCOR & -0.12 & 0.85 & WGRCOR & -0.16 & 0.84 & WGRCOR & -0.16 & 0.83 \\
\hline 5 & WGRCOR & -0.12 & 0.87 & HALPOR & -0.11 & 0.86 & SALPRES & 0.12 & 0.85 & SALPRES & 0.11 & 0.84 \\
\hline 6 & SALPRES & 0.11 & 0.88 & SALPRES & 0.10 & 0.87 & WASTHICK & -0.09 & 0.86 & HALPRM & 0.11 & 0.85 \\
\hline 7 & HASTKTCK & -0.08 & 0.89 & WASTHTCX & -0.08 & 0.88 & HALPRM & 0.09 & 0.87 & HASTHICK & -0.09 & 0.86 \\
\hline 8 & WGRMII & -0.06 & 0.89 & WGRMICI & -0.06 & 0.88 & SHRGSSAT & -0.05 & 0.87 & SHRGSSIT & -0.05 & 0.86 \\
\hline
\end{tabular}

\begin{tabular}{|c|c|c|c|c|c|c|c|c|c|c|c|c|}
\hline \multirow[b]{2}{*}{ Step } & \multicolumn{3}{|c|}{ MB 139 Nonth: BRMBSNIC } & \multicolumn{3}{|c|}{ MB 139 Soutr: BRM39SJC } & \multicolumn{3}{|c|}{ MBs Total: BRAALIC } & \multicolumn{3}{|c|}{ Repository Total: BRNREPTC } \\
\hline & Variable & SRRC & $R^{2}$ & Variabie & SRRC & $R^{2}$ & Variable & SRRC & $R^{2}$ & Variable & SRRC & $R^{2}$ \\
\hline 1 & HМICDFLG & -0.65 & 0.22 & HMICDFLG & -0.65 & 0.43 & HMCDFLG & -0.66 & 0.43 & H.ALPOR & 0.88 & $0 . \pi$ \\
\hline 2 & ANHPRM & 0.60 & 0.78 & ANHPRM & 0.57 & 0.75 & ANHPRM & 0.59 & 0.75 & WMICDFLG & -0.26 & 0.85 \\
\hline 3 & HALPOR & -0.16 & 0.80 & H.LLPRH & 0.19 & 0.79 & HALPOR & -0.16 & 0.80 & ANHPRH & 0.18 & 0.88 \\
\hline 4 & HALPRM & 0.15 & 0.83 & H.ALPOR & -0.16 & 0.81 & H'GRCOR & -0.15 & 0.82 & WRBRNSAT & -0.09 & 0.89 \\
\hline 5 & HGRCOR & -0.15 & 0.85 & HGRCOR & -0.15 & 0.84 & HALPRM & 0.14 & 0.85 & HALPRM & 0.09 & 0.89 \\
\hline 6 & SALPRES & 0.12 & 0.86 & SALPRES & 0.12 & 0.85 & SALPRES & 0.12 & 0.86 & WGRCOR & -0.08 & 0.90 \\
\hline 7 & HASTWCX & -0.10 & 0.87 & НАSTHTCK & -0.10 & 0.86 & H'ASTHICK & -0.10 & 0.87 & WASTWTCK & -0.06 & 0.90 \\
\hline
\end{tabular}

- Steps in stepuise regression anajysis.

b Variables listed in order of selection in regression analysis with ANHCOMP and HALCOMP excluded from envy into the regression model.

- Standardized rank regression coefficients in final regression model.

d Cumulative $R^{2}$ value with entry of ach variable into regression model.

Table 3. Rank Correlations between ANHPRM, ANHCOMP, HALPRM, HALCOMP and Cumulative Brine Flow from the Marker Beds over 10,000 yr under Undisturbed Conditions

\begin{tabular}{|lrccc|}
\hline ANHPRM & 1.0000 & & & \\
ANHCOMP & -0.9887 & 1.0000 & & \\
HALPRM & 0.0131 & -0.0026 & 1.0000 & \\
H.ALCOMP & -0.0084 & -0.0021 & -0.9836 & 1.0000 \\
BRM38NIC & 0.7343 & -0.7222 & -0.1670 & 0.1773 \\
BRM38SIC & 0.7162 & -0.7036 & -0.1384 & 0.1496 \\
BRA.ABNIC & 0.5890 & -0.5740 & 0.1314 & -0.1160 \\
BRAABSIC & 0.5769 & -0.5621 & 0.1518 & -0.1355 \\
BRM39NIC & 0.5840 & -0.5670 & 0.1931 & -0.1775 \\
BRM39SIC & 0.5599 & -0.5429 & 0.2274 & -0.2115 \\
BRAALIC & 0.5804 & -0.5640 & 0.1850 & -0.1694 \\
& $A N H P R M$ & ANHCOMP & HALPRM & HALCOMP \\
\hline
\end{tabular}


Table 4. Stepwise Regression Analyses with Rank-Transformed Data for Cumulative Gas Generation over 10,000 yr due to Corrosion of Steel (FE_MOLE) and to Corrosion of Steel and Microbial Degradation of Cellulose (GAS_MOLE) under Undisturbed Conditions

\begin{tabular}{|c|l|c|c|c|c|c|}
\cline { 2 - 7 } \multicolumn{1}{c|}{} & \multicolumn{3}{c|}{ Corrosion of Steel: FE_MOLE } & \multicolumn{3}{c|}{$\begin{array}{c}\text { Corrosion of Steel and Microbial Degradation } \\
\text { of Cellulose: GAS_MOLE }\end{array}$} \\
\hline Step $^{2}$ & \multicolumn{1}{c|}{ Variable $^{\mathrm{b}}$} & SRRC & $R^{2 \mathrm{~d}}$ & Variable & SRRC & $R^{2}$ \\
\hline 1 & HALPOR & 0.73 & 0.55 & WMICDFLG & 0.62 & 0.39 \\
2 & WGRCOR & 0.39 & 0.69 & HALPOR & 0.57 & 0.72 \\
3 & WMICDFLG & -0.20 & 0.73 & WGRCOR & 0.28 & 0.80 \\
4 & W.ASTWICK & 0.11 & 0.74 & ANHPRM & 0.08 & 0.81 \\
5 & SHRGSSAT & 0.09 & 0.75 & WASTWICK & 0.07 & 0.81 \\
6 & ANHPRM & 0.09 & 0.76 & SHRGSSAT & 0.07 & 0.82 \\
7 & BPINTPRS & 0.07 & 0.76 & & & \\
\hline
\end{tabular}

- Steps in stepwise regression amalysic

b Variables listed in orier of selection in regression analysis with ANHCOMP and HALCOMP excluded from entry into regression model.

t Standardized rank regression coefficients in final regression model.

d Cumulative $R^{2}$ vahe with entry of ach variable into regression model.

Table 5. Stepwise Regression Analyses with Rank-Transformed Data for Fraction of Steel Remaining and Total Gas Generation in Upper (FEREM_R, GASMOL_R) and Lower (FEREM_W, GASMOL_W Waste Panels at 10,000 yr Under Undisturbed Conditions

\begin{tabular}{|c|c|c|c|c|c|c|c|c|c|c|c|c|}
\hline \multirow[b]{2}{*}{ Step ${ }^{2}$} & \multicolumn{3}{|c|}{$\begin{array}{c}\text { Fraction Sted Remaining Upper } \\
\text { Wiaste Panets: FEREM_R }\end{array}$} & \multicolumn{3}{|c|}{$\begin{array}{c}\text { Fraction Steel Remaining Lowet } \\
\text { Waste Panek: FEREM_W }\end{array}$} & \multicolumn{3}{|c|}{$\begin{array}{l}\text { Total Gas Generation Lipper } \\
\text { Waste Panels: GASMOL_R }\end{array}$} & \multicolumn{3}{|c|}{$\begin{array}{l}\text { Total Gas Generation Lower } \\
\text { Waste Panels: GASMOL_H. }\end{array}$} \\
\hline & Variable ${ }^{b}$ & SRRC & $R^{2 d}$ & Variable & SRRC & $R^{2}$ & Variable & SRRC & $R^{2}$ & Variable & SRRC & $R^{2}$ \\
\hline 1 & $H A L P O R$ & -0.78 & 0.63 & WMICDFLG & 0.46 & 0.20 & WMICDFLG & 0.65 & 0.43 & WGRCOR & 0.47 & 0.23 \\
\hline 2 & W'GRCOR & -0.35 & 0.75 & WGRCOR & -0.45 & 0.41 & HALPOR & 0.58 & 0.77 & HALPOR & 0.45 & 0.44 \\
\hline 3 & WMICDFLG & 0.12 & 0.76 & HALPOR & -0.38 & 0.56 & WGRCOR & 0.24 & 0.83 & ANHPRM & 0.33 & 0.55 \\
\hline 4 & WASTWICK & -0.10 & 0.77 & ANHPRM & -0.25 & 0.63 & КASTHTCK & 0.07 & 0.83 & WMICDFLG & 0.17 & 0.58 \\
\hline 5 & SHRGSSAT & -0.08 & 0.78 & HALPRM & -0.09 & 0.63 & SHRGSSAT & 0.06 & 0.83 & HALPRS & 0.12 & 0.59 \\
\hline 6 & BPINTPRS & -0.06 & 0.78 & SHRGSSAT & -0.09 & 0.64 & & & & SHRGSSAT & 0.08 & 0.60 \\
\hline
\end{tabular}

- Steps in stepwise regession aralysis.

b Variables listed in order of selection in regression analysis with ANHCOMP and HALCOMP excluded from entry into regression model.

c Standardized rani regression coefficients in final regression model.

- Cumulative $R^{2}$ vaiue ujth entry of each variable into regression model. 
Table 6. Stepwise Regression Analysis with Rank-Transformed Data for Pressure in the Repository (WAS_PRES) at 10,000 yr Under Undisturbed Conditions

\begin{tabular}{|c|l|c|c|}
\hline Step $^{\mathrm{a}}$ & \multicolumn{1}{|c|}{ Variable $^{\mathrm{b}}$} & SRRC $^{\mathrm{c}}$ & $R^{2 \mathrm{~d}}$ \\
\hline 1 & WMICDFLG & 0.71 & 0.52 \\
2 & HALPOR & 0.45 & 0.73 \\
3 & WGRCOR & 0.23 & 0.79 \\
4 & ANHPRM & 0.11 & 0.80 \\
5 & SALPRES & 0.07 & 0.80 \\
6 & SHRGSSAT & 0.06 & 0.81 \\
\hline
\end{tabular}

- Steps in stepwise regression analysis.

b Variables listed in order of selection in regression analysis with ANHCOMP and HALCOMP excluded from entry into regression model.

' Standardized rank regression coefficients in final regression model.

dCumulative $R^{2}$ value with entry of each variable into regression model.

Table 7. Stepwise Regression Analyses with Rank-Transformed Data for Brine Saturation in the Upper (REP_SATB) and Lower (WAS_SATB) Waste Panels at 10,000 yr Under Undisturbed Conditions

\begin{tabular}{|c|c|c|c|c|c|c|}
\hline \multirow[b]{2}{*}{ Step ${ }^{2}$} & \multicolumn{3}{|c|}{$\begin{array}{c}\text { Brine Saturation } \\
\text { Upper Waste Panels: REP_SATB }\end{array}$} & \multicolumn{3}{|c|}{$\begin{array}{c}\text { Brine Saturation } \\
\text { Lower Waste Panel: } W A S \_S A T B\end{array}$} \\
\hline & Variableb & SRRC & $R^{2 \mathrm{~d}}$ & Variable & SRRC & $R^{2}$ \\
\hline 1 & HALPOR & 0.53 & 0.27 & $W M J C D F L G$ & -0.59 & 0.39 \\
\hline 2 & WGRCOR & -0.53 & 0.55 & WGRCOR & -0.43 & 0.57 \\
\hline 3 & WASTWICK & -0.35 & 0.67 & ANHPRM & 0.23 & 0.62 \\
\hline 4 & WMICDFLG & -0.15 & 0.70 & $H A L P O R$ & 0.21 & 0.66 \\
\hline 5 & WRBRNSAT & -0.10 & 0.71 & WRBRNSAT & -0.18 & 0.69 \\
\hline 6 & HALPRM & 0.09 & 0.71 & WASTWICK & -0.16 & 0.72 \\
\hline 7 & ANHPRM & 0.08 & 0.72 & HALPRM & 0.11 & 0.73 \\
\hline
\end{tabular}

- Steps in stepwise regression analysis.

b Variables listed in order of selection in regression analysis with ANHCOMP and HALCOMP excluded from entry into regression model.

- Suandardized rank regression coefficients in final regression model.

d Cumulative $R^{2}$ value with eniry of each variable into regression model. 
Table 8. Stepwise Regression Analyses with Rank-Transformed Data for Brine Volume in the Upper (BRNVOL_R) and Lower (BRNVOL_W) Waste Panels at 10,000 yr Under Undisturbed Conditions

\begin{tabular}{|c|l|r|r|l|r|c|}
\cline { 2 - 7 } \multicolumn{1}{c|}{} & \multicolumn{3}{c|}{ Brine Volume } & \multicolumn{3}{c|}{ Brine Volume } \\
\hline Step $^{\mathrm{a}}$ & Uariabler Waste Panels: BRNVOL_R & \multicolumn{2}{c|}{ Lower Waste Panel: BRNVOL_W } \\
\hline 1 & SRRC & $R^{2 \mathrm{~d}}$ & Variable & SRRC & $R^{2}$ \\
2 & WGRCOR & 0.57 & 0.31 & WMICDFLG & -0.52 & 0.30 \\
3 & WASTWICK & -0.51 & 0.57 & WGRCOR & -0.39 & 0.44 \\
4 & WMICDFLG & -0.34 & 0.69 & HALPOR & 0.33 & 0.55 \\
5 & ANHPRM & 0.10 & 0.70 & ANHPRM & 0.28 & 0.63 \\
6 & WRBRNSAT & -0.10 & 0.71 & WRBRNSAT & -0.20 & 0.67 \\
7 & HALPRM & -0.09 & 0.73 & WASTWICK & -0.15 & 0.69 \\
\hline
\end{tabular}

Steps in seprise regression analysis.

b Variables listed in order of selection in regression anabsis with ANHCOMP and HALCOMFP excluded from entry into regression model

- Standaräzod rank regression coefficients in final regression model.

- Cumulative $R^{2}$ value with enty of each variable into regression model.

Table 9. Stepwise Regression Analyses with Rank-Transformed Data for Cumulative Brine Flow over 10,000 yr away from Repository in Marker Beds (BRM38NOC, BRM38SOC, BRAABNOC, BRAABSOC, BRM39NOC, BRM39SOC, BRAALOC) and Up Shaft (BSCL8AOC) Under Undisturbed Conditions

\begin{tabular}{|c|c|c|c|c|c|c|c|c|c|c|c|c|}
\hline \multirow[b]{2}{*}{ Step ${ }^{2}$} & \multicolumn{3}{|c|}{ MB 138 North: BRM/38NOC } & \multicolumn{3}{|c|}{ MB 138 South: BRM38SOC } & \multicolumn{3}{|c|}{ Anh $a$ and $b$ North: $B R A A B N O C$} & \multicolumn{3}{|c|}{ Anh $a$ and $b$ South: BRAABSOC } \\
\hline & Variableb & SRRC & $R^{2 d}$ & Variable & SRRC & $R^{2}$ & Variable & SRRC & $R^{2}$ & Variable & $\stackrel{\overrightarrow{S R R C}}{-}$ & $R^{2}$ \\
\hline 1 & WMICDFLG & 0.57 & 0.32 & WMICDFLG & 0.55 & 0.30 & WMICDFLG & 0.57 & 0.31 & WMICDFLG & 0.57 & 0.31 \\
\hline 2 & HALPOR & 0.33 & 0.43 & HALPOR & 0.35 & 0.42 & HALPOR & 0.48 & 0.55 & HALPOR & 0.44 & 0.51 \\
\hline 3 & SALPRES & -0.18 & 0.47 & ANHPRM & 0.17 & 0.45 & WGRCOR & 0.18 & 0.58 & WGRCOR & 0.17 & 0.54 \\
\hline 4 & ANHPRM & 0.17 & 0.49 & WGRCOR & 0.16 & 0.48 & SALPRES & -0.15 & 0.60 & SALPRES & -0.15 & 0.56 \\
\hline 5 & WGRCOR & 0.14 & 0.51 & SALPRES & -0.16 & 0.51 & HALPRM & 0.09 & 0.61 & ANHPRM & 0.12 & 0.57 \\
\hline 6 & WASTHTCK & 0.10 & 0.52 & & & & & & & HALPRM & 0.09 & 0.58 \\
\hline
\end{tabular}

\begin{tabular}{|c|c|c|c|c|c|c|c|c|c|c|c|c|}
\hline \multirow[b]{2}{*}{ Step } & \multicolumn{3}{|c|}{ MB 139 Nonh: BRH39NOC } & \multicolumn{3}{|c|}{ MB 139 South: BRM39SOC } & \multicolumn{3}{|c|}{ MBs Total: BRAALOC } & \multicolumn{3}{|c|}{ Up Shaft: $B S C L 8 A O C$} \\
\hline & Variable ${ }^{b}$ & SRRCe & $R^{2 d}$ & Variable & SRRC & $R^{2}$ & Variable & SRRC & $R^{2}$ & Variable & SRRC & $R^{2}$ \\
\hline 1 & HMIICDFLG & 0.59 & 0.34 & HMICDFLG & 0.61 & 0.37 & HMICDFLG & 0.61 & 0.36 & WAICDFLG & 0.48 & 0.25 \\
\hline 2 & HALPOR & $0 \leq 5$ & 0.55 & HALPOR & 0.40 & 0.53 & HALPOR & 0.44 & 0.56 & SHRGSSAT & 0.33 & 0.36 \\
\hline 3 & WGRCOR & 0.19 & 0.58 & HGRCOR & 0.18 & 0.56 & WGRCOR & 0.19 & 0.59 & HALPRA & -0.25 & 0.42 \\
\hline 4 & S.ALPRES & -0.15 & 0.61 & SALPRES & -0.15 & 0.59 & SALPRES & -0.15 & 0.61 & HALPOR & 0.24 & 0.48 \\
\hline 5 & HALPRM & 0.00 & 0.61 & & & & HALPRM & 0.09 & 0.62 & H'GRCOR & 0.20 & 0.52 \\
\hline & & & & & & & & & & SHPRMHAL & 0.18 & 0.55 \\
\hline & & & & & & & & & & "'ASTHZCK & 0.09 & 0.56 \\
\hline & & & & & & & & & & SHBCEXP & 0.10 & 0.57 \\
\hline & & & & & & & & & & $A N H B C V^{\prime} G P$ & 0.09 & 0.58 \\
\hline
\end{tabular}

"Steps in stepuise regression analusis.

bVariables listed in order of seiection in regression analysis uith AAHCOMP and HALCOMP excluded from entry into regressinn modei

'Standardized rani regression coefficients in final regression model.

¿Cumulative $R^{2}$ value with ent:- of each tariable into regression model. 
Table 10. Stepwise Regression Analyses with Rank-Transformed Data for Cumulative Brine Flow over 10,000 yr Away From Repository in Individual Marker Beds at Land Withdrawal Boundary Away from Repository (BRM38NLW, BRM38SLW, BRAABNLW, BRAABSLW, $B R M 39 N L W, B R M 39 S L W, B R A A L L W C)$ and in Shaft at Boundary with Rustler Formation (BRNSHUC) Under Undisturbed Conditions

\begin{tabular}{|c|c|c|c|c|c|c|c|c|c|c|c|c|}
\hline \multirow[b]{2}{*}{ Step } & \multicolumn{3}{|c|}{ MB 138 North: BRM38NLW } & \multicolumn{3}{|c|}{ MB 138 South: BRM $38 S L W$} & \multicolumn{3}{|c|}{ Anh $\mathrm{a}$ and $\mathrm{b}$ North: $B R A A B N L W$} & \multicolumn{3}{|c|}{ Anh $a$ and $b$ South: BRAABSLW } \\
\hline & Variable $^{b}$ & SRRC & $R^{2 d}$ & Variable & SRRC & $R^{2}$ & Variable & SRRC & $R^{2}$ & Variabie & SRRC & $R^{2}$ \\
\hline 1 & ANHPRM & 0.88 & 0.78 & HMICDFLG & 0.30 & 0.09 & ANHPRM & 0.70 & 0.50 & HMCDFLG & 0.31 & 0.10 \\
\hline 2 & HMICDFLG & 0.12 & 0.79 & ANHPRM & 0.23 & 0.14 & WMICDFLG & 0.19 & 0.54 & ANHPRM & 0.22 & 0.15 \\
\hline 3 & HALPOR & 0.08 & 0.80 & HALPOR & 0.16 & 0.17 & HALPRM & 0.18 & 0.57 & HALPOR & 0.16 & 0.17 \\
\hline 4 & & & & $A N H B C V G P$ & -0.16 & 0.19 & WRGSSAT & -0.11 & 0.58 & $A N H B C V G P$ & -0.16 & 0.20 \\
\hline 5 & & & & SALPRES & -0.14 & 0.21 & $A N H B C V G P$ & -0.09 & 0.59 & SALPRES & -0.14 & 0.22 \\
\hline 6 & & & & WASTWICK & 0.13 & 0.23 & & & & & & \\
\hline
\end{tabular}

\begin{tabular}{|c|c|c|c|c|c|c|c|c|c|c|c|c|}
\hline & \multicolumn{3}{|c|}{ MB 139 North: BRM39NLW } & \multicolumn{3}{|c|}{ MB 139 South: BRM39SLW } & \multicolumn{3}{|c|}{ MBs Total: $B R A A L L W C$} & \multicolumn{3}{|c|}{ Shaft to Culebra: BRNSHUC } \\
\hline Step & Variable & SRRC & $R^{2}$ & Variable & SRRC & $R^{2}$ & Variable & SRRC & $R^{2}$ & Variable & SRRC & $R^{2}$ \\
\hline 1 & HALPRM & 0.37 & 0.13 & HMICDFLG & 0.30 & 0.10 & ANHPRA & 0.72 & 0.53 & SHPRMCLY & 0.72 & 0.51 \\
\hline 2 & ANHPRA & 0.34 & 0.25 & $A N H P R M$ & 0.26 & 0.16 & HALPRM & 0.24 & 0.59 & HALPRH & 0.49 & 0.75 \\
\hline 3 & KMIICDFLG & 0.22 & 0.30 & H.ASTHICK & 0.16 & 0.19 & WMICDFLG & 0.19 & 0.63 & SHPRMHAL & 0.19 & 0.79 \\
\hline 4 & $A N H B C V G P$ & -0.14 & 0.32 & HALPOR & 0.13 & 0.20 & $A N H B C V G P$ & -0.09 & 0.63 & HMICDFLG & 0.07 & 0.79 \\
\hline 5 & HASTWICK & 0.12 & 0.33 & & & & WASTWCK & 0.08 & 0.64 & SALPRES & 0.07 & 0.80 \\
\hline 6 & & & & & & & WRCSSAT & -0.08 & 0.65 & & & \\
\hline
\end{tabular}

Steps in stepuise regression anajysis.

b Variables listed in order of selection in regression analysis with ANHCOMP and HALCOMP excluded from enty into regression model $\#$

c Standardized rank regression coefficients in final regression model.

${ }^{d}$ Cumularive $R^{2}$ value with entry of each variable into regression model. 
Table 11. Stepwise Regression Analyses with Rank-Transformed Data for Cumulative Gas Flows over 10,000 yr Away From Repository in Individual Marker Beds (GSM38NOC, GSM38SOC, GSAABNOC, GSAABSOC, GSM39NOC, GSM39SOC, GSAALOM) and in Shaft at Boundary with Rustler Formation (GSMSHUPC) Under Undisturbed Conditions

\begin{tabular}{|c|c|c|c|c|c|c|c|c|c|c|c|c|}
\hline \multirow[b]{2}{*}{ Step ${ }^{a}$} & \multicolumn{3}{|c|}{ MB 138 North: GSM38NOC } & \multicolumn{3}{|c|}{ MB 138 South: GSM38SOC } & \multicolumn{3}{|c|}{ Anh a and b North: GSAABNOC } & \multicolumn{3}{|c|}{ Anh $\mathrm{a}$ and $\mathrm{b}$ South: $G S A A B S O C$} \\
\hline & Variable $^{b}$ & SRRC & $R^{2 \mathrm{~d}}$ & Variable & SRRC & $R^{2}$ & Variable & SRRC & $R^{2}$ & Variable & SRRC & $R^{2}$ \\
\hline 1 & WMICDFLG & 0.59 & 0.35 & WMICDFLG & 0.59 & 0.35 & WMICDFLG & 0.60 & 0.37 & WMICDFLG & 0.59 & 0.36 \\
\hline 2 & HALPOR & 0.26 & 0.43 & HALPOR & 0.29 & 0.44 & HALPOR & 0.33 & 0.49 & HALPOR & 0.32 & 0.46 \\
\hline 3 & $A N H B C V G P$ & -0.28 & 0.50 & $A N H B C V G P$ & -0.24 & 0.50 & $A N H B C V G P$ & -0.22 & 0.53 & $A N H B C V G P$ & -0.20 & 0.50 \\
\hline 4 & WGRCOR & 0.19 & 0.54 & WGRCOR & 0.15 & 0.52 & WGRCOR & 0.19 & 0.57 & WGRCOR & 0.16 & 0.52 \\
\hline 5 & SALPRES & -0.16 & 0.56 & ANHPRM & 0.15 & 0.54 & ANHPRM & 0.17 & 0.60 & SALPRES & -0.16 & 0.55 \\
\hline 6 & HALPRM & 0.16 & 0.58 & SALPRES & -0.15 & 0.56 & SALPRES & -0.10 & 0.61 & ANHPRM & 0.13 & 0.57 \\
\hline 7 & SHRGSSAT & 0.10 & 0.59 & HALPRM & 0.13 & 0.58 & & & & & & \\
\hline 8 & & & & SHRGSSAT & 0.09 & 0.58 & & & & & & \\
\hline
\end{tabular}

\begin{tabular}{|c|c|c|c|c|c|c|c|c|c|c|c|c|}
\hline \multirow[b]{2}{*}{ Step } & \multicolumn{3}{|c|}{ MB 139 North: GSM39NOC } & \multicolumn{3}{|c|}{ MB 139 South: GSM39SOC } & \multicolumn{3}{|c|}{ MBs Total: GSAALOM } & \multicolumn{3}{|c|}{ Up Shaft at Rustler: GSMSHUPC } \\
\hline & Variable & SRRC & $R^{2}$ & Variable & SRRC & $R^{2}$ & Variable & SRRC & $R^{2}$ & Variable & SRRC & $R^{2}$ \\
\hline 1 & WMICDFLG & 0.66 & 0.44 & WMICDFLG & 0.49 & 0.24 & WMICDFLG & 0.61 & 0.38 & SHPRMCON & -0.43 & 0.20 \\
\hline 2 & $A N H B C V G P$ & -0.18 & 0.47 & SALPRES & -0.17 & 0.27 & HALPOR & 0.34 & 0.50 & SHRGSSAT & -0.41 & 0.37 \\
\hline 3 & ANHPRM & 0.15 & 0.50 & WGRCOR & 0.13 & 0.28 & $A N H B C V G P$ & -0.22 & 0.54 & SHPRMCLY & 0.35 & 0.49 \\
\hline 4 & SALPRES & -0.13 & 0.51 & & & & WGRCOR & 0.20 & 0.58 & & & \\
\hline 5 & WGRCOR & 0.11 & 0.53 & & & & ANHPRM & 0.15 & 0.61 & & & \\
\hline 6 & & & & & & & SALPRES & -0.11 & 0.62 & & & \\
\hline
\end{tabular}

Steps in stepwise regression analysis.

b Variables listed in order of selection in regression analysis with ANHCOMP and HALCOMP excluded from entry into regression model.

' Standardized rank regression coefficients in final regression model.

${ }^{\mathrm{d}}$ Cumulative $R^{2}$ value with entry of each variable into regression model. 
Table 12. Stepwise Regression Analyses with Rank-Transformed Data for Pore Volume Increase Due to Fracturing in Individual Marker (PVOLI38N, PVOLI38S, PVOLIABN, PVOLIABS, PVOLI39N, PVOLI39S, PVOLI_T) Beds at 10,000 yr Under Undisturbed Conditions

\begin{tabular}{|c|c|c|c|c|c|c|c|c|c|c|c|c|}
\hline & \multicolumn{3}{|c|}{ MB 138 North: PVOLI38N } & \multicolumn{3}{|c|}{ MB 138 South: PVOLI38S } & \multicolumn{3}{|c|}{ Anh a and b North: PVOLJABN } & \multicolumn{3}{|c|}{ Anh a and b South: PVOLIABS } \\
\hline Step ${ }^{\mathrm{a}}$ & Variable $^{b}$ & SRRC ${ }^{c}$ & $R^{2 \mathrm{~d}}$ & Variable & SRRC & $R^{2}$ & Variable & SRRC & $R^{2}$ & Variable & SRRC & $R^{2}$ \\
\hline 1 & WMICDFLG & 0.42 & 0.16 & WMICDFLG & 0.42 & 0.17 & WMICDFLG & 0.49 & 0.24 & WMICDFLG & 0.44 & 0.19 \\
\hline 2 & HALPOR & 0.29 & 0.25 & HALPOR & 0.29 & 0.26 & HALPOR & 0.28 & 0.32 & HALPOR & 0.30 & 0.28 \\
\hline 3 & SALPRES & -0.20 & 0.29 & SALPRES & -0.20 & 0.30 & SALPRES & -0.24 & 0.38 & SALPRES & -0.18 & 0.31 \\
\hline 4 & $W G R C O R$ & 0.13 & 0.31 & WGRCOR & 0.13 & 0.32 & $W G R C O R$ & 0.12 & 0.39 & WGRCOR & 0.12 & 0.33 \\
\hline 5 & & & & & & & SHRGSSAT & 0.11 & 0.41 & SHRGSSAT & 0.12 & 0.34 \\
\hline 6 & & & & & & & HALPRM & -0.11 & 0.42 & & & \\
\hline
\end{tabular}

\begin{tabular}{|c|l|r|r|l|l|l|l|r|r|r|}
\cline { 2 - 10 } \multicolumn{1}{c|}{} & \multicolumn{2}{c|}{ MB 139 North: PVOLI39N } & \multicolumn{2}{c|}{ MB 139 South: PVOLI39S } & \multicolumn{3}{c|}{ MBs Total: PVOLI T } \\
\hline Step & Variable & SRRC & $R^{2}$ & Variable & SRRC & $R^{2}$ & Variable & SRRC & $R^{2}$ \\
\hline 1 & WMICDFLG & 0.53 & 0.27 & WMICDFLG & 0.52 & 0.26 & WMICDFLG & 0.54 & 0.28 \\
2 & HALPOR & 0.37 & 0.41 & HALPOR & 0.34 & 0.38 & HALPOR & 0.37 & 0.42 \\
3 & SALPRES & -0.21 & 0.45 & SALPRES & -0.21 & 0.42 & SALPRES & -0.20 & 0.46 \\
4 & WGRCOR & 0.15 & 0.47 & WGRCOR & 0.14 & 0.44 & WGRCOR & 0.16 & 0.49 \\
\hline
\end{tabular}

a Steps in stepwise regression analysis.

${ }^{b}$ Variables listed in order of selection in regression analysis with ANHCOMP and HALCOMP excluded from entry into regression model.

c Standardized rank regression coefficients in final regression model.

${ }^{\text {d }}$ Cumulative $R^{2}$ value with entry of each variable into regression model.

Table 13. Number of Observations Producing Fracture Zones of Different Lengths in Individual Marker Beds (FRACX38N, FRACX38S, FRACXABN, FRACXABS, FRACX39N, FRACX39S) at 10,000 yr under Undisturbed Conditions

\begin{tabular}{|l|c|c|c|c|c|c|}
\cline { 2 - 7 } \multicolumn{1}{c|}{} & \multicolumn{7}{c|}{ Fracture Distance } \\
\hline Marker Bed & $5 \mathrm{~m}$ & $30 \mathrm{~m}$ & $100 \mathrm{~m}$ & $400 \mathrm{~m}$ & $1030 \mathrm{~m}$ & $1900 \mathrm{~m}$ \\
\hline MB 138 (N): $F R A C X 38 N$ & $0^{\mathrm{a}}$ & 9 & 10 & 5 & 2 & 5 \\
MB 138 (S): FRACX38S & 0 & 6 & 14 & 6 & 5 & 0 \\
Anh A,B (N): FRACXABN & 1 & 6 & 11 & 14 & 7 & 5 \\
Anh A,B (S): FRACXABS & 1 & 6 & 12 & 12 & 2 & 0 \\
MB 139 (N): FRACX39N & 10 & 15 & 19 & 16 & 3 & 0 \\
MB 139 (S): FRACX39S & 8 & 15 & 25 & 5 & 1 & 0 \\
\hline
\end{tabular}

a Number of observations out of 300 